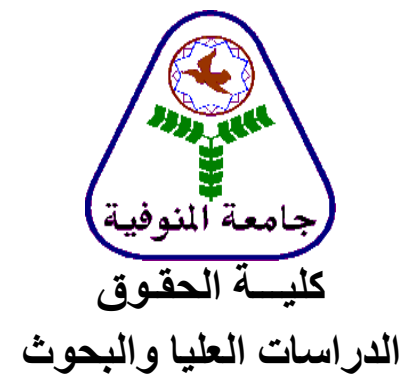

\title{
تطور مفهوم الحياة الخاصة في القانون الجنائي
}

الدكتور

محمود أبو الفتوح عبد الشافي البغدادي

Y. 1 . 


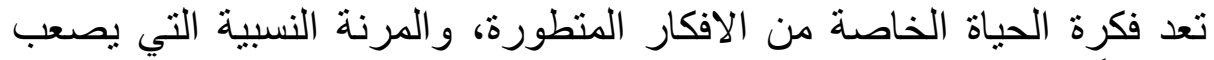

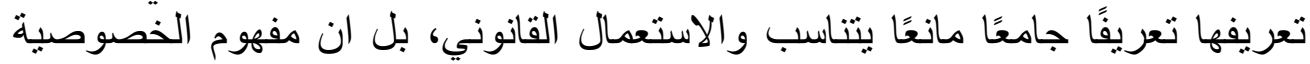

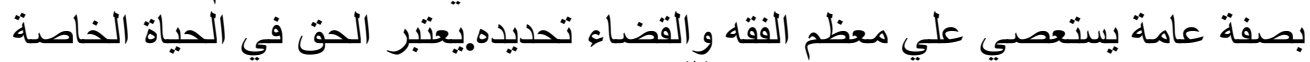

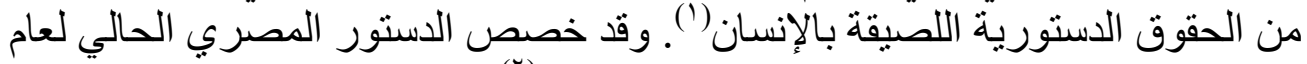

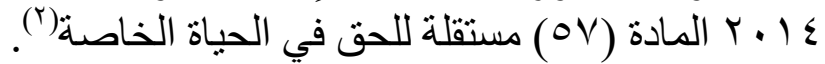

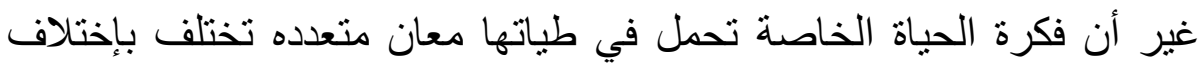

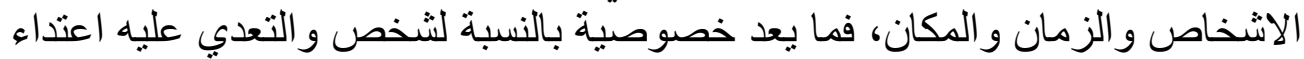

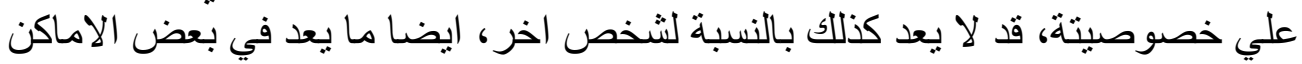

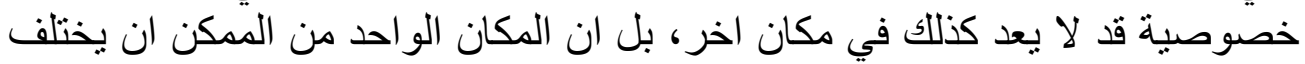

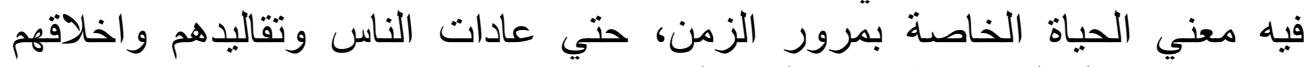
تهضمها عو امل البيئة وتطور ات الحياة لتخرجة منها اعر اف جديدة قد لا تمت لاسلافهم بصلة.

و أمام صعوبة تحديد مدلول للحياة الخاصة وكثرة محاو لات الفقهاء ايجاد مفهوم الفاء

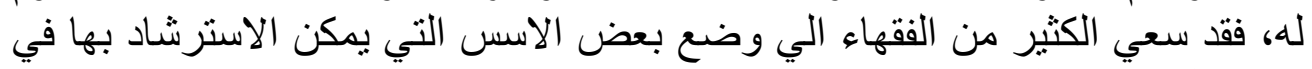
تحديد المقصود بالحياة الخاصة. لهن.

$$
\text { ثانيًا أهمية البحث: }
$$

ترجع أهمية البحث إلي تطور وتزايد الوسائل التقنية الحديثة التي تغزو الحياة

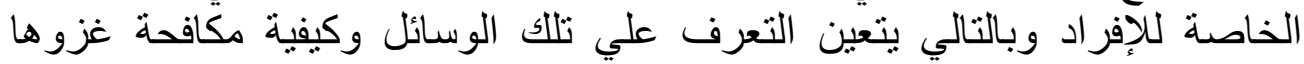

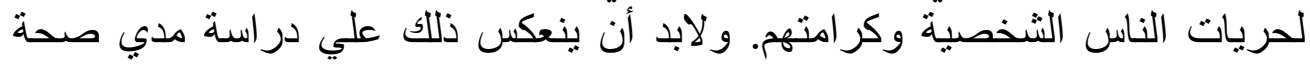

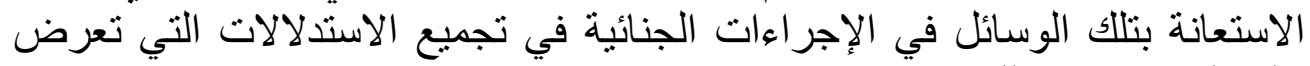
علي المحكمة بعد ذلك.

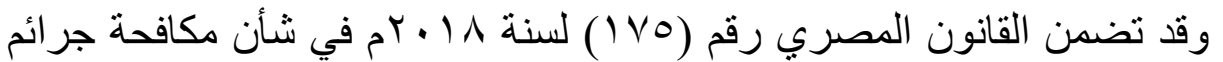
تقنية المعلومات في الفصل الأول من الباب الثالث بعنوان "الجرائم المتعلقة بالاعتداء

(1) (1)شيماءعبدالغني عطا الله، تراجع الحق في الخصوصية في مواجهة الاتصالات الإلكترونية،

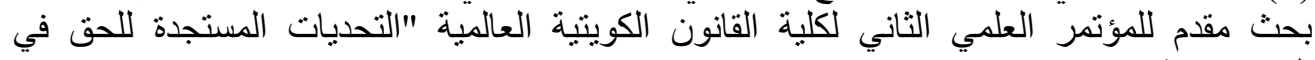

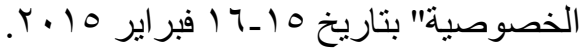

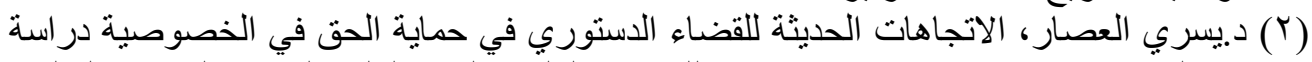

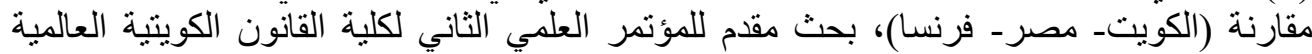

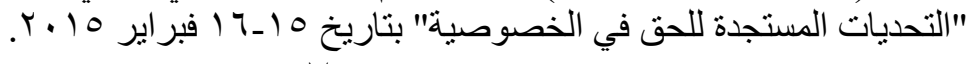


علي حرمه الحياة الخاصة والمحتوي المعلوماتي غير المشروع"، وهي المنصوص

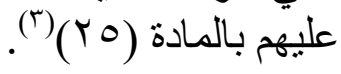

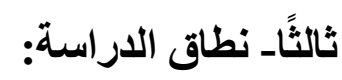

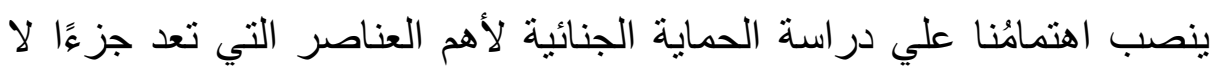

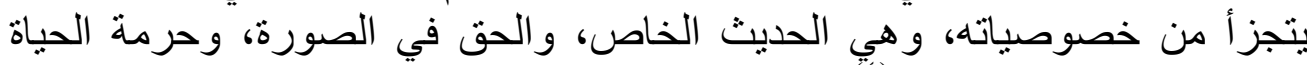

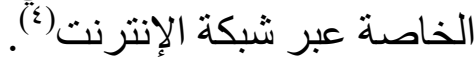

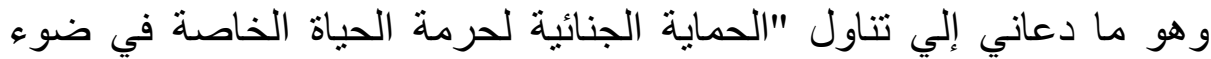

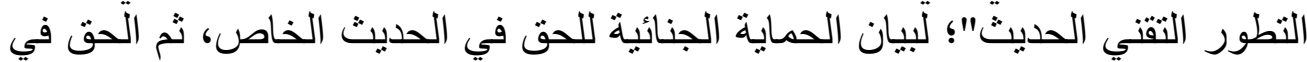

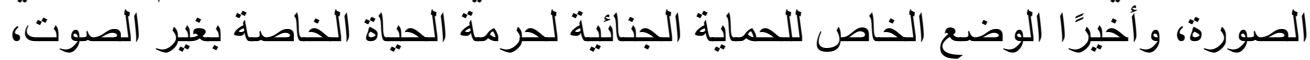

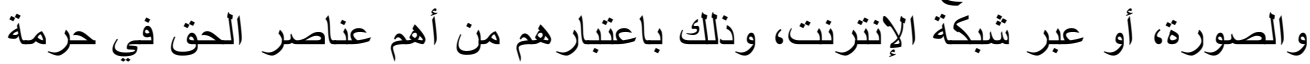

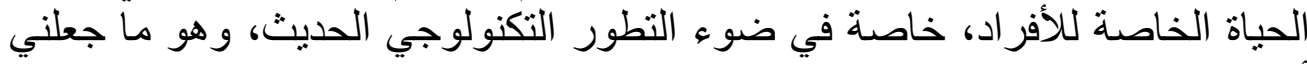
أتناول ذلك بالدر اسة.

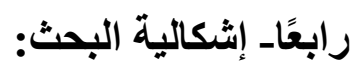

يرمي هذا البحث إلي الإجابة علي التساؤلات التهاء التالية:

- ما - مقصود بالحياة الخاصة في مفهوم القانون الجنائي؟ هل يختلف ذللك المفهوم في التشريعات ذات الأصل اللاتيني عن التشريعات ذات

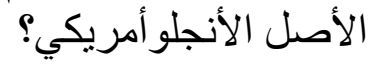

- ما هي عناصر الحق في الحياة الخاصة وهل تتفق في التشريعات المختلفة؟

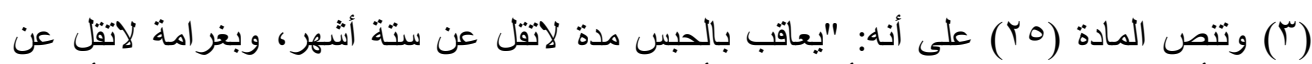

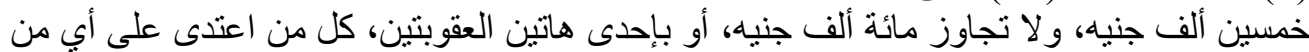

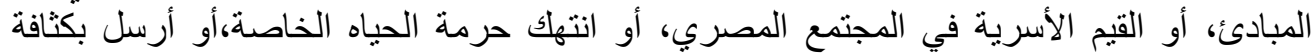

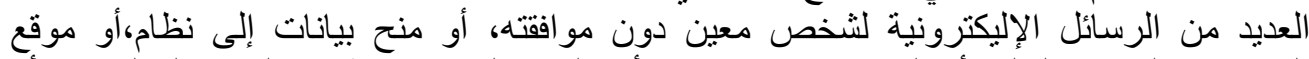

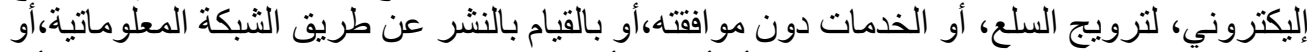

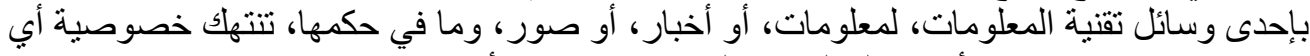

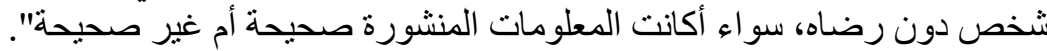

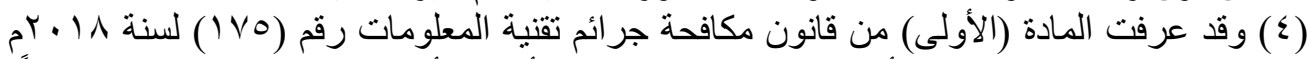

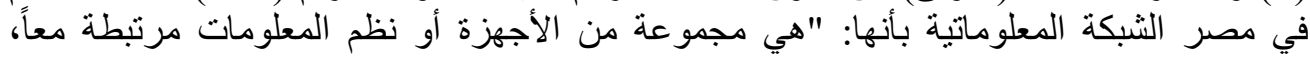

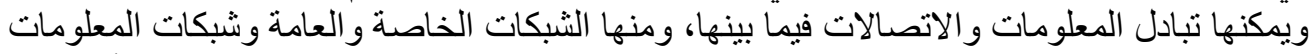

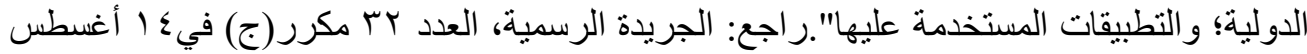




\section{خامسًا منهج البحث.}

يتبع الباحث في هذه الدراسة المنهج التأصيلي، والتحليلي، والدقارن. فهو التهو

تأصيلي، إذ يبدأ بالفروع وينتهي بها إلي الأصول، أي يرد الفروع إلي أصولها، والئه وهو

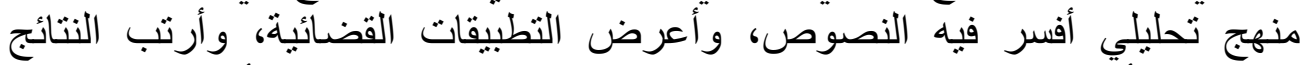

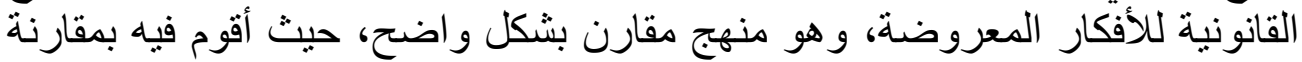
بين التثريعات التي تتنمي إلي النظام اللاتيني، وتلكي التي تنتمي إلي النظام الأنجلو أمريكي.

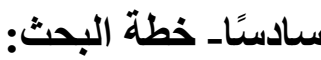
نعالج موضوع هذا البحث من خلال مقدمة عامة، ومبحثين وذلك علي النحو الآتي: المبحث الأول: مفهوم الحياة الخاصة. المطلب الأول: الاتجاهات الموضو عية لتعريف الحق في الحياة الخاصة. المطلب الثاني: فكرة نسبية الحياة الخاصة. المبحث الثاني: عناصر الحق في الحياة الخاصة. المطلب الاول: عناصر الحق في الحياة الخاصة محل الاتفاق. المطلب الثاني: عناصر الحق في الحياة الخاصة محل الاختلاف.

\section{المبحث الاول

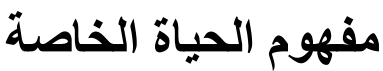

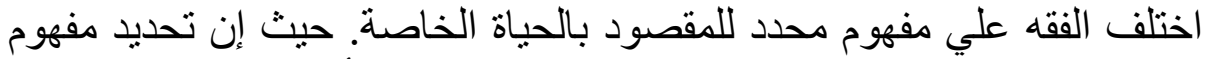

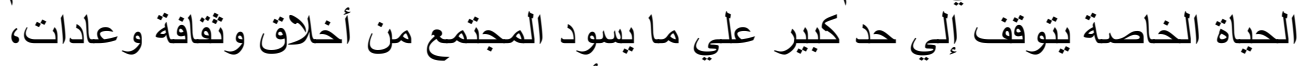

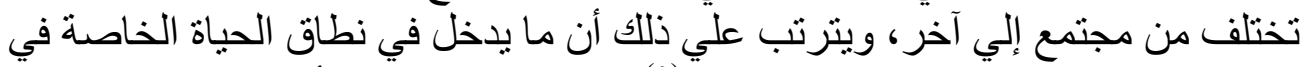

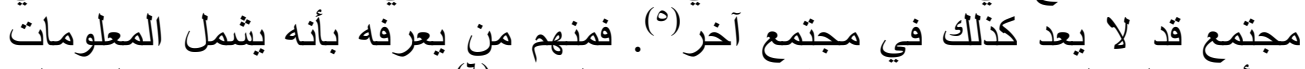

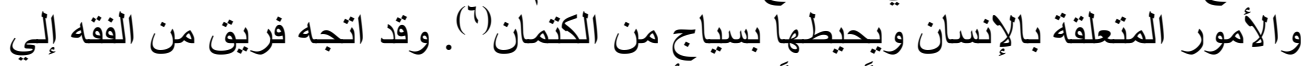

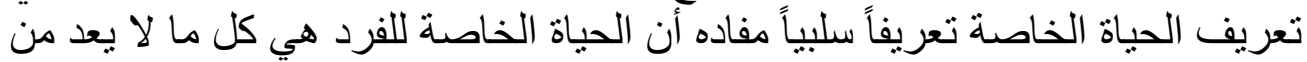

(0) د.أشرف توفيق شمس الدين، الصحافة و الحماية الجنائية للحياة الخاصة "دراسة مقارنة"، دار

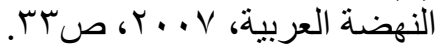

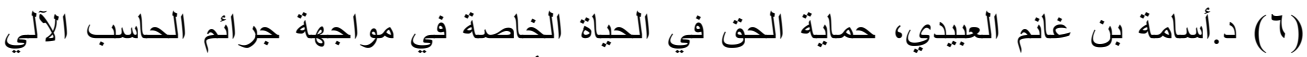

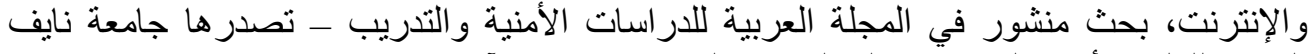

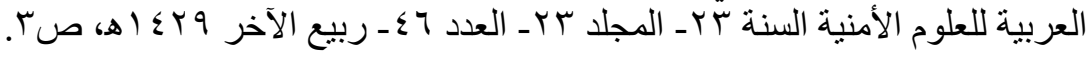


حياته العامة'(V).

وسوف يعالج هذا المبحث الاتجاهات الموضوعية في تعريف الحق في الحياة الخاصة في المطلب الأول ويعالج فكرة نسبية الحياة الخاصة في المطلب التبات الثاني.

\section{المطاب الأول \\ الاتجاهات الموضوعية لتعريف الحق في الحياة الخاصة}

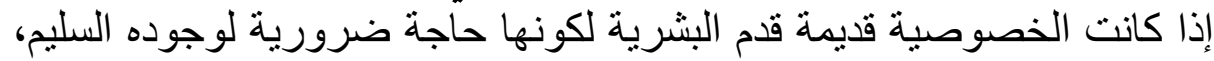

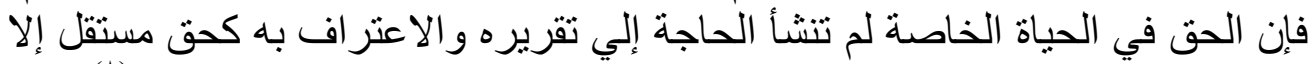

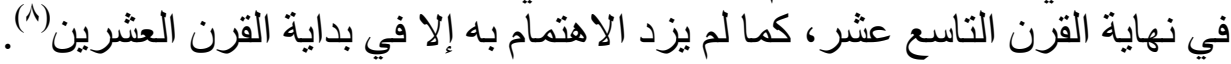

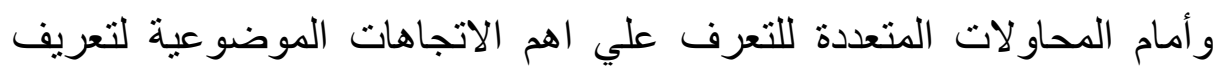

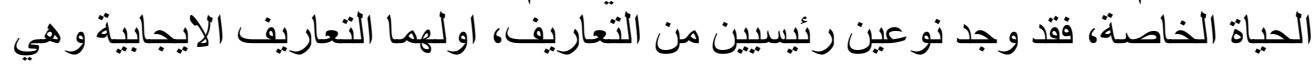

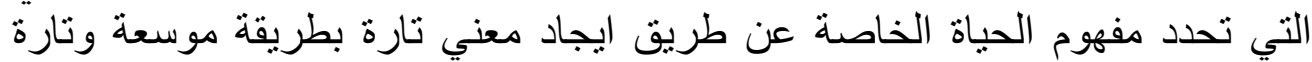

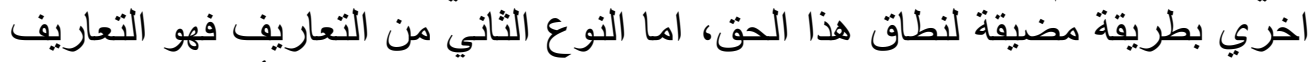

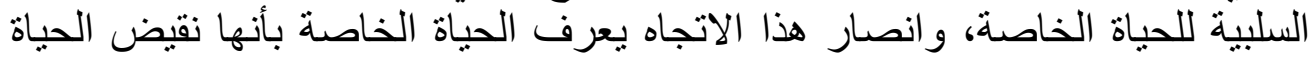
العامةة.

وفي ضو ء ما تقدم سوف نقسم هذا المطلب الي فرعين: الفرع الاول: التعريف الايجابي للحياة الخاصة. الفرع الثاني: التعريف السلبي للحياة الخاصة.

\section{الفرع الاول الاول \\ التعريف الايجابي للحياة الخاصة الأفة الفيرة}

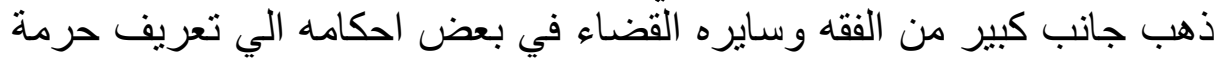

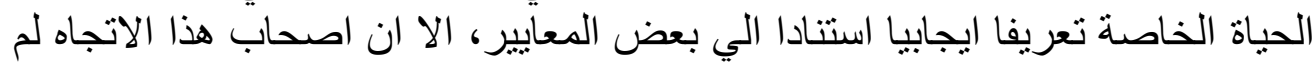

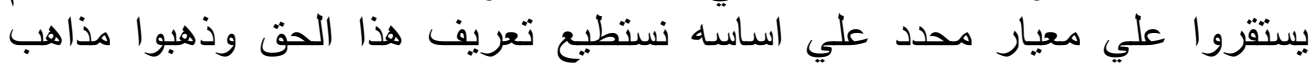

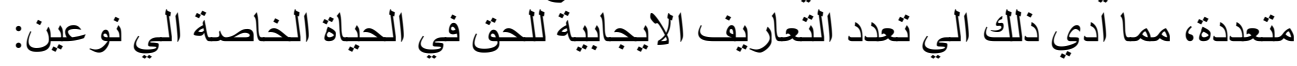

النوع الاول: التعاريف الموسعة لمفهوم الحياة الخاصة.

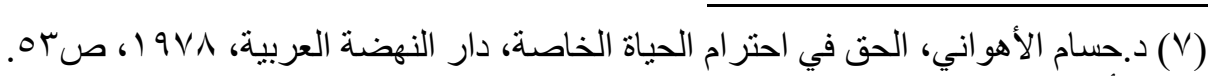

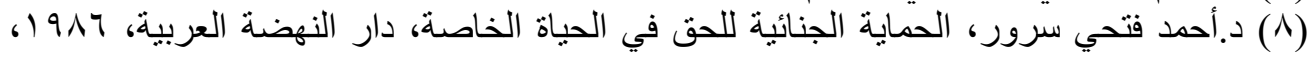




\section{1 ـ تعريف الحياة الخاصة اعتماد علي معيار الخلوة:}

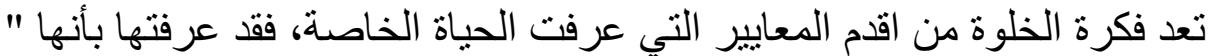

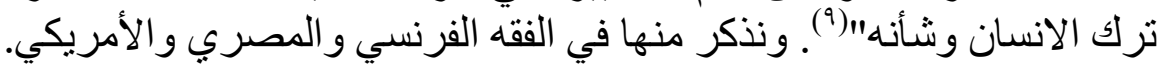

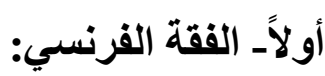

لقد تعددت التعاريف التي وردت في بيان الحق في حرمة الحياة الخاصة استنادآ

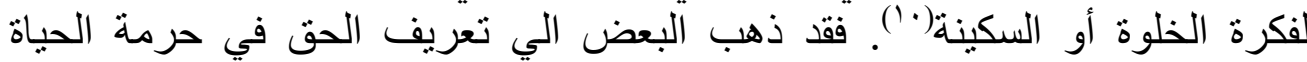

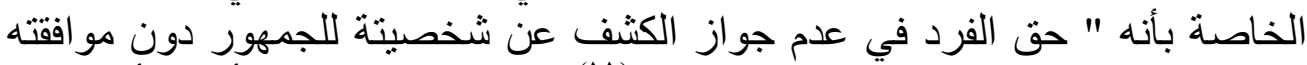

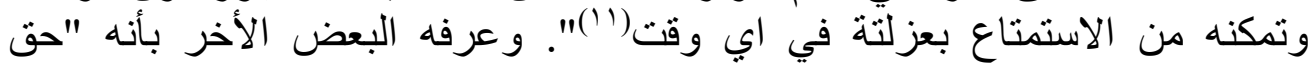

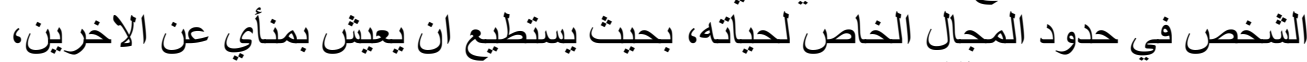

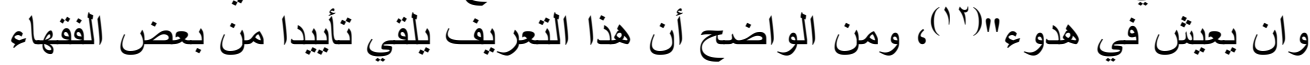

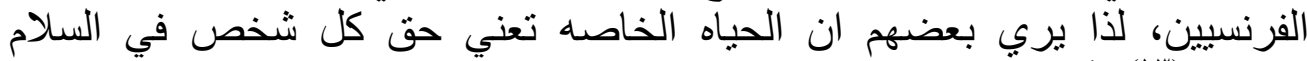

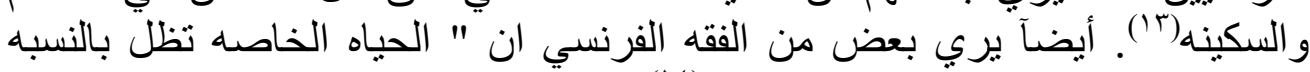

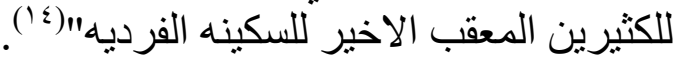

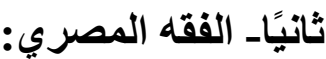

فقد عرف الفقه في مصر الحق في حرمة الحياة الخاصة استنادآ إلي فكرة الخلوه

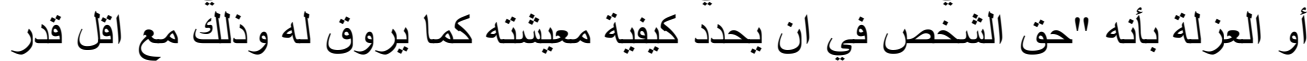

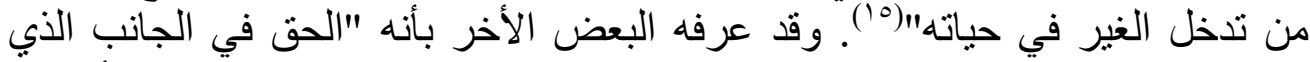

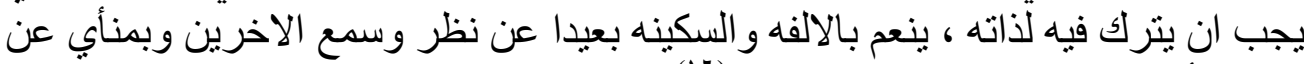

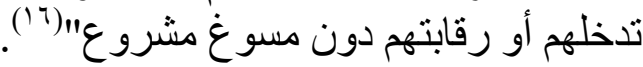

(9) د. ابراهيم عيد نايل، الحماية الجنائية لحرمة الحياة الخاصة فى قانون العقوبات الفرنسى،

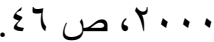

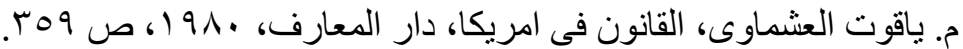
(·) (1) د. محمود عبد الرحمن، المسئولية عن مضار الرعار الجوار غير المألوفة، دار النهضة العربية،

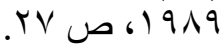

$\left({ }^{11}\right)$ Nerson "la protection de 1 intimate" journ des trib 1959, p. 713.

(12) Carbonnier, briot civil, 1971, tome1, no. 71, p. 239.

(13) Conclusions de $\mathrm{ml}$ avocet general cabanes sous paris 15 mai 1970-466.

(14) Franciose- gailove (g) "le secret de la information " le monde 20 septembre 1970.p.36.

(10) د. ممدوح خليل بحر، حماية الحياه الخاصه فى القانون الجنائى دراسة مقارنه، دار النهضه

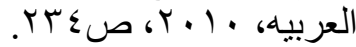
(7 (1) د. محمود عبد الرحمن محمد، نطاق الحق فى الحياه الخاصه"دراسه مقارنه"، دار النهضه العربيه، .99 19، صود صو الرحن. 


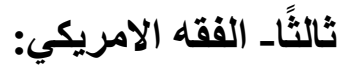

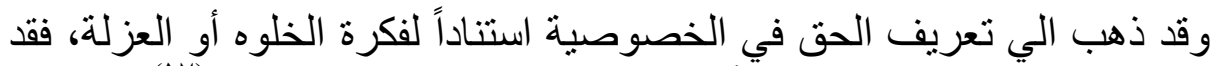

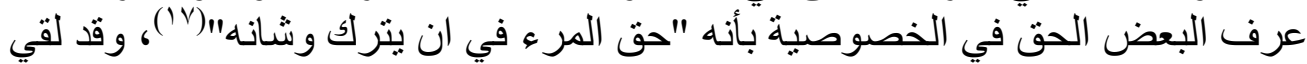

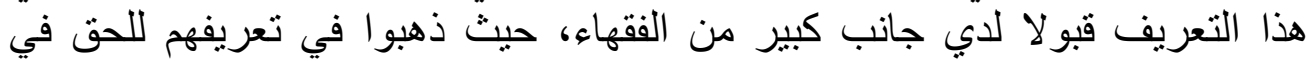

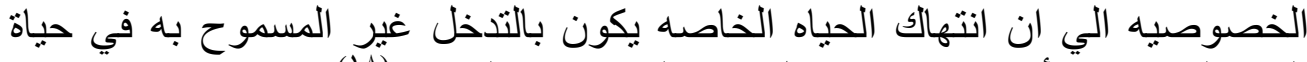

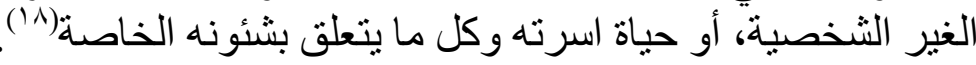

\section{r ـ تعريف الحياة الخاصة اعتماد علي معيار الحرية

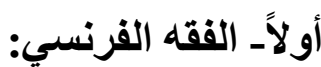

اتجه جانب من الفقه الفرنسي في تعريفه الحق في حرمة الحياة الخاصة استنادآ لفكرة الحرية لأكثر من تعريف، فقد ذهب البعض منهم التي تعريف الحياة الخاصة بأنها

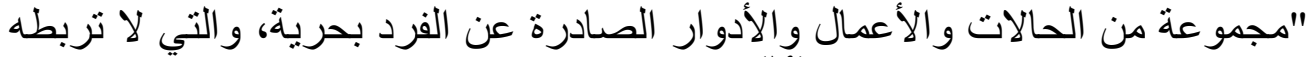

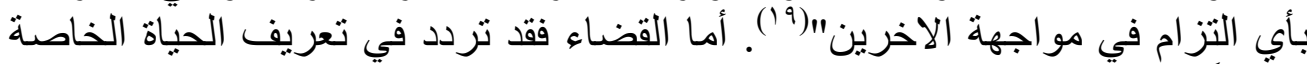

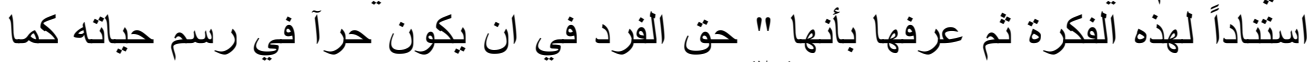

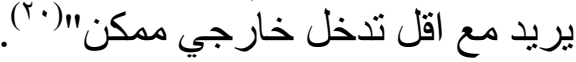

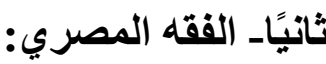

اتجه جانب من الفقه المصري في تعريفه الحق في حرمة الحياة الخاصة استنادآ

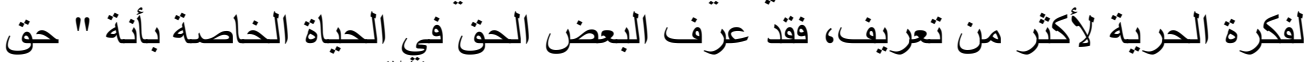

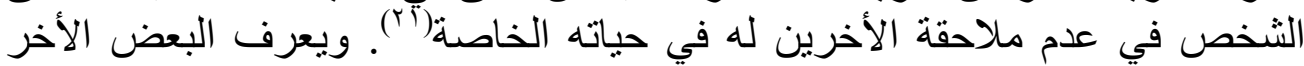
الحق في الحياة الخاصة استنادآ لهذه الفكرة بأنه" الحق في فئه الخيادة الانسان لذاته بالكون

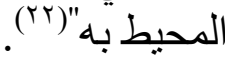

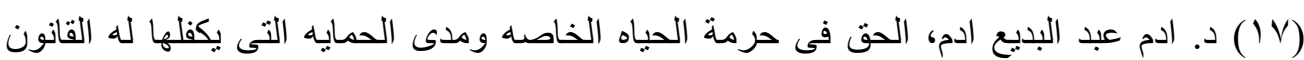

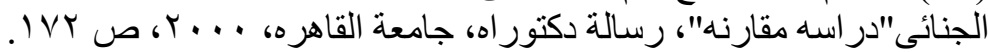

(18) Wintield: "torts"seventh edition1963, p.720.

$\left({ }^{19}\right)$ D ferrer: "la protection dela vie privee" these toulouse 1973, p. 12 et 26.

$\left({ }^{20}\right)$ Arret cour de paris 15 mai $1970 \mathrm{~d} 1970 \mathrm{j} \mathrm{p} 466$ note d a et $\mathrm{h} \mathrm{m}$.

مشار اليه عند د. كاظم السيد عطية، الحماية الجنائية لحق المتهم فى الخصوصية" دراسة

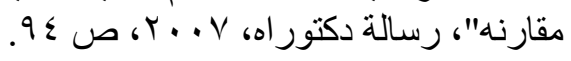

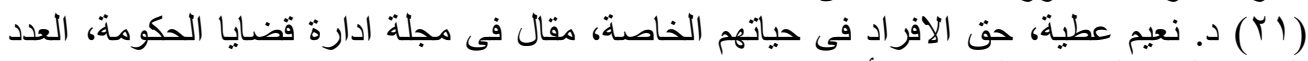

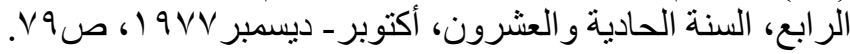

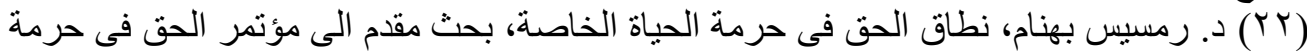

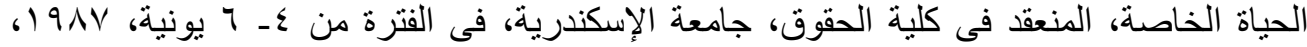




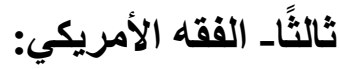

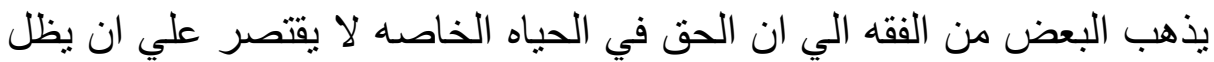

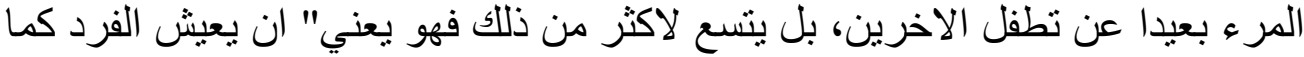

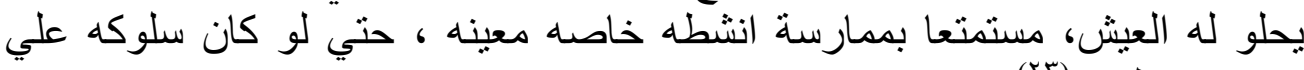

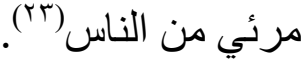

\section{النوع الثاني: التعاريف الضيقة لمفهوم الحياة الخاصة.} لقد اختلف الفقهاء في وضع معايير معينه لتعريف الحياه الخاصها من المفهوم

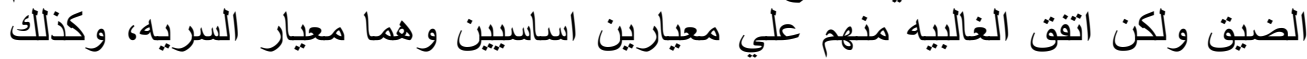

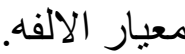

\section{1 ـ تعريف الحياة الخاصة اعتمادآ علي معيار السرية:}

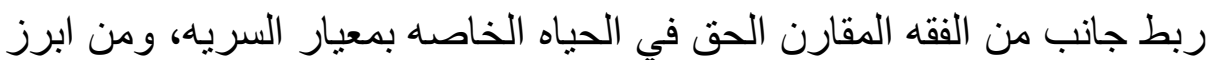
التعاريف التي تربط بين فكرة الحياه الخاصنه وفكرة السريه الفيه ما يلي:

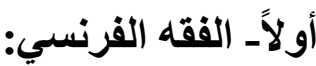

فقد ربط جانب من الققهاء بين الحياه الخاصه و السرية، حيث ذهب البه الي ان حياة

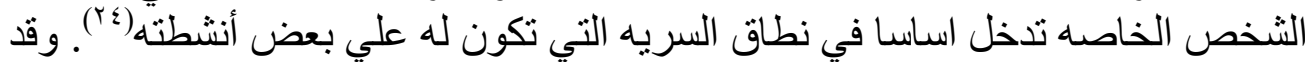

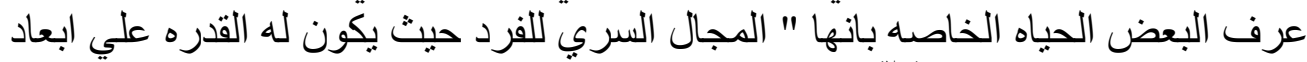

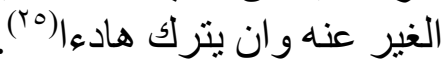

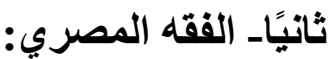

لقد ظهر في الفقه اتجاه يضيق من مفهوم الحياة الخاصة ويربطها بفكرة السرية،

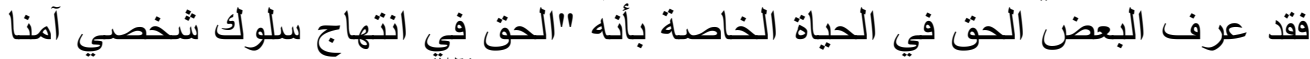

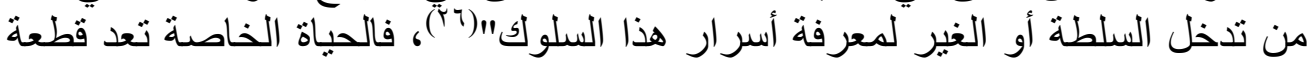

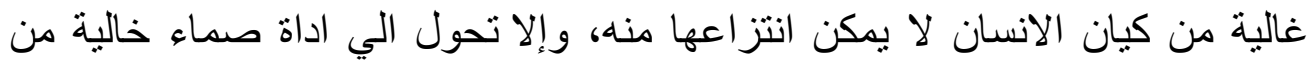

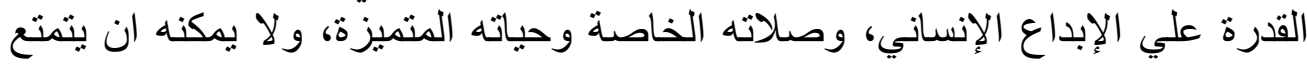

$\left({ }^{23}\right)$ Gohn H .F. Shattuck: "right of privacy", national text book company, 1977, P.197.

$\left({ }^{24}\right)$ A.Decaq "rapport sur le secret de la vie privee en droit francais "journees libanaises de 1 association. h. capitan, travaux de 1 association. h. capitan, t.25, ed.dlloz paris, 1974, p.1;martin: "le secret de la vie privee" rev. trim. civ., 1959, p. 222.

$\left({ }^{25}\right)$ Carbonnier: dtiot civil,tom1, 1969,no. 41.

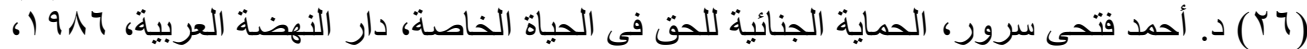




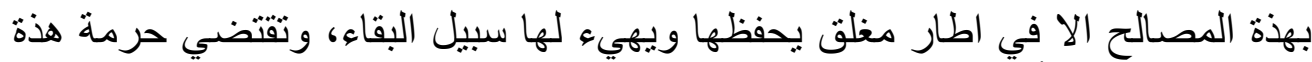

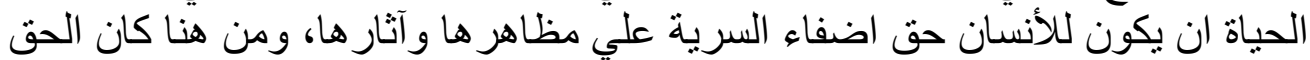

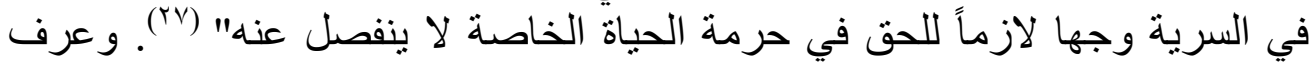

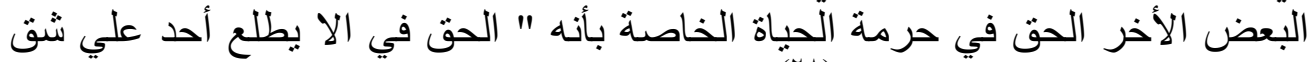

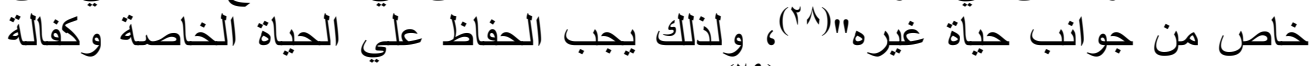

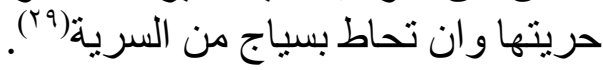

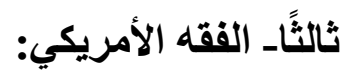

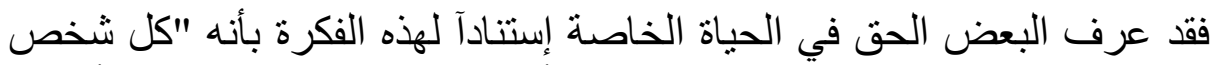

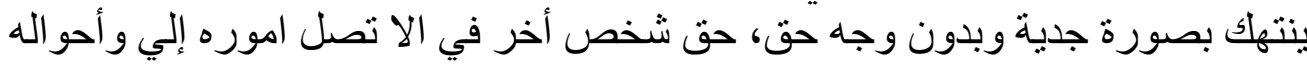

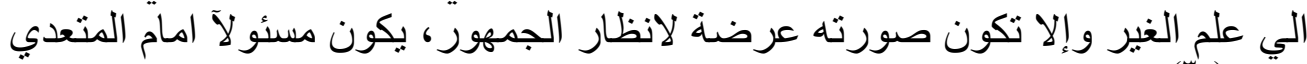
عليه"(r).

\section{r- تعريف الحياة الخاصة اعتماداً علي معيار الألفة: \\ أولاًَ- الفقه الفرنسي:}

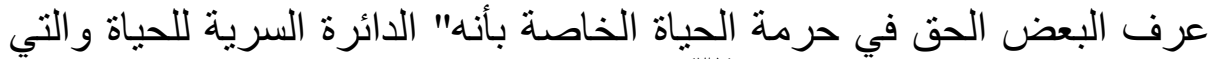

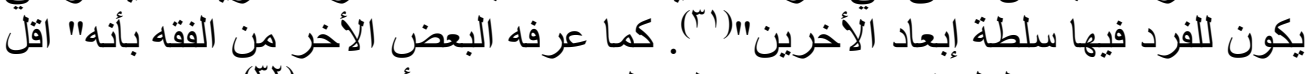

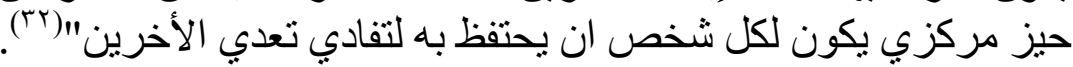

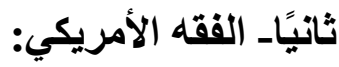

لا يختلف الوضع في القانون الامريكي عن القانون الفرنسي، حيث وفئ وفرت الإني

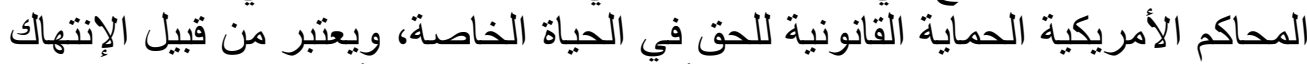

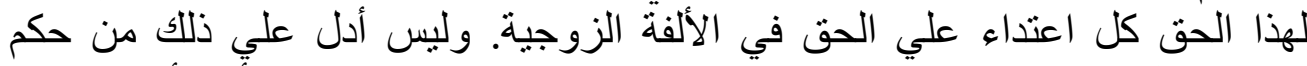

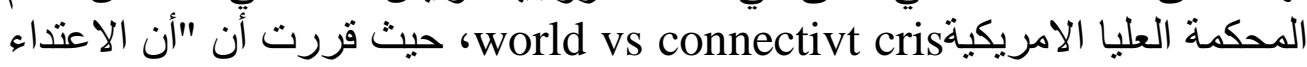

(YV)

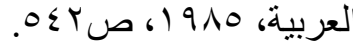

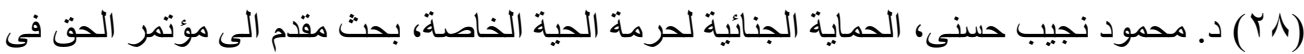

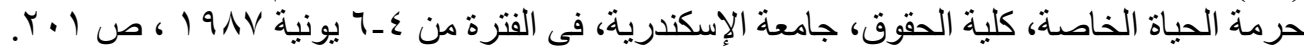

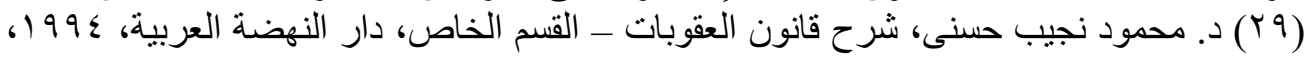
VNT ص

(30) Leio- Brittan: the right of privacy in england and us "Tulane law rev1963, p. 236.

$$
\text { مشار إليه بمؤلف د. ادم عبد البديع ادم، المرجع السابق، ص NV اوما بعدها. }
$$

(31) Carbonier: "droit civil"tome 11969, no. 41.

(32) Nerson "la protection de la personnalite en droitprive francais" trvaux de 1 asso citation h capitant t 13, p. 79. 
علي الفة الحياة الخاصة الزوجية أمرينطوي علي افتئات علي الحق في الحياة الخاصة

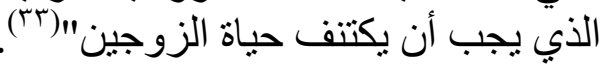

\section{الفرع الثاني

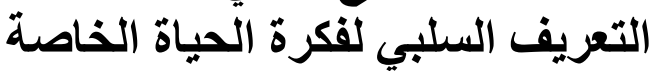

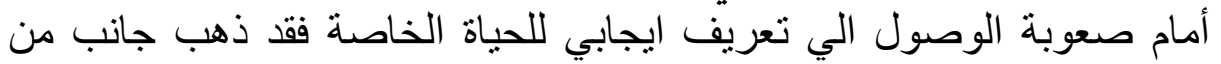

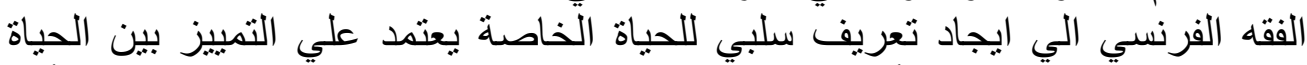

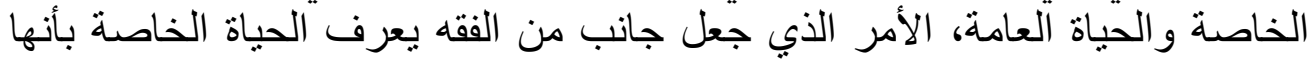

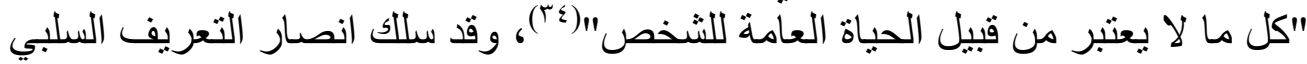
اتجاهين في تعريفهم للحياة العامة علي النحو التير التالي: الاتجاه الأول: و هو الذي يعريف الحياة العامة استنادآ لمعيار معين. الاتجاه الثاني: وهو الذي يعرف الحياة العامة استتادآ علي حصر وتعداد الحالات التي تدخل في نطاق الحياة العامة

\section{النوع الأول \\ الاتجاه المعياري في تعريف الحياة العامة التهاة}

وقد اعتمد انصار هذه الاتجاه في تعريفهم للحياة العامة علي معيارين علي النحو التالي:

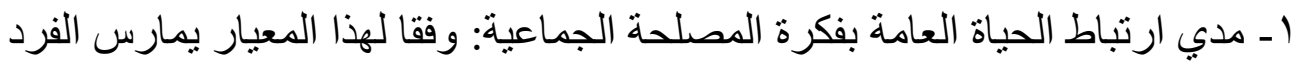

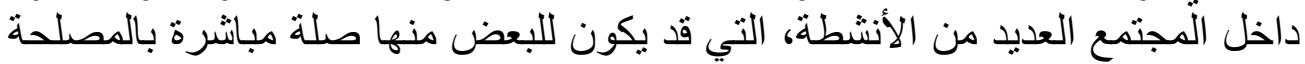

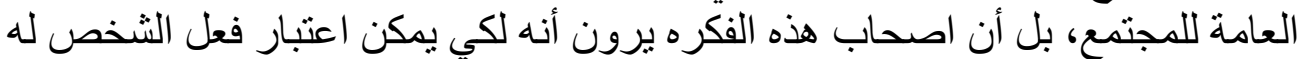

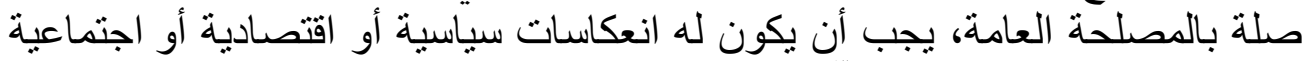
تمس المصالح العليا للمجتمع (ب0)

(1970/0/V 1 مشار اليه بمؤلف د. آدم عبد البديع المحكمة الأمريكية العليا الصادر بتاريخ

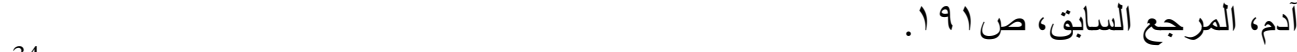
$\left({ }^{34}\right)$ Badintir : le droit au respect de la vie priveej c p 1968 - 2136.

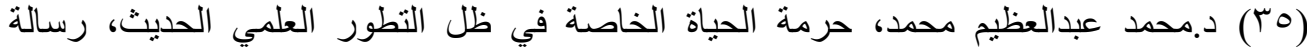

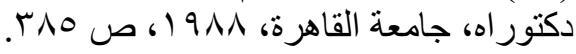




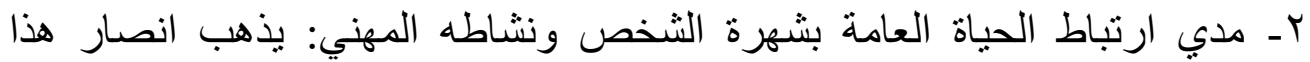

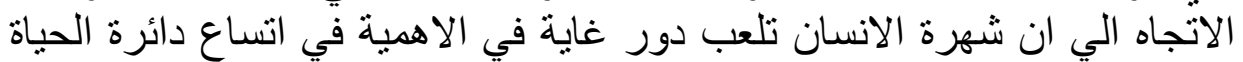

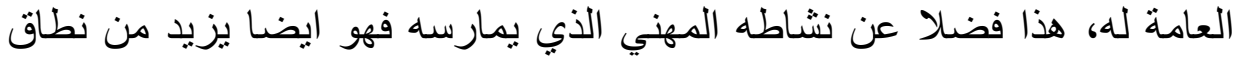

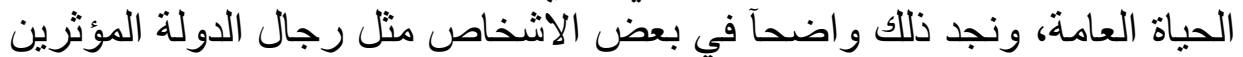

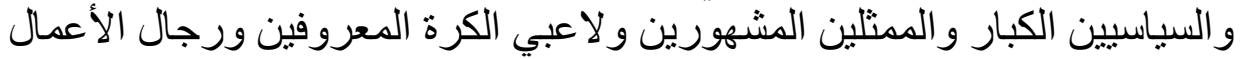

$$
\text { و والمستثرين اللامعين. }
$$

وتطبيقا لذلك في قضية عرفت بقضية "بيكاسو" والتي تتلخص وقائ وقائعها في أن

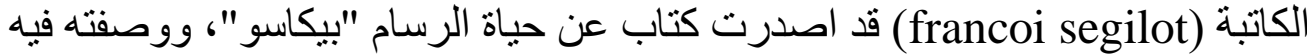

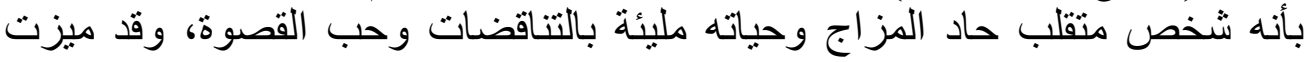

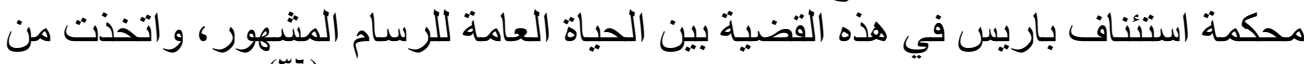

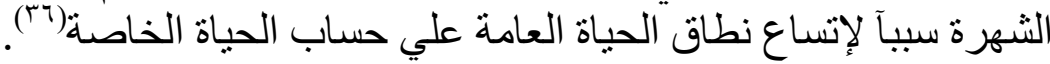

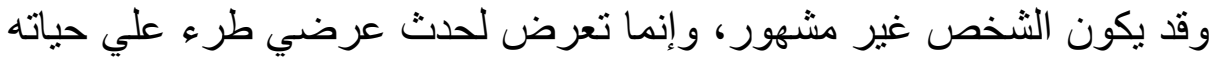

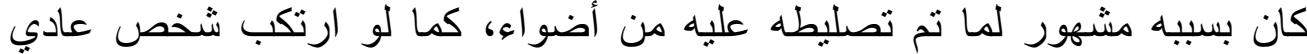

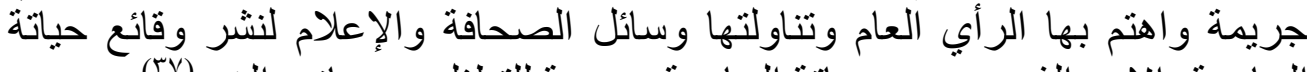

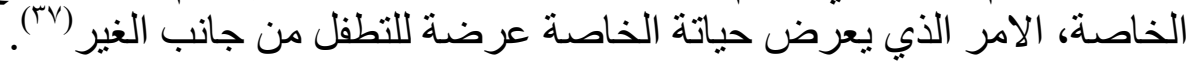

\section{الاتجاه التعدادي في تعريفت الحياة العامة التُاني}

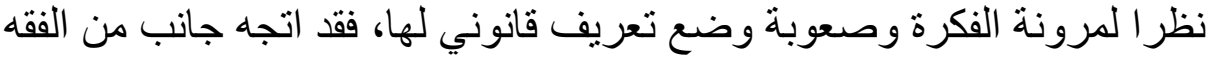

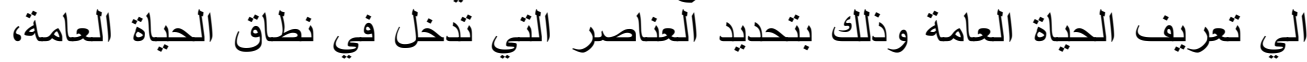
بحيث يصبح ما عدا ذلك يدخل في نطاق الحياة الخاصةً.

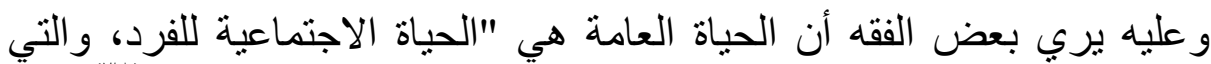

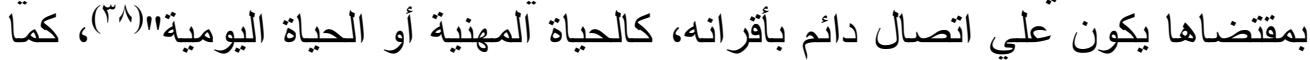

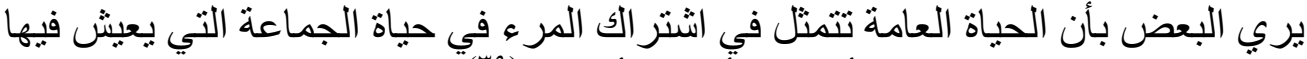

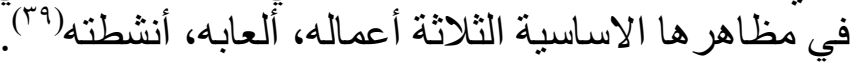
و علي ذلك يمكن ايجاز العناصر التي تشملها الحياة العامة علي النحو الأتي:

$\left({ }^{36}\right)$ Paris6juillet1965, gazpal1366- 1 -37.

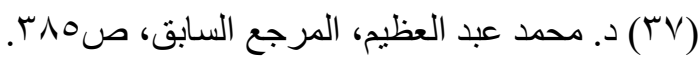

(38) Martin "le secret de la vie privee" op cit p 230 .

(39) Badinter: "le droit au respect de la vie privee" J.C.P. 1968, 1236. 
تعد من قبيل الحياة العامة للأشخاص الأنشطة المهنية أو الحرفية، التي يكون فيها

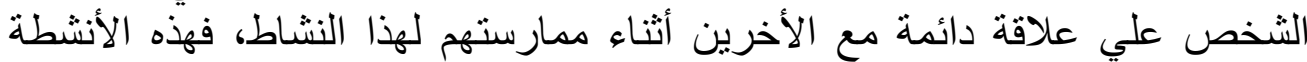

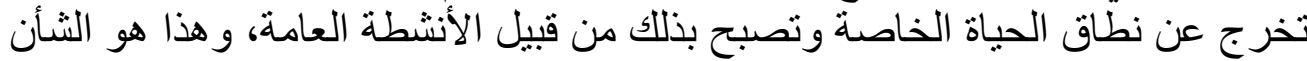

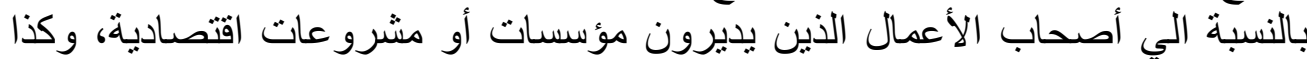

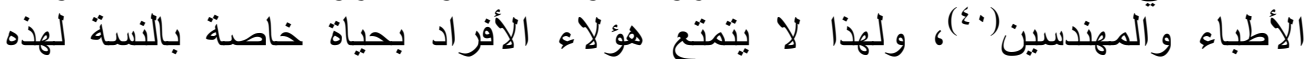
الأنشطة، ولذلك أقر القضاء الفرنسي في بعض أحكامه أن الحياة المهنية للفنان تدخل

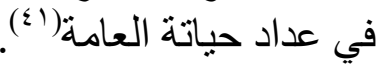

ثانيًا- الانشطة المتعلقة بالسلطات العامة:

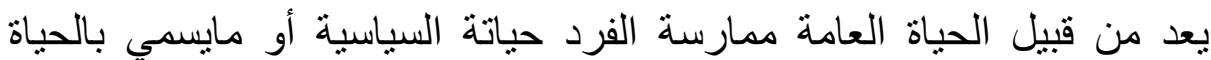

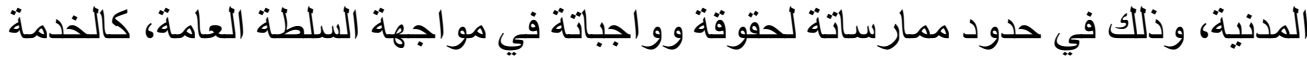
العسكرية وممارسة حق التصويت وحق الإنتخاب وغير ذلكة فئه فكل هذه الأعمال تدخل في نطاق الحياة العامة(بك).

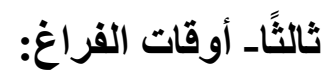
يقصد بأوقات الفراغ هنا تللك التي يقضيها الفرد في الأماكن العامة فقط("آ؛)؛

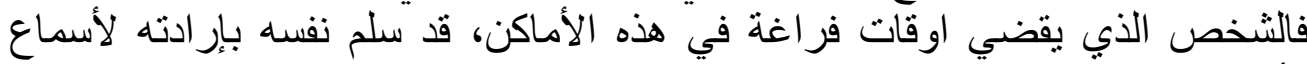

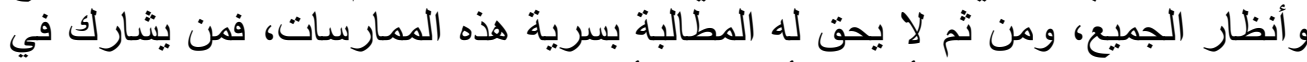

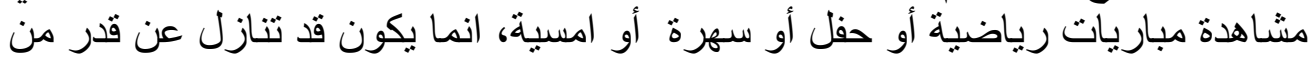

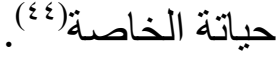

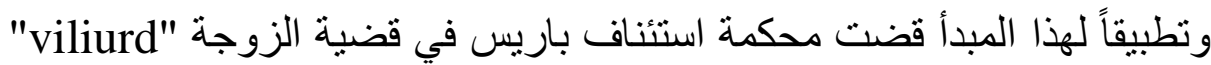

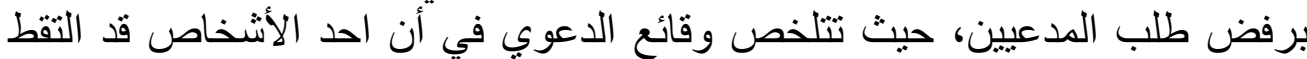

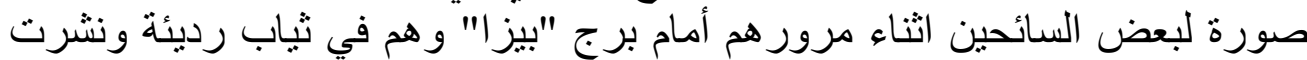

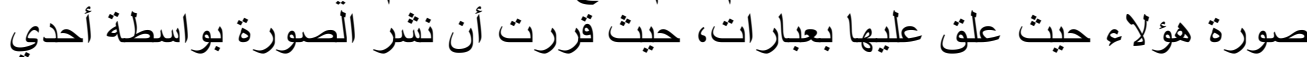

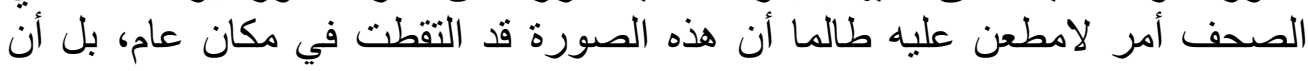

$$
\text { ( • • ( ) د. ابر اهيم عبد نايل، المرجع السابق، ص }
$$

(41) Paris 17 mars 1966 dalloz 1966- 749; T g I seine 24 nov 1965 j c p 1966- 11- 14521; Paris 27 fev 1967, Dalloz 1967, 450 not foulon- piganiel. (r (₹) د. ادم عبد البديع ادم، المرجع السابق، ص 99 1؛ د. ممدوح خليل بحر، المرجع السابق،

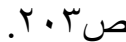

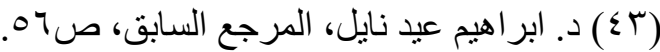

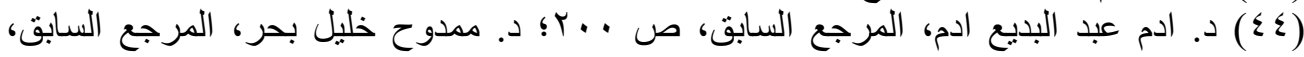


المحكمة قررت أن المبدأ بسري بالنسبة لكل حالة لم يحاول من التقطت صورته أن

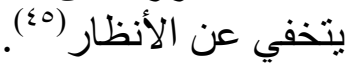

\section{تعريف الباحث:}

من جماع هذه الآراء يتضح أن تعريف الحياة الخاصة هي: حق الفرد في ألا

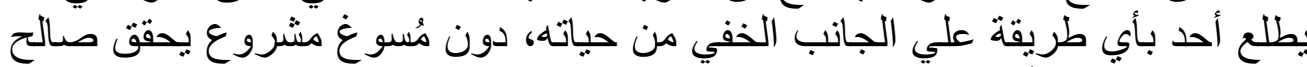

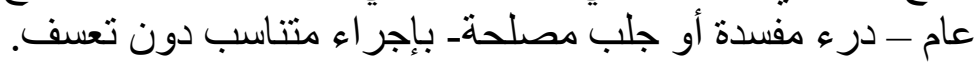

\section{فكرة نسبية الحياة الخياصة الثاني}

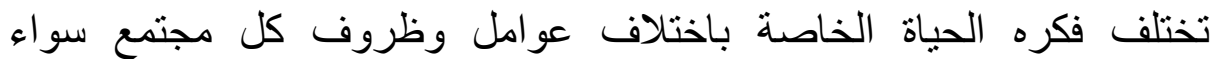

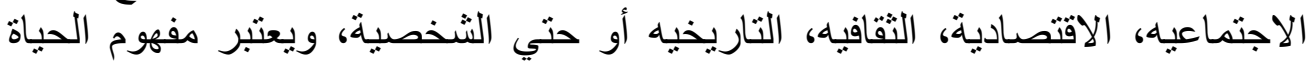

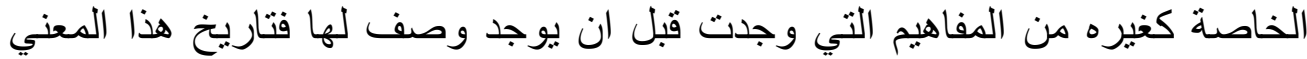

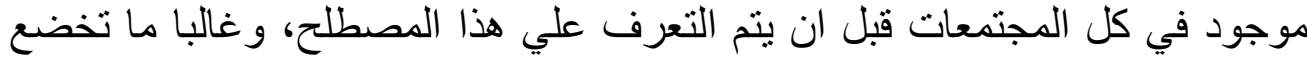

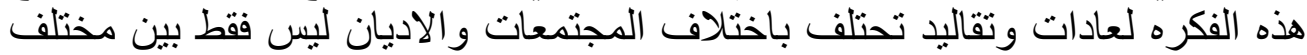

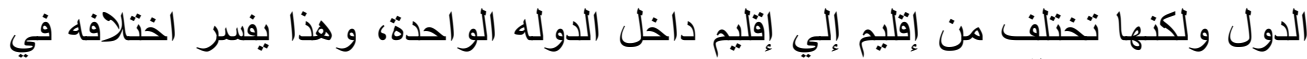

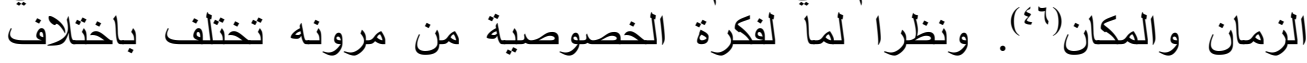

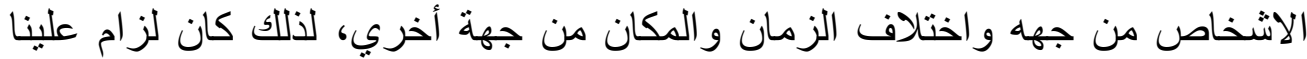
توضيح ذللك علي التقصيل التالي: الفرع الاول: اختلاف فكرة الحياة الخاصة باختلاف الأشخاص. الفرع الثاني: اختلاف الحياة الخاصة باختلاف الزمان والمكان.

\section{الفرع الأول \\ اختلاف فكرة الخصوصبة باختلاف الأشخاص الخاص}

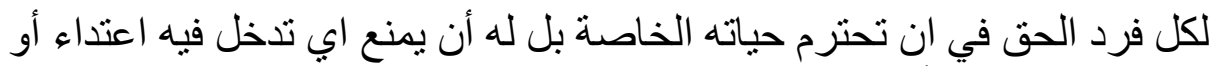

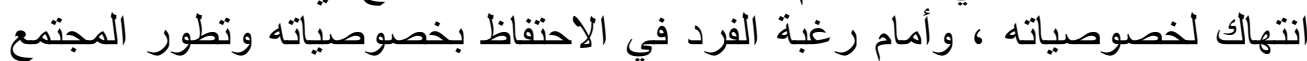

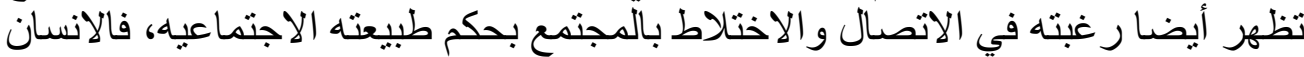

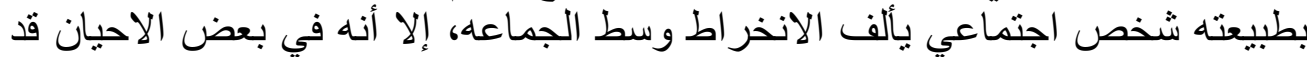

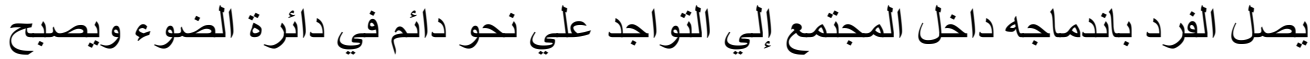

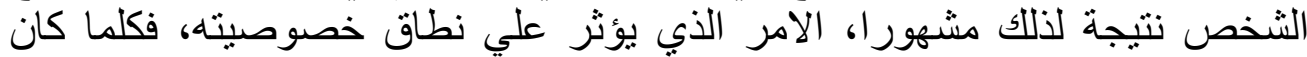

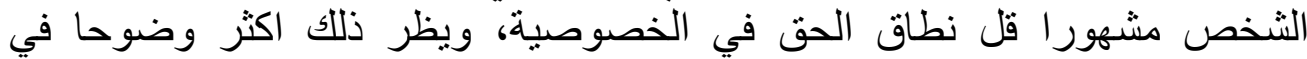

(45) Paris 25 mars 1965 j c p 1965- 1- 14305.

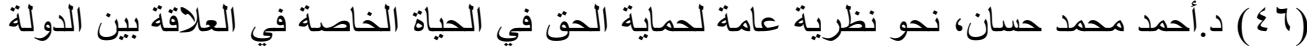

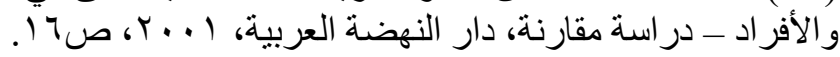


الثخصيات العامة ونجوم الرياضة أو الفن و السياسيين الكبار، فحياتهم الخاصة تصبح

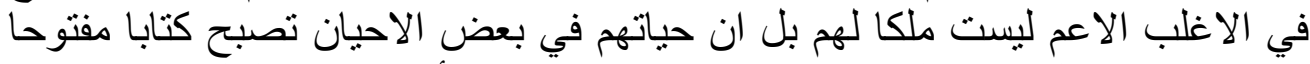

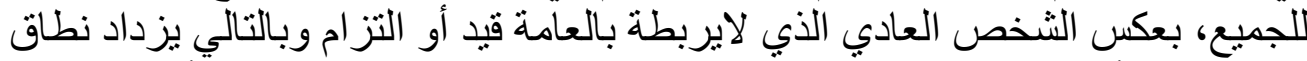

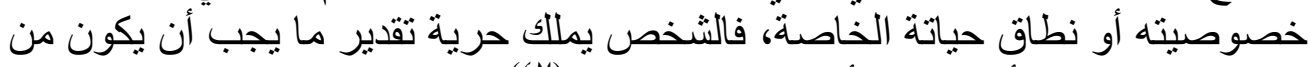

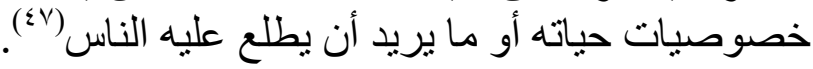

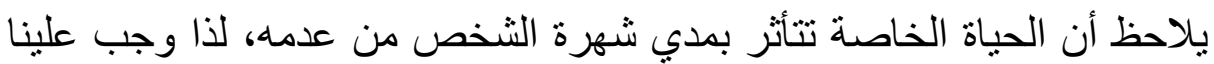

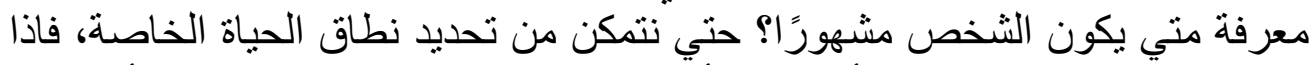

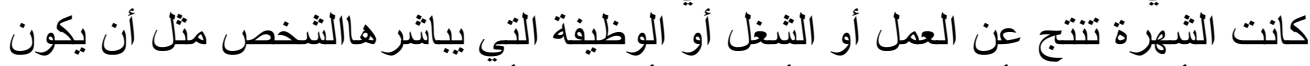

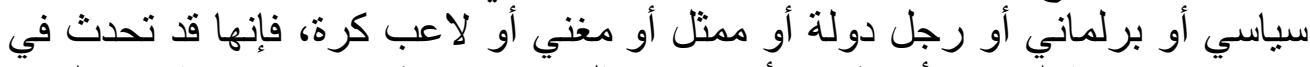

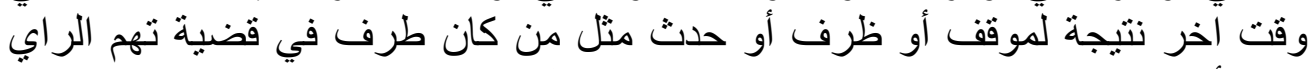

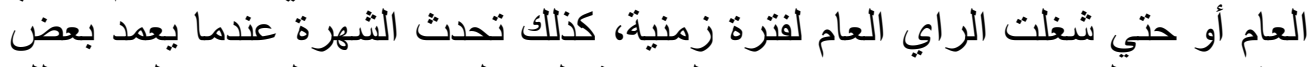

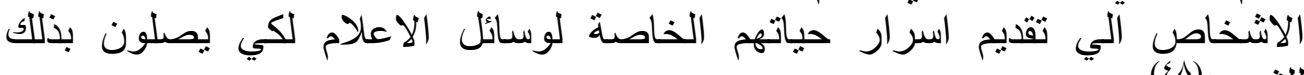
للشيرة: (ఓ^)

نخلص من ذلك ان الخصوصية تختلف باختلاف الاشخاص يزيد نطاقها

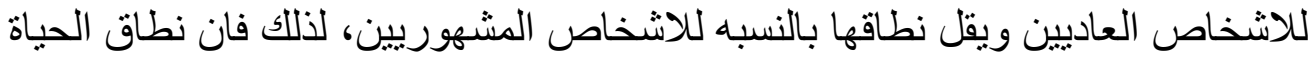

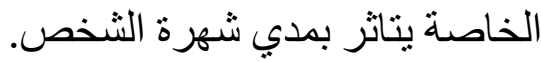

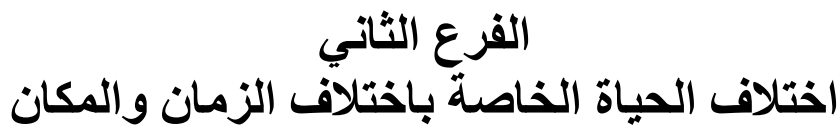

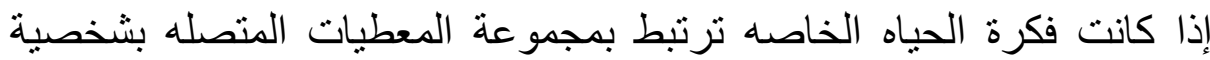

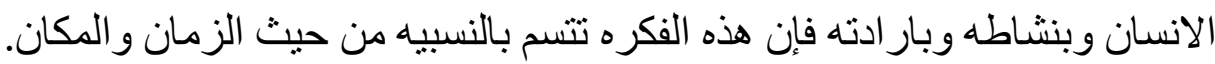
فالخصوصية تتغير ضيقا و اتساعا بمجموعه من الاعر اف و التقاليد و الاخلاق

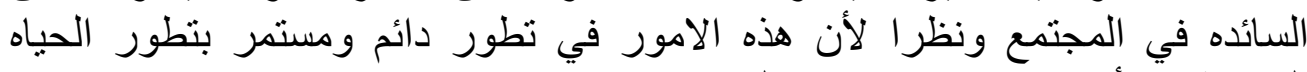
البشرية كما أنها تتغير بحسب ونظب تغير المكان.

أولاً نسبية الحياة الخاصة عبر الزمان:

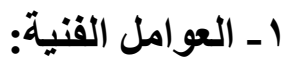

نظراً للتطور التقني المتمثل في شبكات التواصل الاجتماعي وظهور وسائل

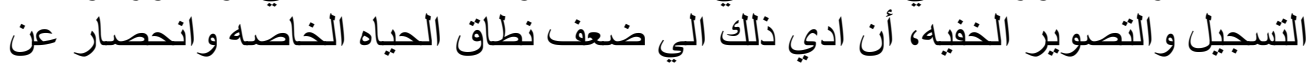

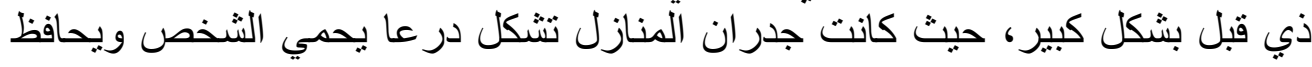

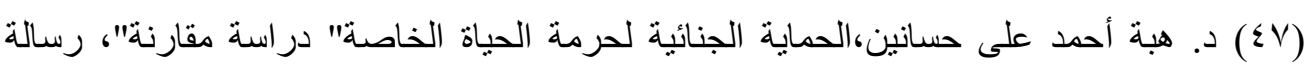

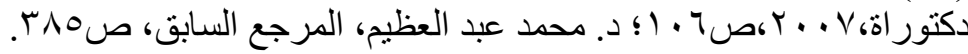

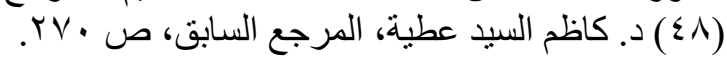




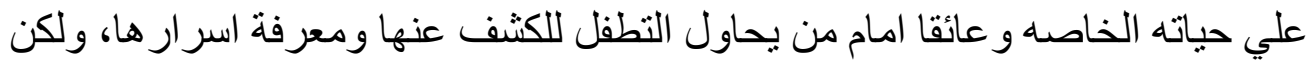

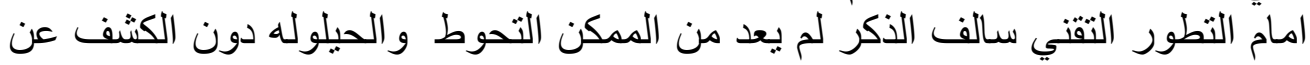

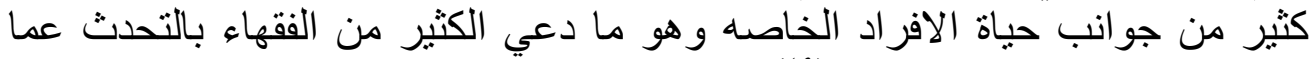
اسماه بنهاية فكرة الحياه الخاصه(

فقد أدي التطور التكنولوجي إلي زيادة المخاطر التي يتعرض لها الحقا الحق في

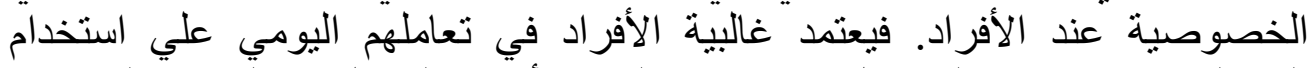

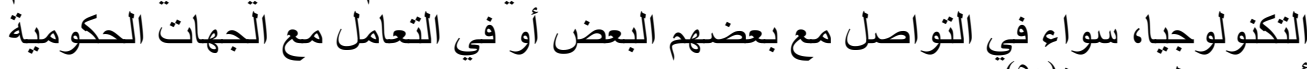
أو غير الحكومية)(0).

\section{r ـ العوامل الاجتماعيه والنفسية:}

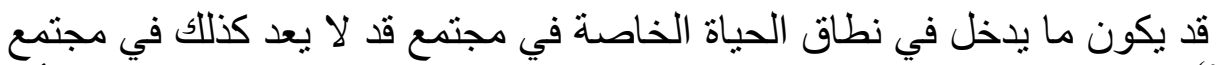

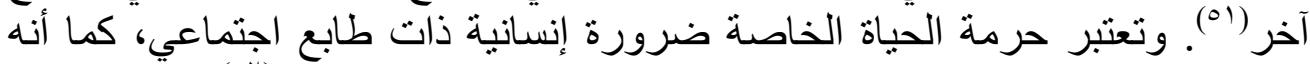

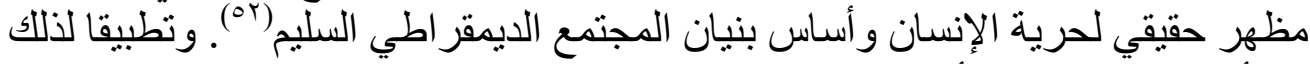

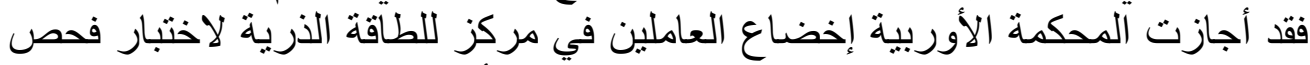

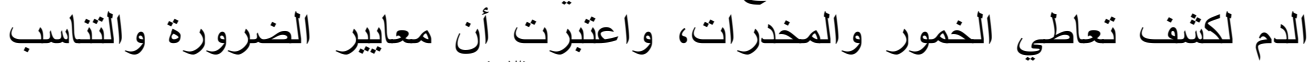

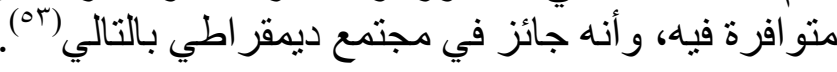

كما أجازت المحكمة الأوربية إخضاع العاملين في مركز للطاقة الذرية لاختبار

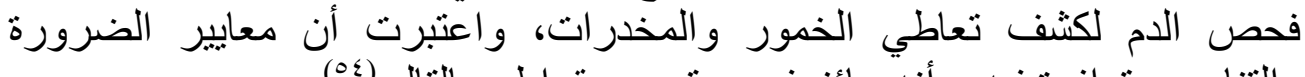
و التناسب متو افرة فيه، و أنه جائز في مجتمع ديمقر اطي بالتالي (\&).

ثانيًا نسبية فكرة الحياة الخاصة مكاتيا:

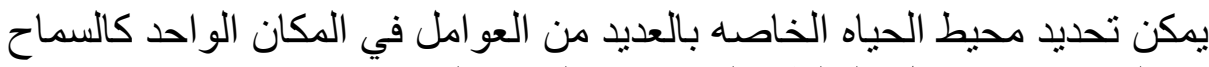

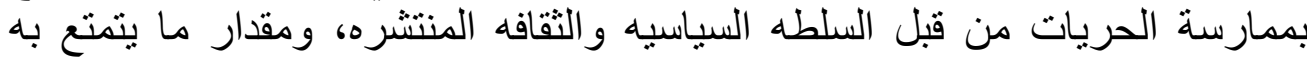
المجتمع من تحرر اخلاقي وذللك علي النحو التالي:

1 - بالنسبة لنظام الحكم:

(49) Gerald messadie “le fin de la vie privee” ed calmann levy 1974- imprim en france p. 170

(•) د. جاسم محمد العنتلي، الجرائم و التكنولوجيا الحديثة"دراسة مقارنة"، الطبعة الأولى، دار

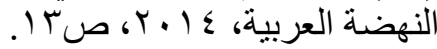

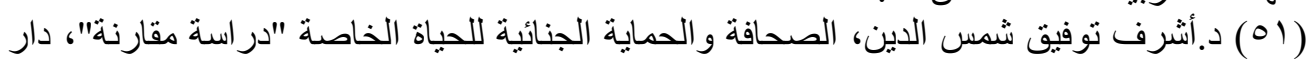

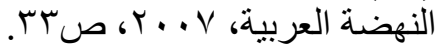

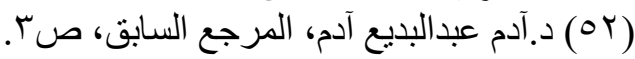

(53) Arrêt du 7 mars 2002 (Madsen c/ Danemark): Vanessa Barbé, id.

(54) Arrêt du 7 mars 2002 (Madsen c/ Danemark): Vanessa Barbé, id. 
تختلف فكرة الحياه الخاصه باختلاف النظام السياسي السائد، فبالنسبة للنظام

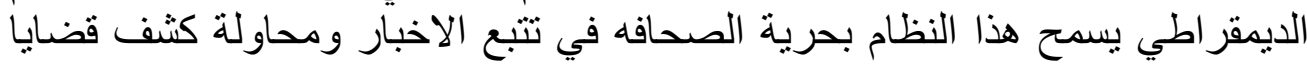

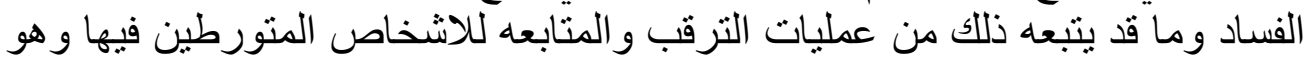

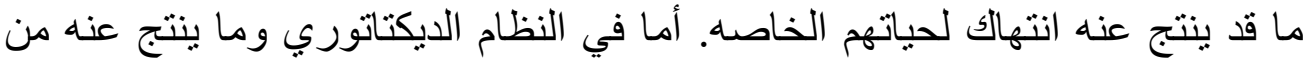

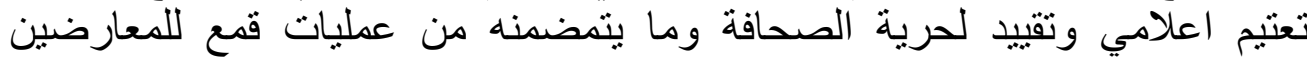

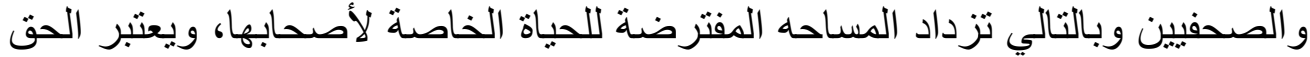

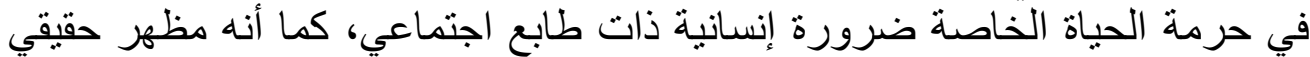

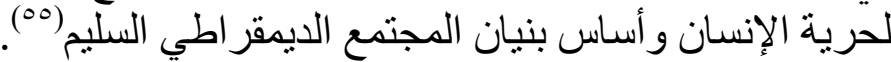

وتطبيقا لذلك فقد أكدت المحكمة الأوربية لحقوق الإنسان هذا المبدأ واعتبرت أن

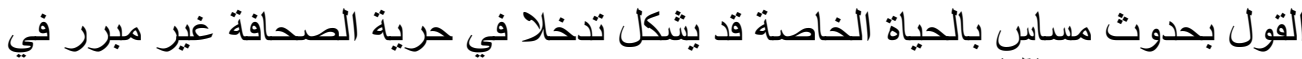
مجتمع ديمقر اطي (07).

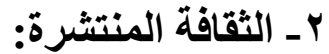

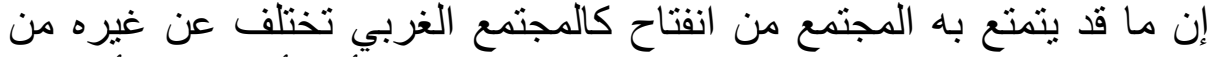

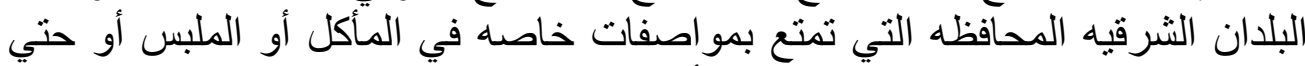

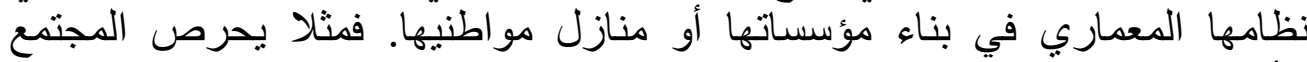

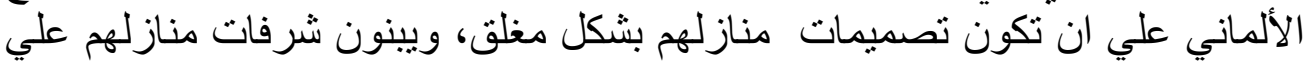

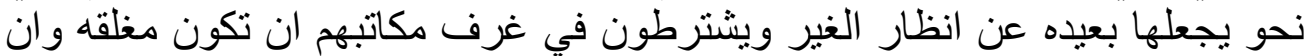

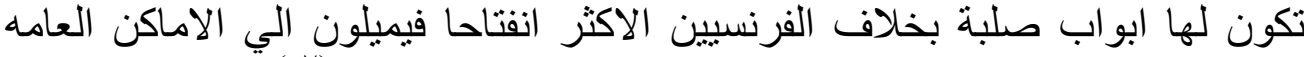

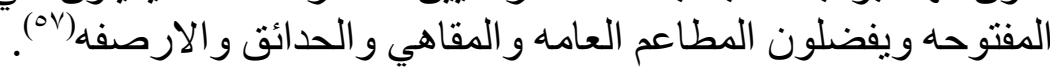

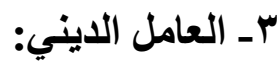

تثكل المعتقدات الدينية التي يعتنقها الثخص عنصر الثن التن عناصر حياته الخاصة

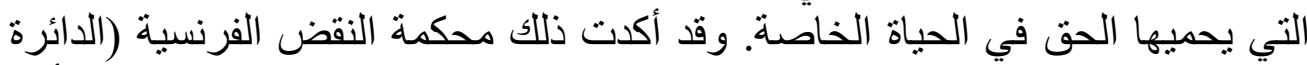

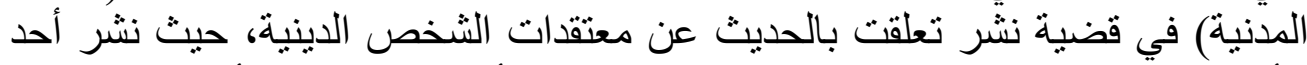

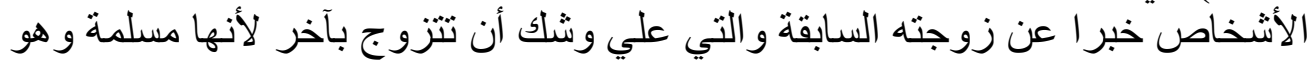

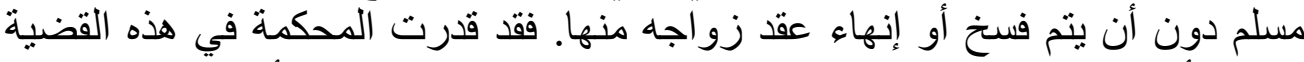

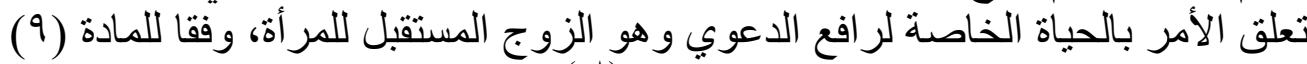

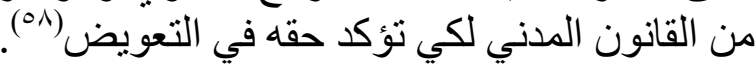

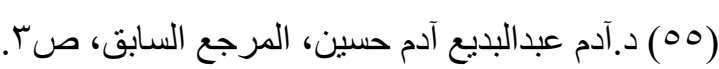
(56) CEDH 23 juill. 2009, Hachette Filipacchi associés c/ France, req. no 2268/03, RDLC 2009/65.3612, obs. Pouliquen

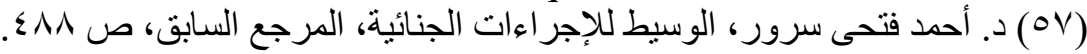

(58) La religion est un élément de la vie privée dont la divulgation ne peut 


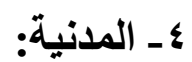

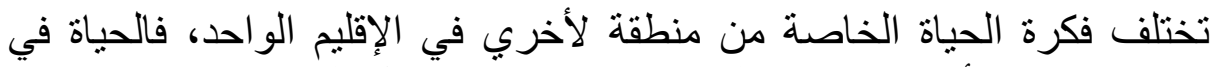

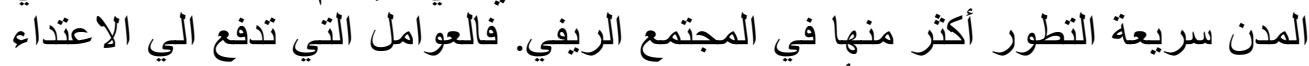

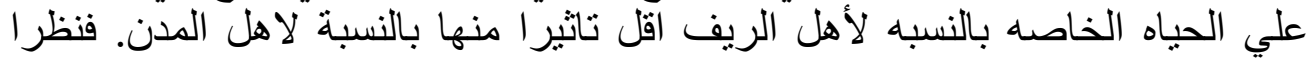

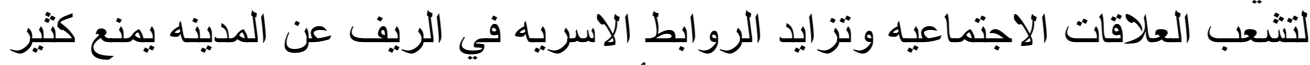

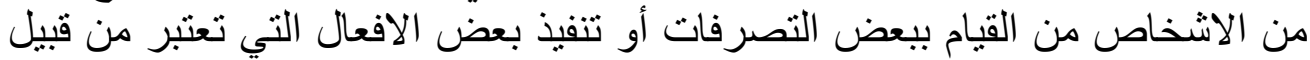

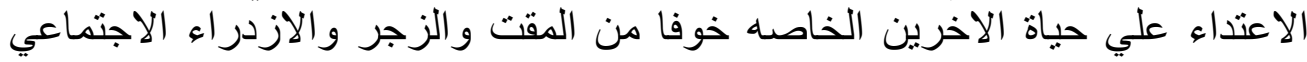

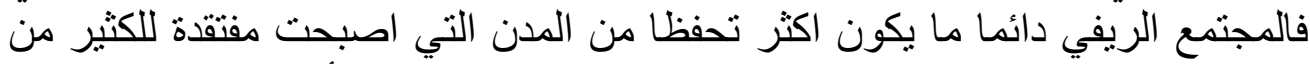

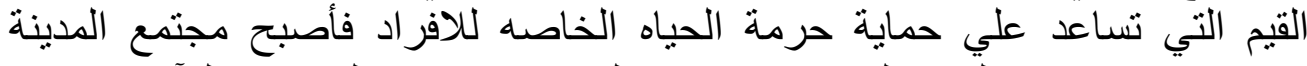

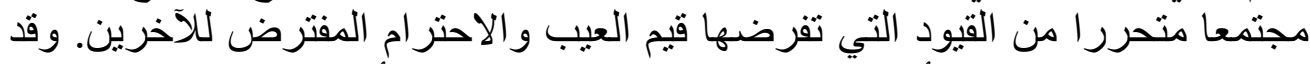

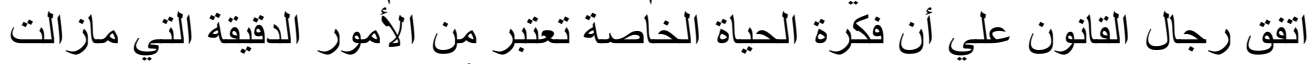

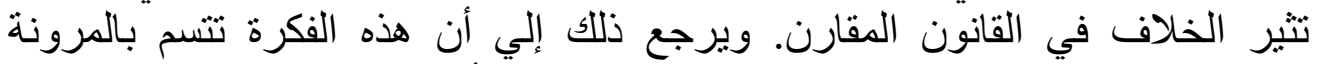

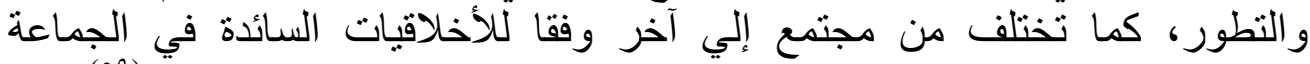

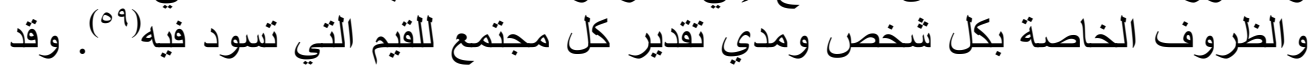

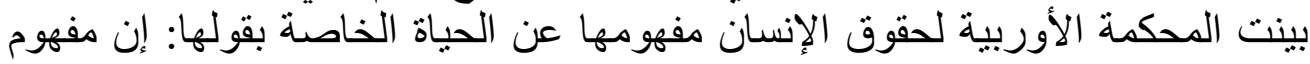

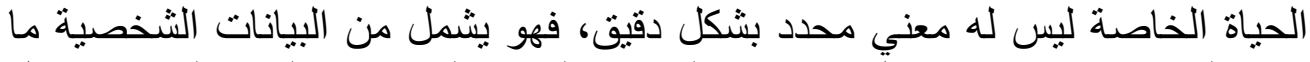

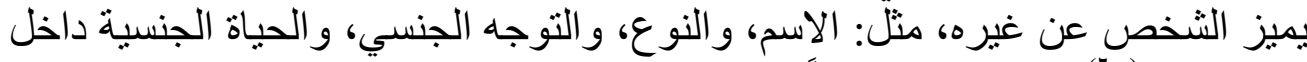

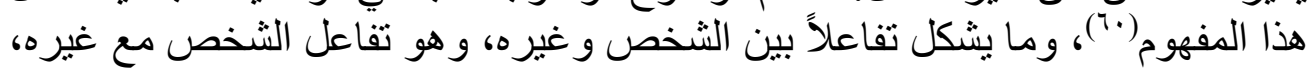

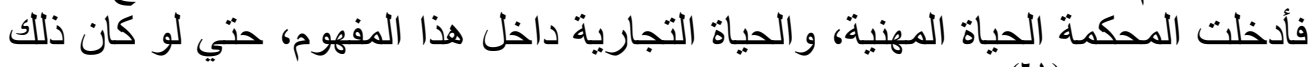

$$
\text { يتم في مكان عام (1). }
$$

بذللك؛ فإن الحياة الخاصة لا تتحصر في رأي المحكمة في الوقائع التي تحدث في

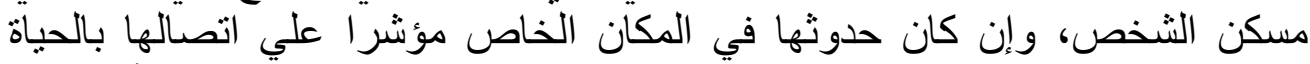

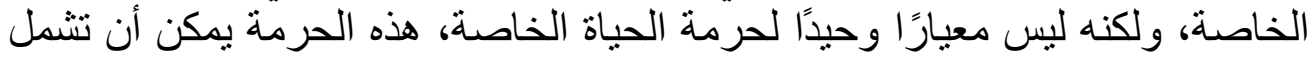
وقائع تحدث في خار ج مسكن الفرد.

être justifiée par la liberté de conscience - Cour de cassation, 1re civ. 6 mars 2001 - D. 2002. 248.

(هو) د.ممدوح خليل العاني، حماية الحياة الخاصة في القانون الجنائي "دراسة مقارنة"، رسالة

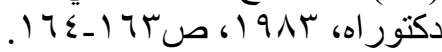

(60) CASE OF PERRY v. THE UNITED KINGDOM, 17 July 2003

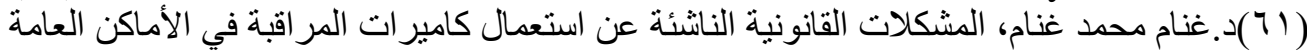

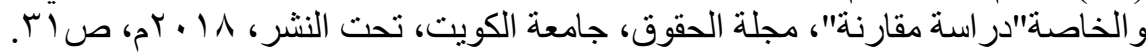
P.G. and J.H. v. the United Kingdom, no. 44787/98, § 56, ECHR 2001-IX 
وقد انحاز المشرع المصري في قانون مكافحة جرائم تقتية المعلومات رقم

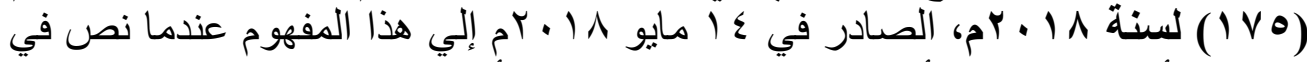

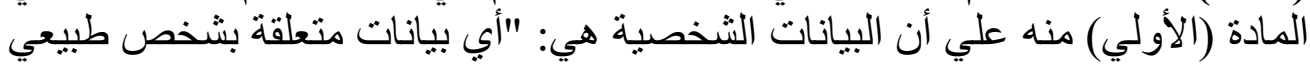
محدد أو يمكن تحديده، بشكل مباشر أو غير مباشنر عن طريق الربط بين بينها وبين بيانات

\section{المبحث الثاني \\ عناصر الحق في حرمة الحياة الخاصة}

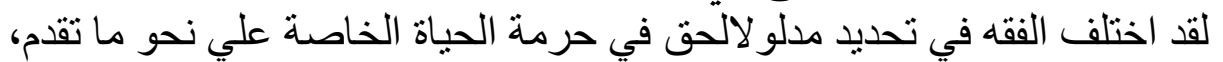

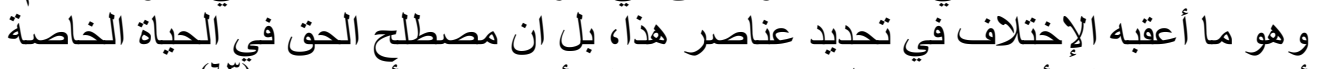

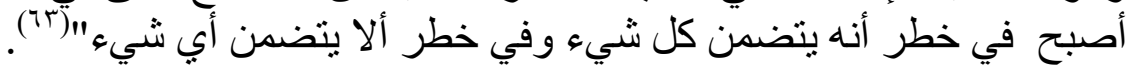
الأمر الذي ترتب عليه اختلاف الفقه في تحديد عناصر الحق في الحياة الخاصة،

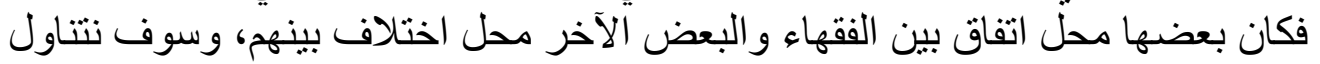
تفسيم هذا المبحث الي مطلبين علي النحو التالي:

المطلب الاول: عناصر الحق في الحياة الخاصة محل الاتفاق. المطلب الثاني: عناصر الحق في الحياة الخاصة محل الاختلاف.

\section{المطلب الأول}

\section{عناصر الحق في الحياة الخاصة محل الأل الاتفاق}

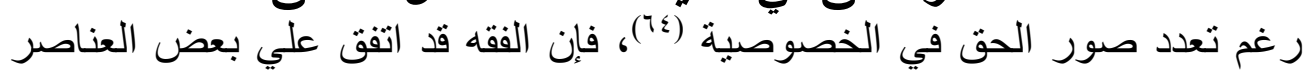
ومنها:

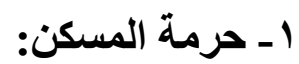

تعد حرمة المسكن من أهم عناصر الحق في حرمة الحئه الحياة الخاصة، بل هي

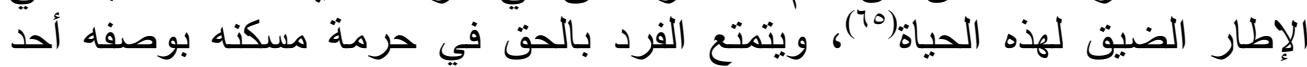

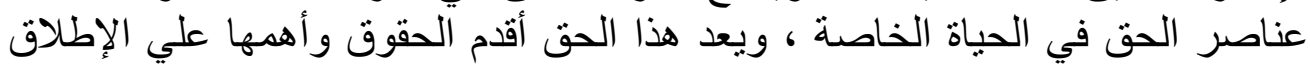

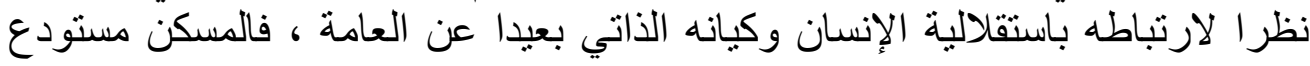

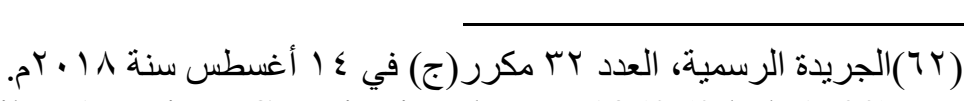

(63) Laurence H. Tribe, American Constitutional Law, 1352 (2ded. 1988).

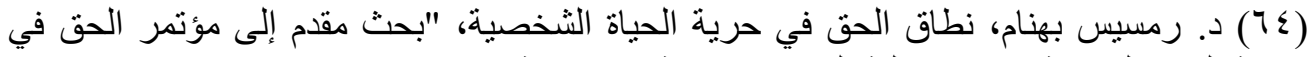

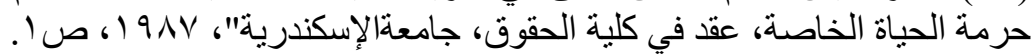

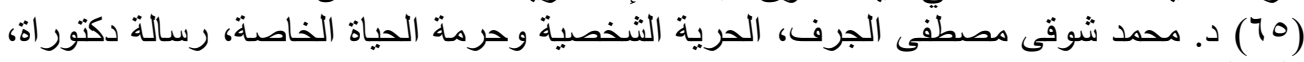

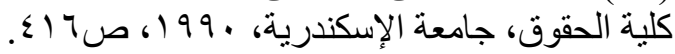
rt 


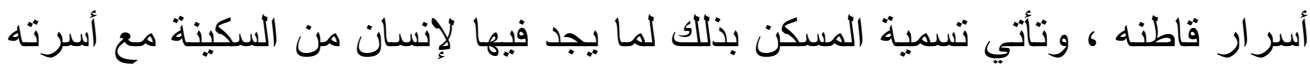

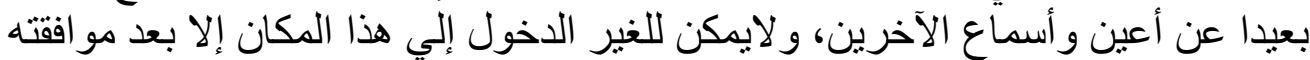

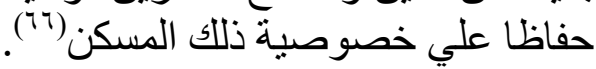

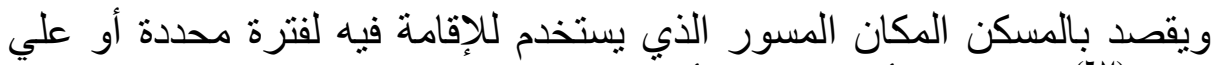

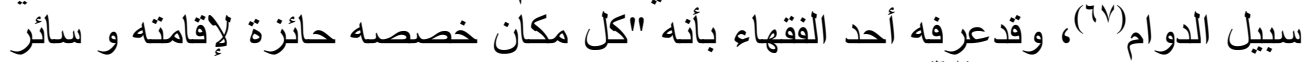

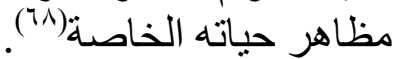

ويقصد بالملحقات تلك المنافع الخاصة باه و هي جزء منهه، ومنها الحديقة وما بها

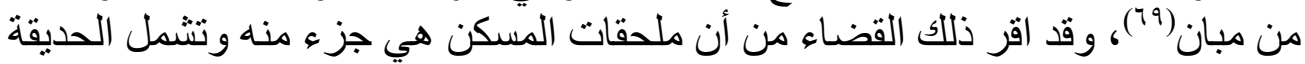

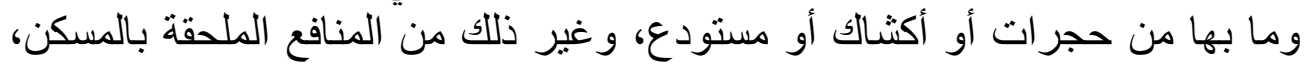

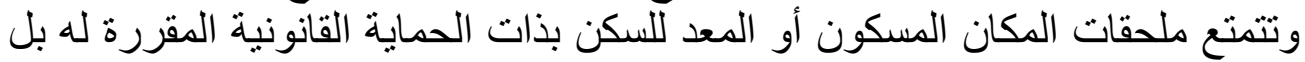

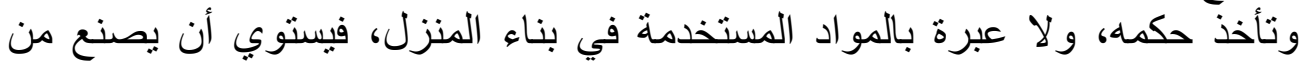

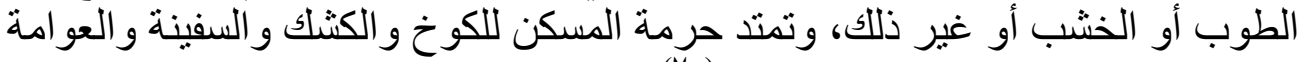

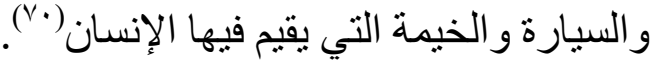

ومعيار السكن هو الإقامة في المكان و السكون بصرف النظر عن أسباب حيازته

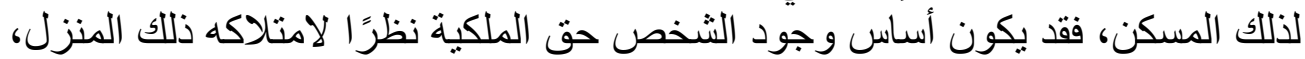

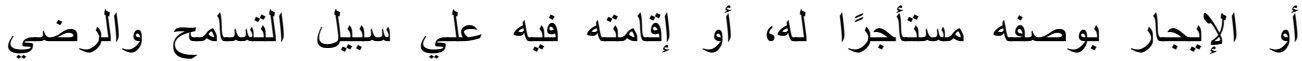

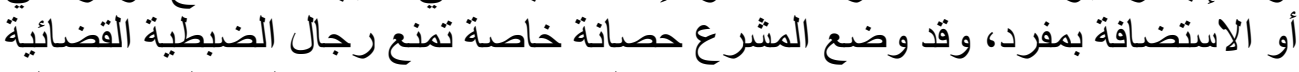

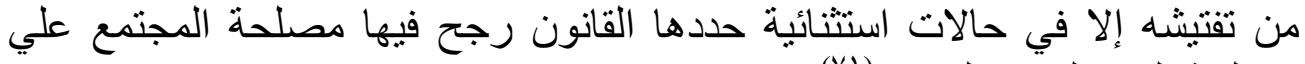
مصلحة الفرد المقيم بالمسكن (V) في لالات

(77) د. ماجد راغب الحلو، القانون الدستوري، دار المطبو عات الجامعية بالإسكندرية، 7191 ا، ص $\Sigma+1$ (7V)(T). رؤوف عبيد، مبادئ الإجر اءات الجنائية في القانون المصري، الطبعة السادسة عشر، دار

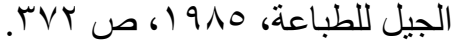

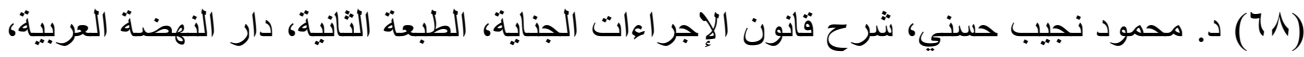

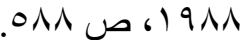
(79) د. رمسيس بهنام، الإجراءات الجنائية تأصيلا وتحليلا، منشأة المعارف بالإسكندرية، مصر،

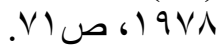

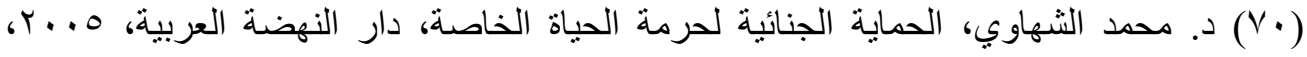
ص ص

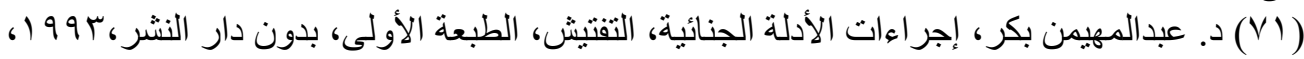




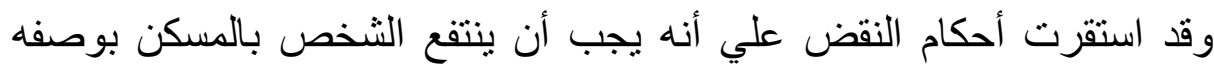

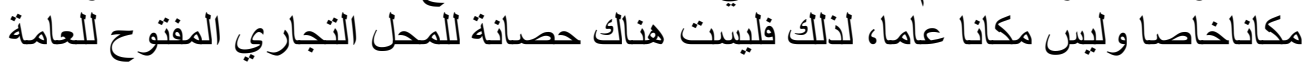
دون تحديد (VT)

ويتمتع المكان المعد للسكن بذات الحصانة والحرمة المقررة للمكان المسكون،

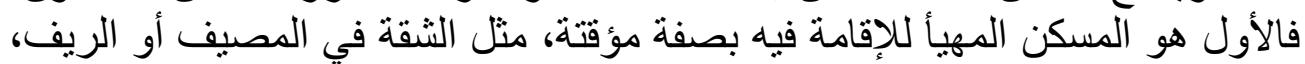

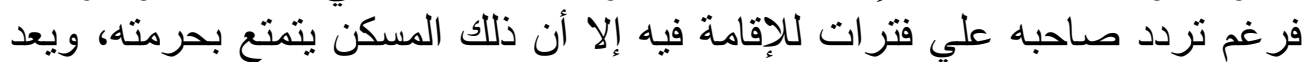

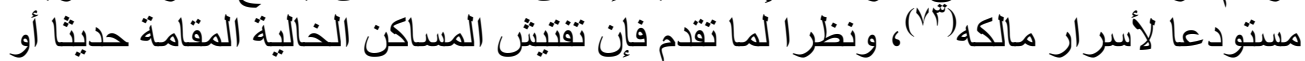

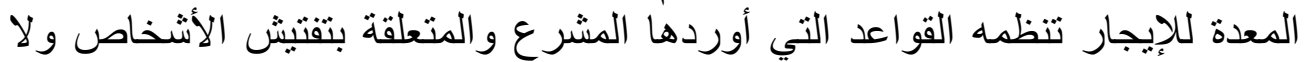

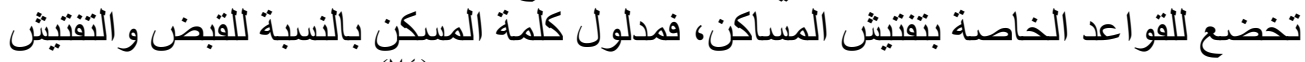

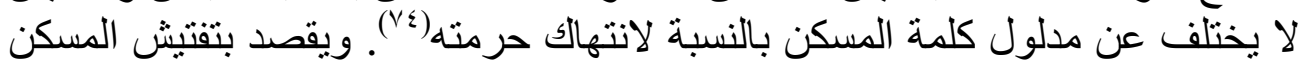

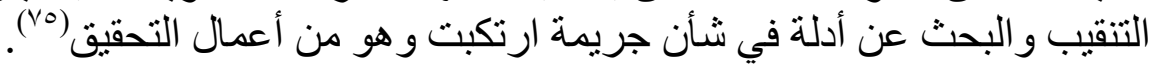

ومن الملاحظ أن حرمة المسكن تمتد لصاحبه وجميع المقيمين معه من أفراد

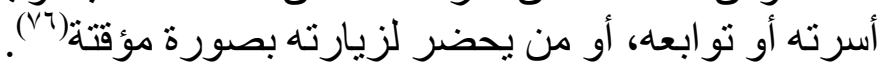
ومما تقدم نلقي الضوء علي بعض الحالات المشابهة لحرمة المسكن علي النحو التالي: أ ـ حرمة المحلات العامة:

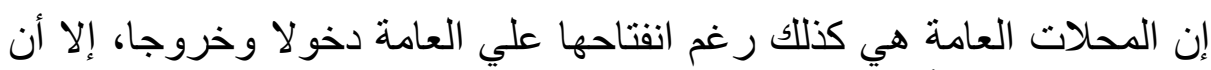

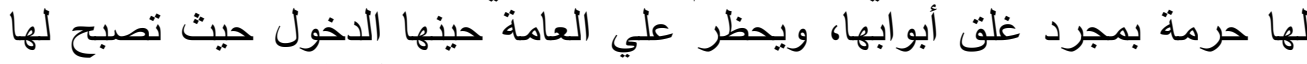

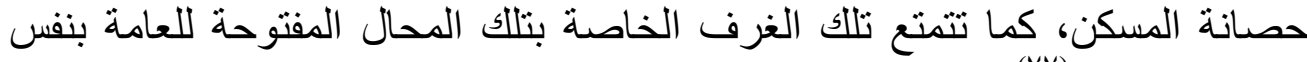

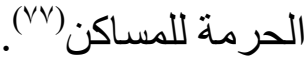

وقد أجاز المشرع لرجال الضبط القضائي سلطة الاخول إلي المحلات العامة، إنداء

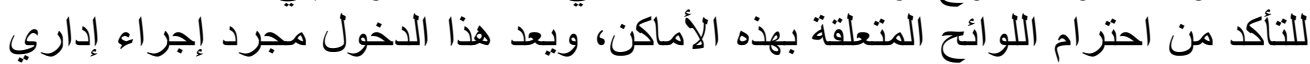

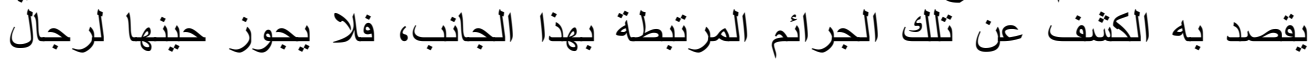

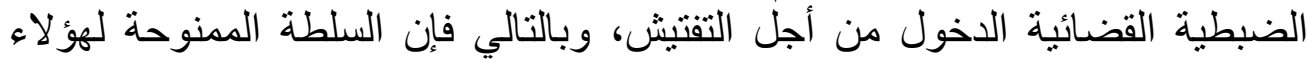

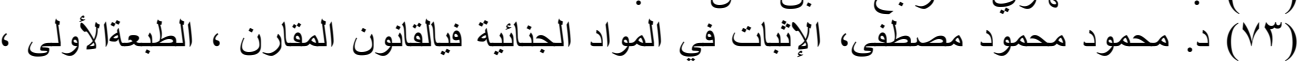

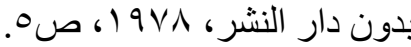

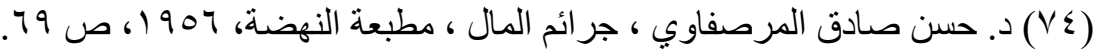

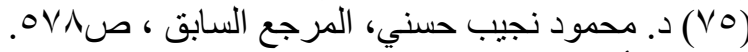

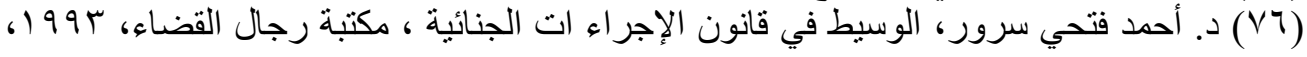

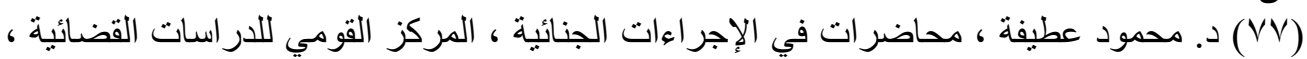

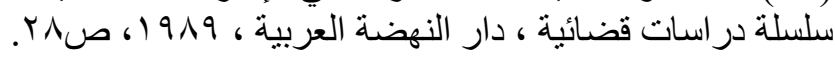




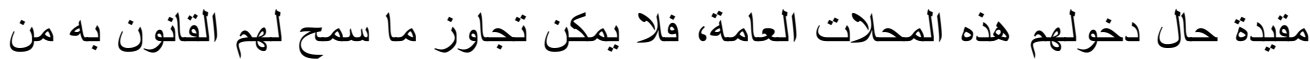

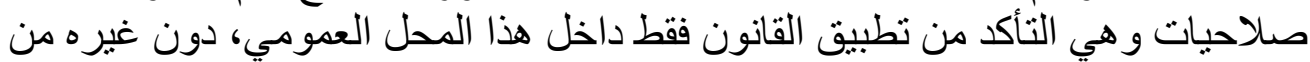

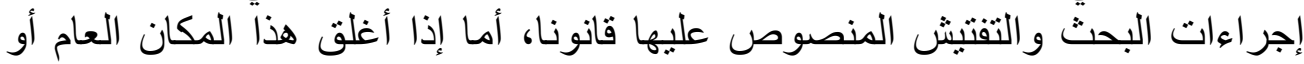

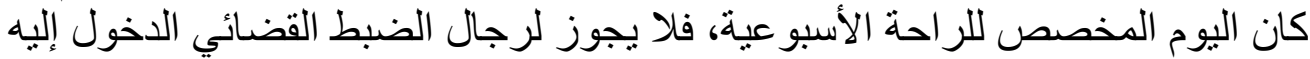

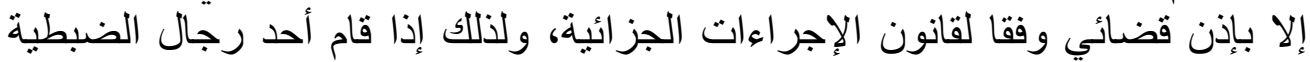

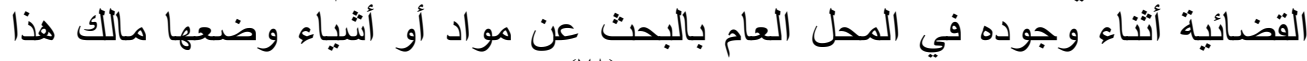

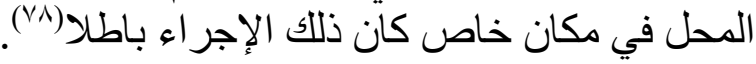

وقد اتجه بعض من الفقه إلي أن الحصانة المقررة للمسكن تمند إلي بعض المضاد

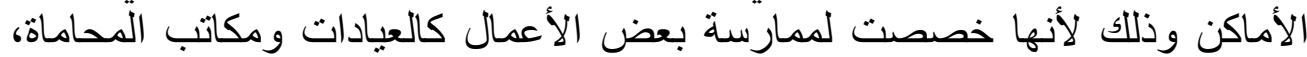

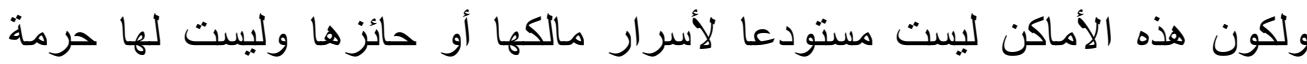

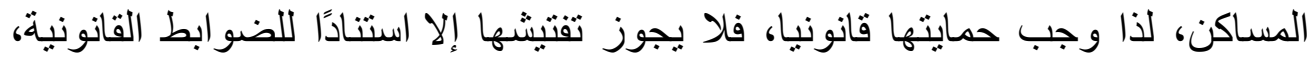

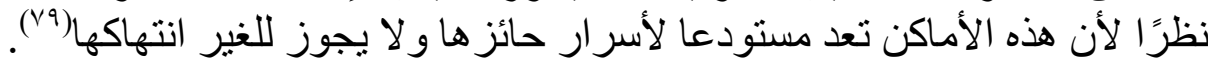

\section{ب- حرمة السيارة:}

لقد تعددت أر اء الفقهاء بشأن السيارة ومدي اعنبار ها تدخل ضدمن مفهوم المكان

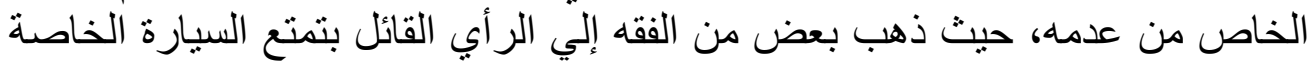

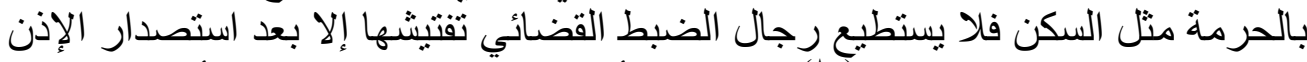

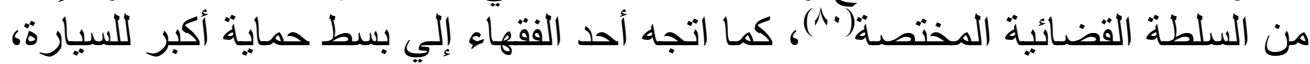

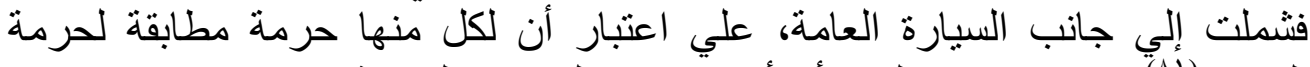

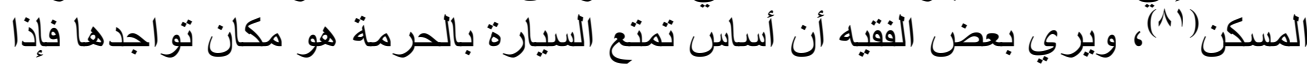

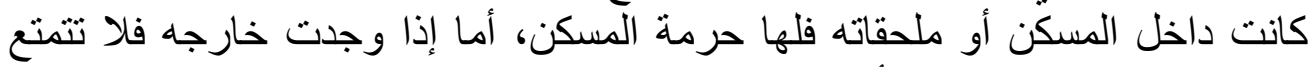

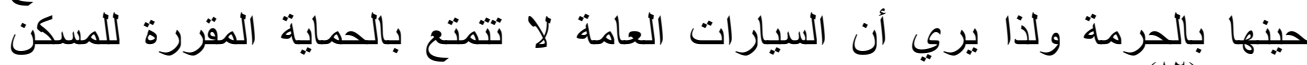

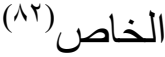

أما محكمة النقض المصرية فقد أخذت بالر أي الذي يجعل السيارة تتمتع بحرمة

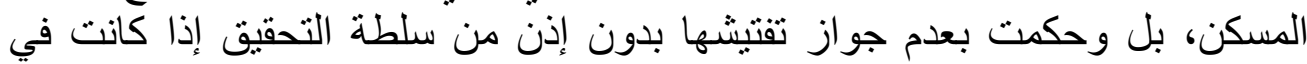

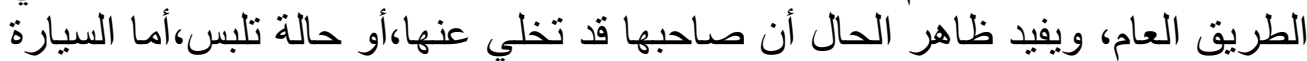

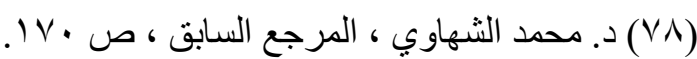

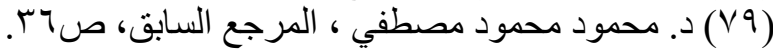

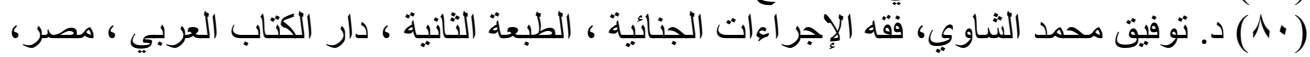
rV 2 ص ( ) ( ) د. علي زكي العرابي ، المبادئ الأساسية للتحقيقات و الإجراءات الجنائية ، بدون دار النشر، ro

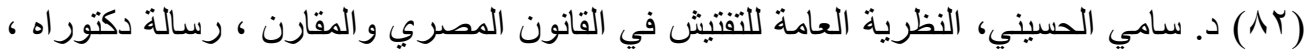

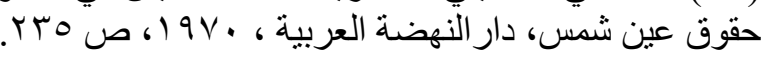




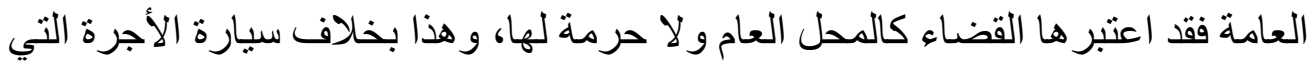

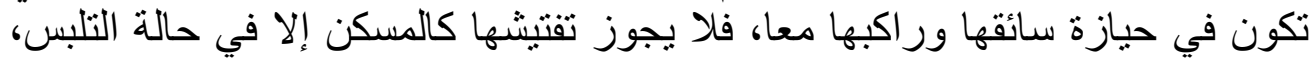

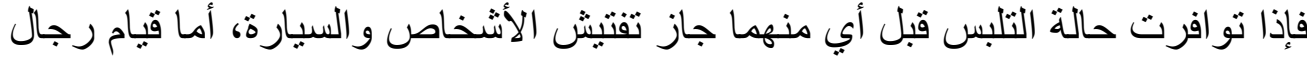

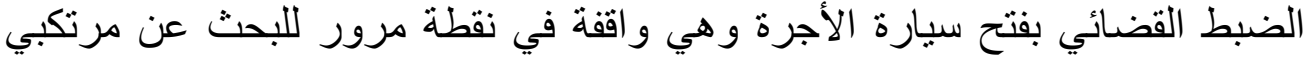

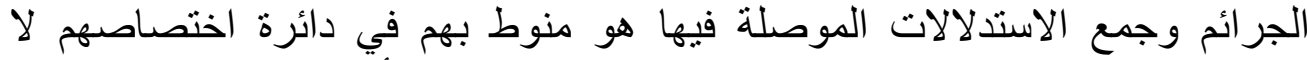

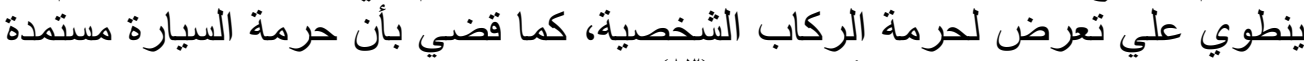

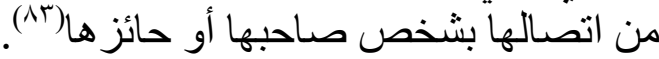

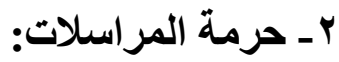

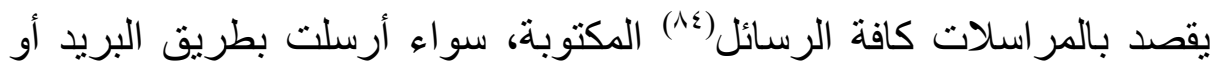

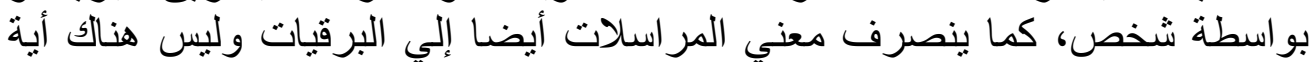

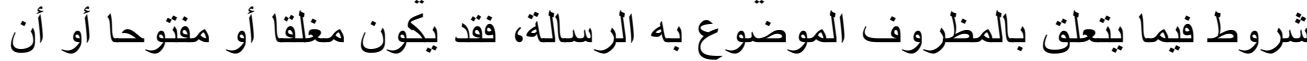

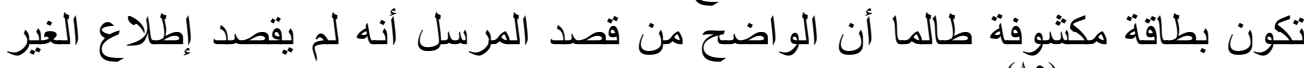
عليها بغير تمبيز (10)

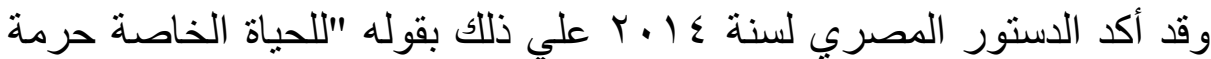

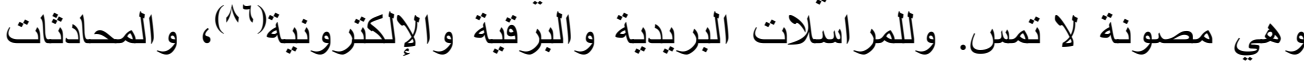

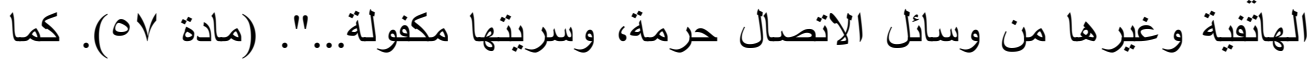

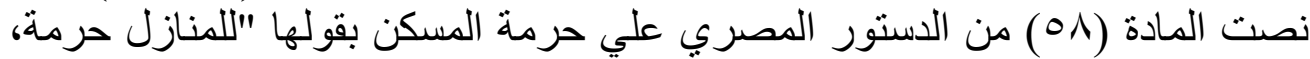

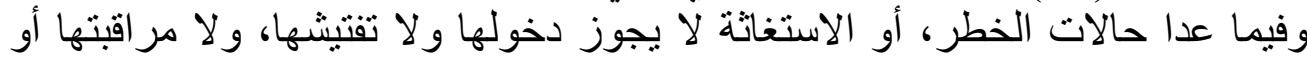

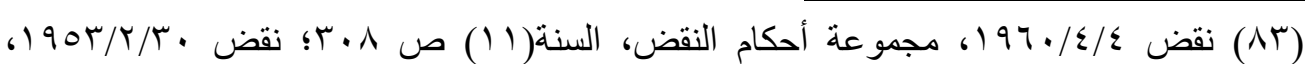

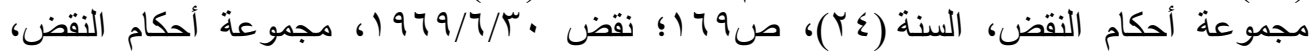

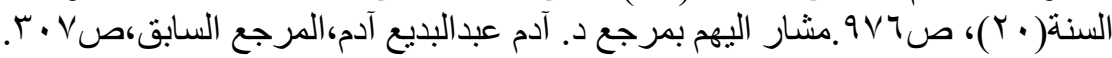

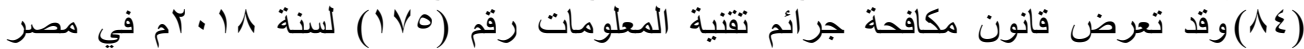

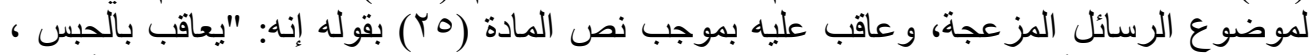

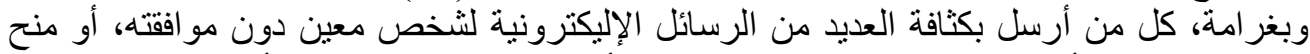

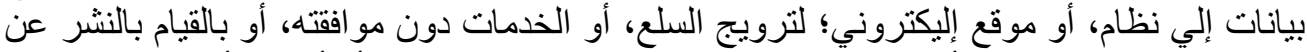

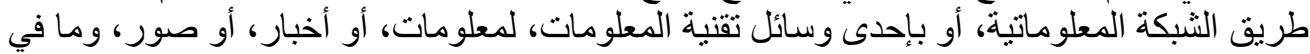

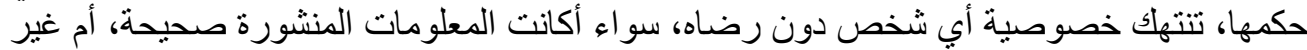

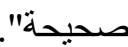

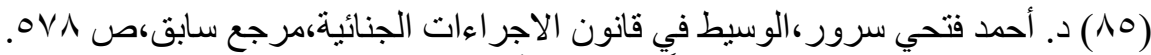

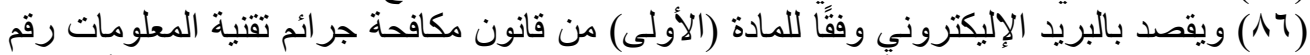

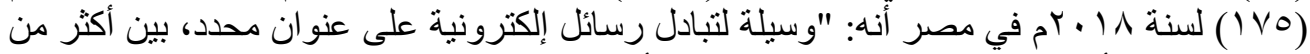

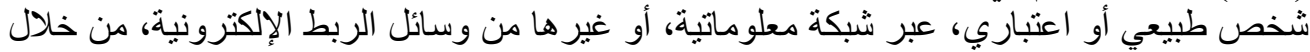

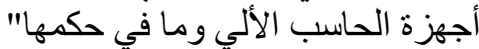

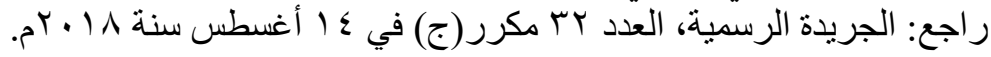


التنصت عليها إلاّ بأمر قضائي مسبب، يحدد المكان والتوقيت و الغرض منها..".

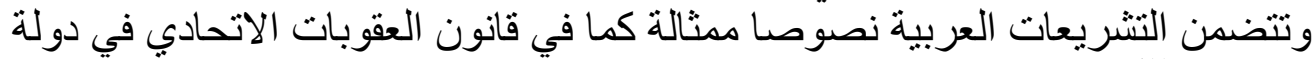

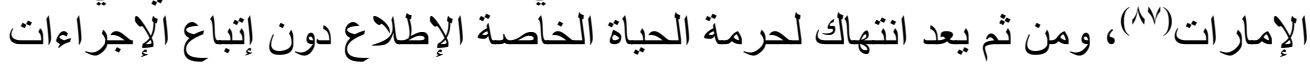

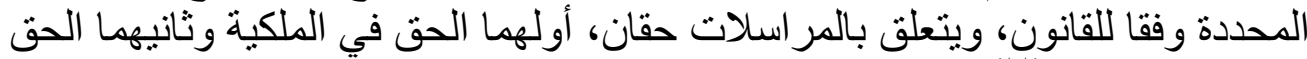

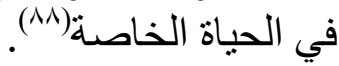

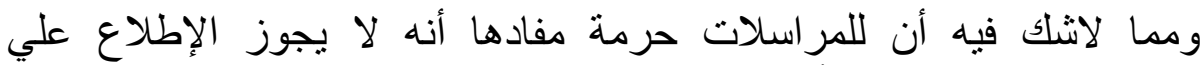

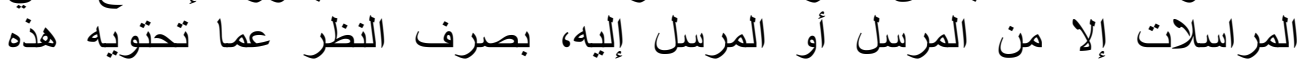
المراسلات، حتي ولوتضمنت معلومات لات لات تتعلق بالحياة الخاصة لهما، فهنا يتعين هين

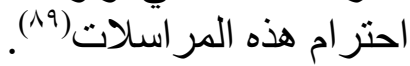

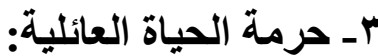

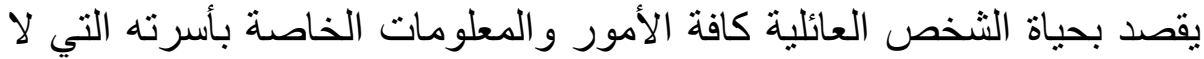

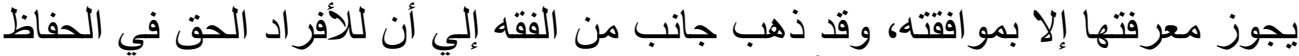

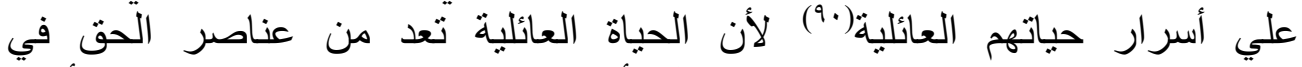

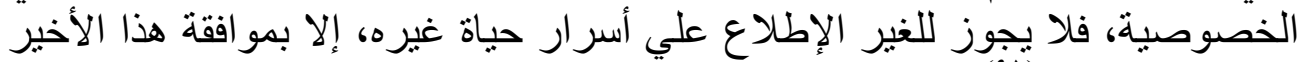

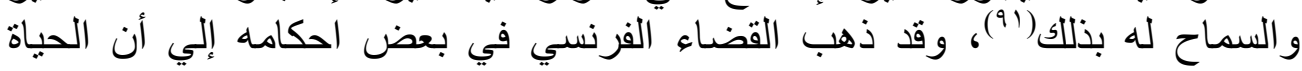

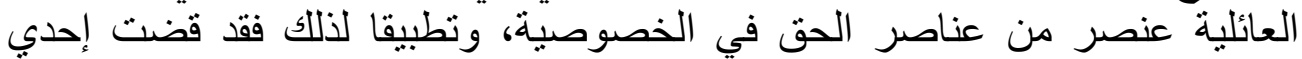

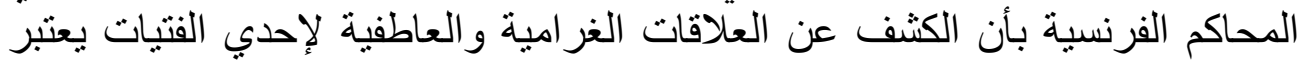

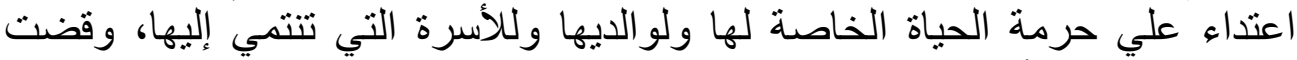

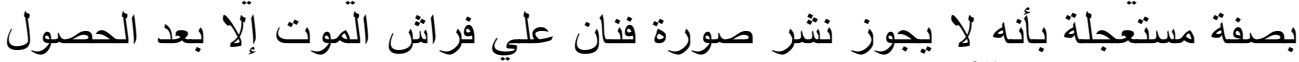

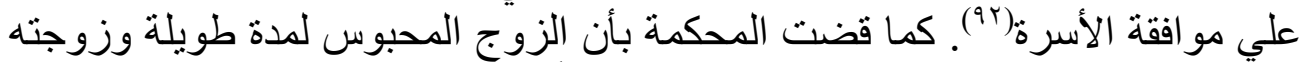

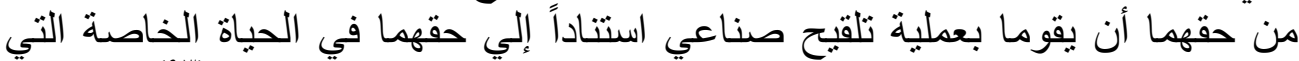

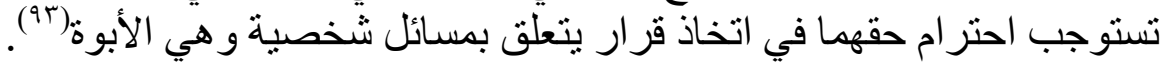

(Av) د.لطيفة حميد الجميلي، شرح قانون العقوبات الإمار اتيـ القسم الخاص، الطبعة الأولى، الآفاق

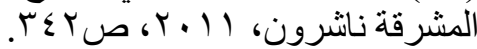

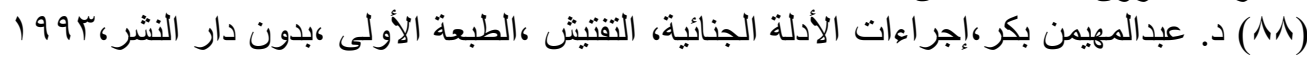

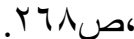

(^9) د. محمد محرم محمد علي ، حرمة استر اق السمع وتسجيل المحادثات التليفونية ، مجلة النيابة

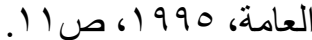

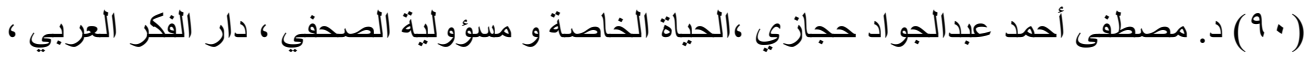

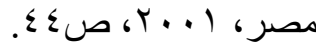

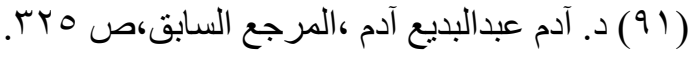
(92) Cass, 11 janv, 1977, J.C.P, 1977-2, P. 8711.

(93) Dickson C/ Royaume-Uni (CEDH, gr. ch., 4 déc. 2007, Dickson c/ Royaume-Uni, req. No. 44362/04 
وقد أيدت محكمة النقض ما ذهبت إليه محكمة باريس من أن المساس بالحياة

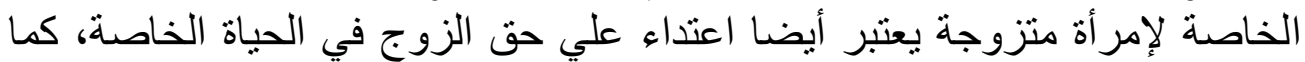

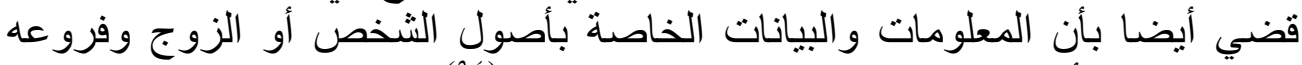

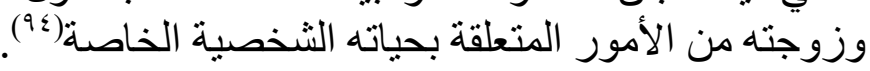

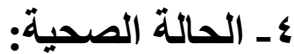

تعد الحالة الصحية من عناصر الحق في الحياة الخاصة:(90)، يقصد بالحالة

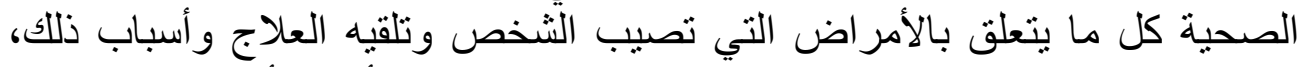

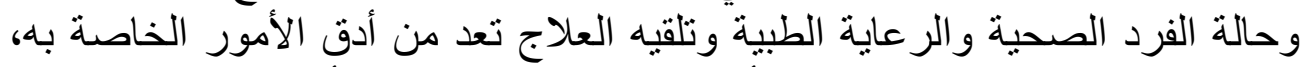

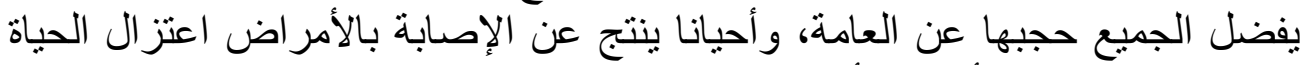

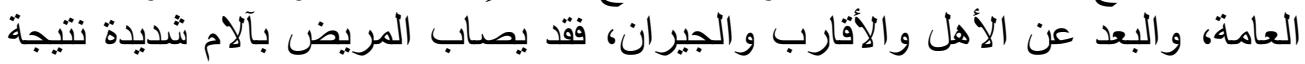

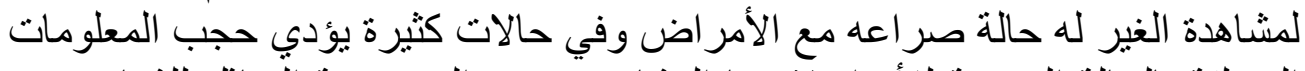

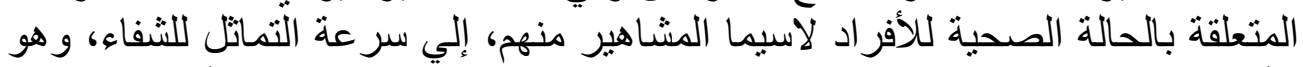

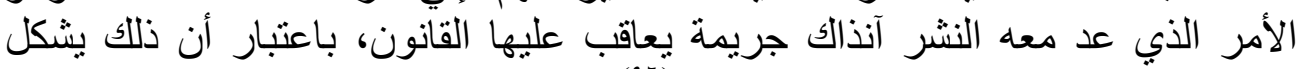

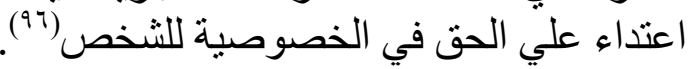

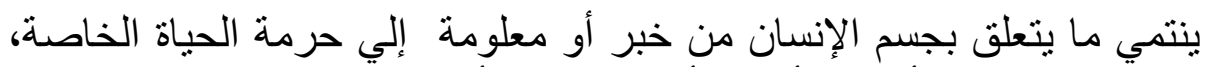

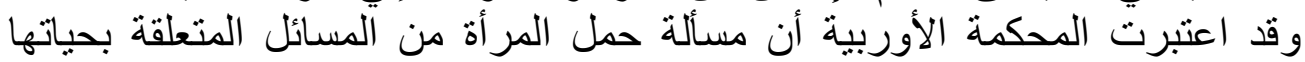

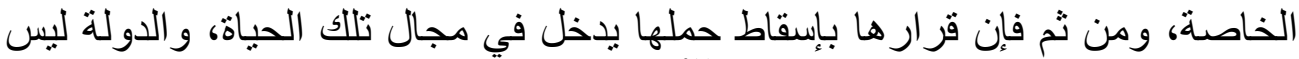

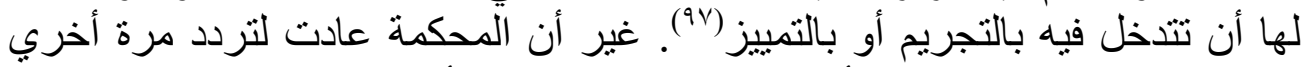

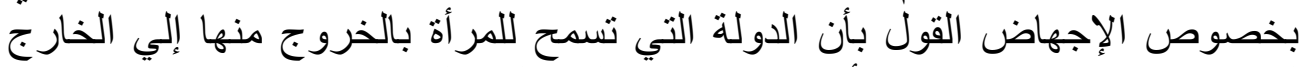

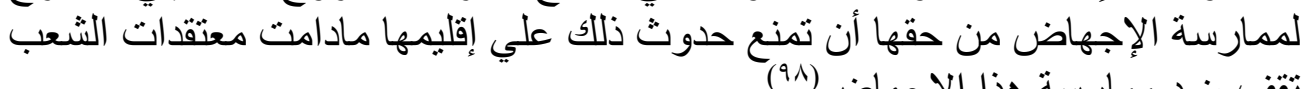

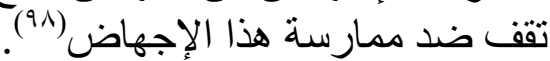

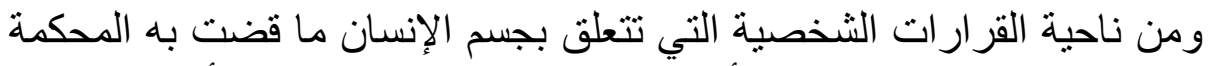

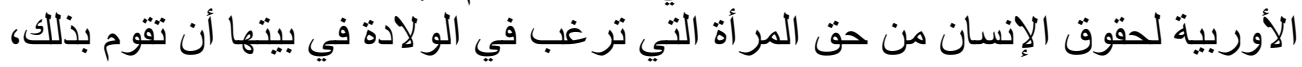

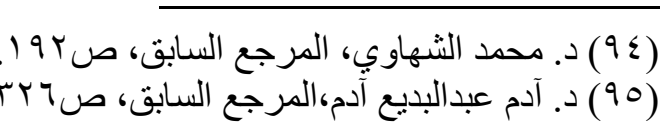
(97) د. محمود عبدالرحمن محمد نطاق الحق في الحياة الخاصة، دار النهضة العربية،مصر، بدون

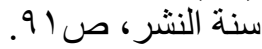

(97) Boso c/ Italie (CEDH 5 sept. 2002, Boso C/ Italie, req. No. 50490/99); l'arrêt Tysiac C/ Pologne (CEDH 20 mars 2007, Tysiac C/ Pologne, req. No. 5410/03),

(98) Arrêt de Grande chambre A. B. et c. C/ Irlande (CEDH, gr. ch., 16 déc. 2010, A. B. et C. C/ Irlande, req. no 25579/05). 
وأن التشريع الذي يمنع أطباء النساء من المساعدة الطبية في المنزل يخل بحق المرأة في الحباة الخاصةُّة (99).

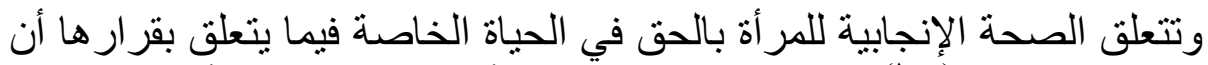

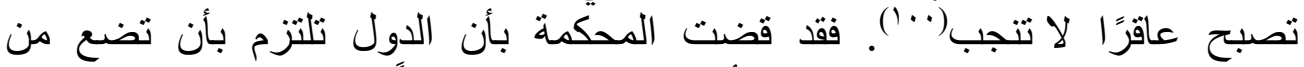

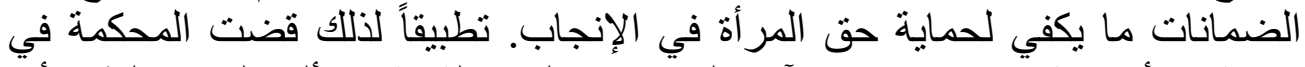

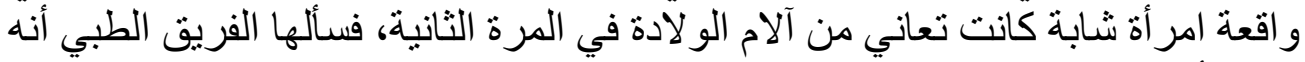

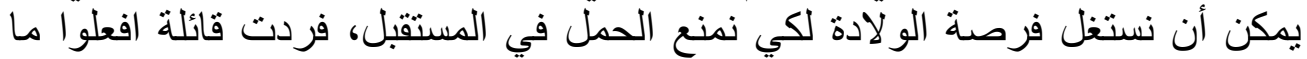

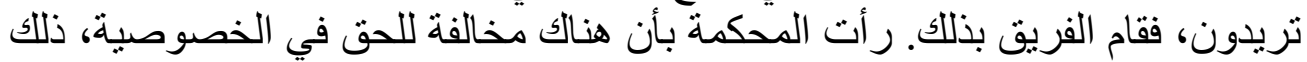

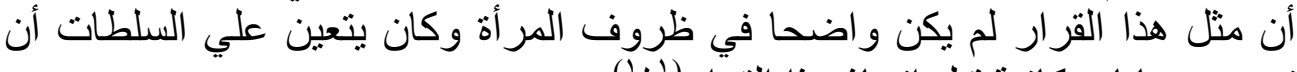
تضع ضمانات كافية قبل اتخاذ هذا القرار (1+').

فقد أصبح من المستقر عليه في قضاء المحكمة الأوربية أن قرار الحمل ولو كان

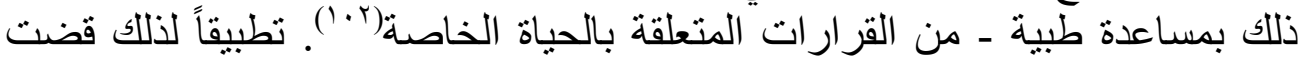

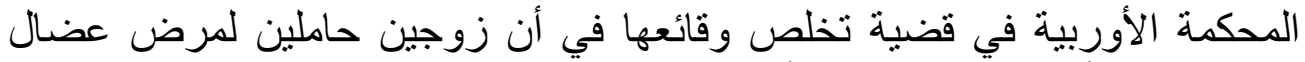

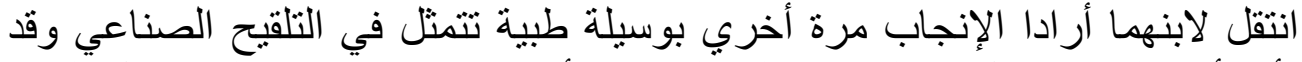

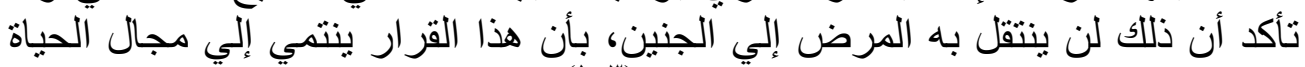
الخاصة و العائلية وأن علي الدولة أن تحترمه (ب). ).

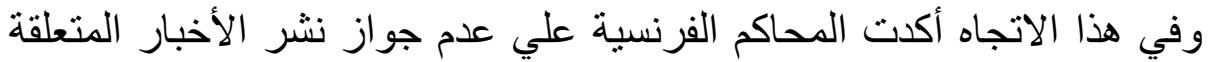

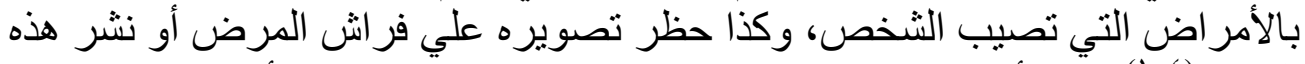

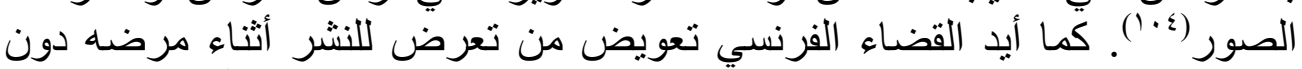

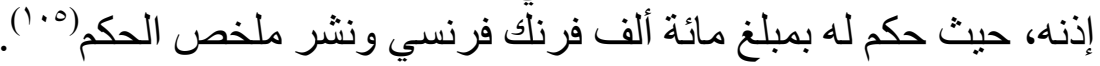

(99) Ternovszky C/ Hongrie (CEDH 14 déc. 2010, Ternovszky c/ Hongrie, req. no 67545/09),

(100) Jean-Pierre MARGUÉNAUD, Conv. EDH, art. 8: vie privée Répertoire de droit européan - avril 2014 (mise à jour : juin 2014), $\mathrm{n}^{\circ} 18$.

(101) C. c/ Slovaquie (CEDH 8 nov. 2011, V. C. c/ Slovaquie, req. no $18968 / 07)$

(102) Arrêt de Grande chambre, S. H. et autres c/ Autriche (CEDH, gr. ch., 3 nov. 2011, S. H. et autres c/ Autriche, req. no 57813/00

(103) Arrêt Costa et Pavan c/ Italie (CEDH 28 août 2012, Costa et Pavan c/ Italie, req. no 54270/10 )

(104) Cass, 9juil, 1980, D, 1981, P. 72 .

(105) Cass, 24 sept, 1990, G.P, 1994,2, P. 992 . 


\section{هـ حرمة المحادثات الشخصية:}

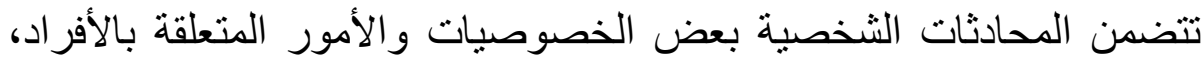

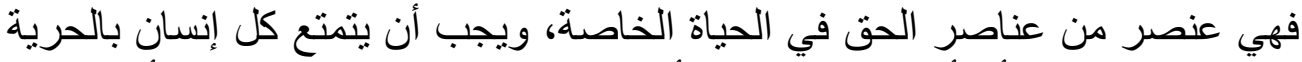

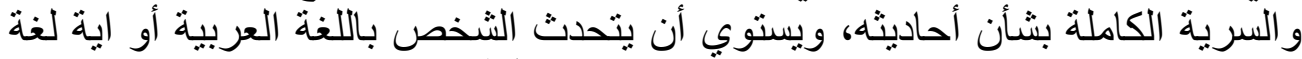

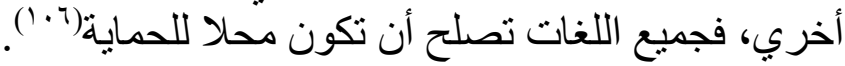

ويأخذ حكم اللغة الثفرة، لأن هذه الأخيرة تعد لغة أيضا، ومفاد ذلك أن الألحان

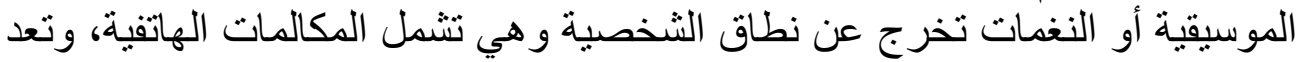

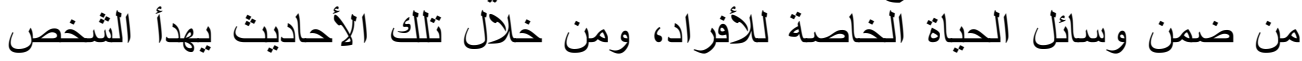

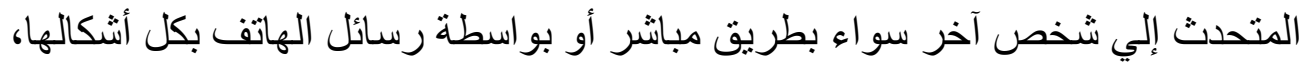

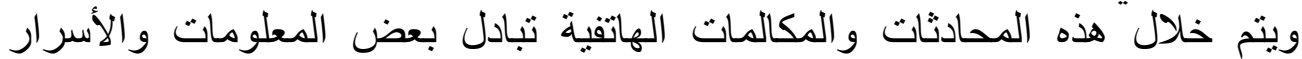

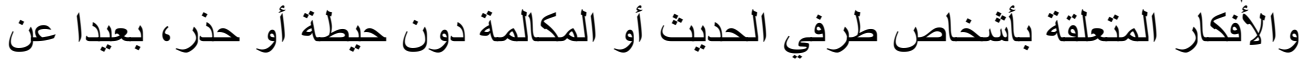

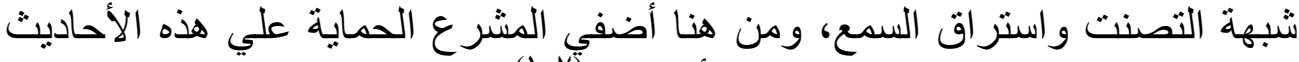

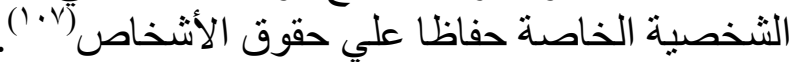

وقد استقر الفقه علي تو افر الاعتداء علي حرمة المحادثات الثخصية أو الخاصة

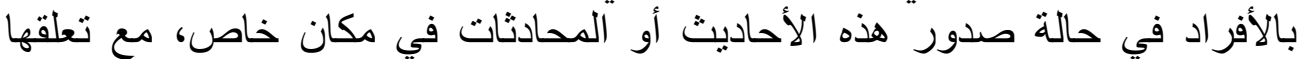

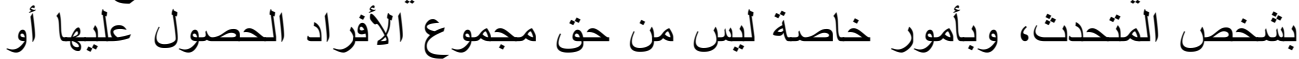

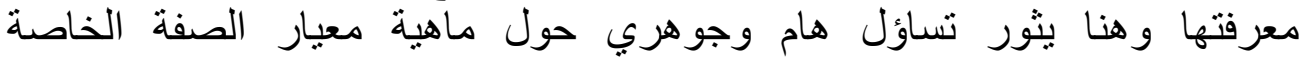
للحديث(^•)؛ هل هو المكان الذي يجري فيه ألحديث أم موضول ماهوع الحديث نفسه ؟

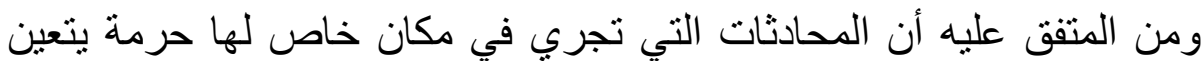

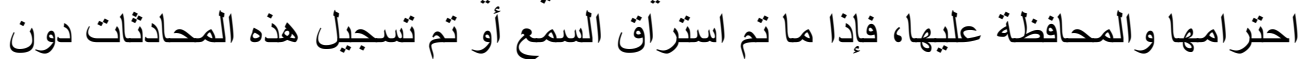

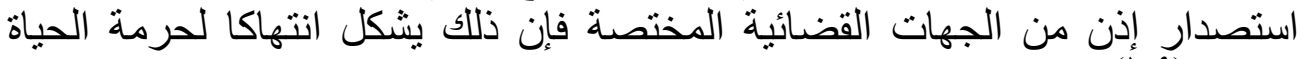

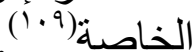

وتتعدد تعريفات الفقهاء للمكان الخاص، حيث أنه يحاط بسياج يحول دون قيام

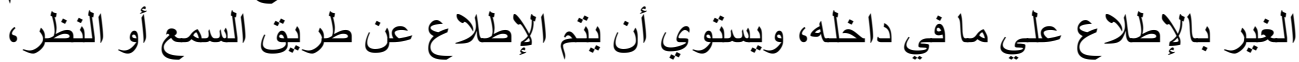

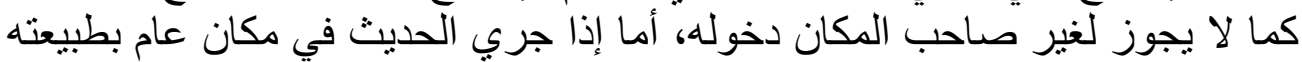

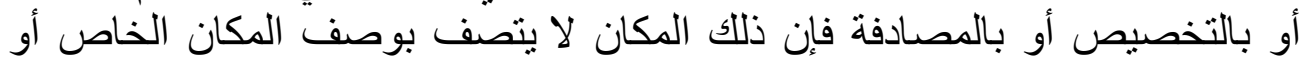

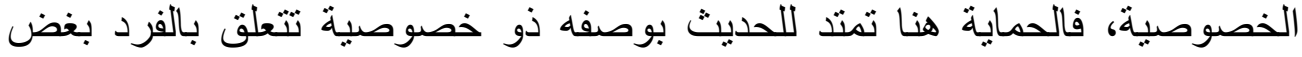

(7 ( 1 ) د. فوزية عبدالستار،شرح قانون العقوبات،القسم الخاص،الطبعة الثانية، دار النهضة العربية، ( - (1...

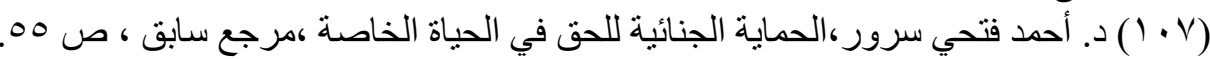

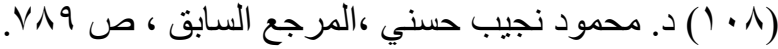

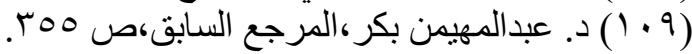


النظر عن مكان نواجد الفرد سواء كان مكانا خاصا أو مكانا عاما مع مر اعاة طبيعة هذا الحديث وخصو مكيته أو عموميته(').

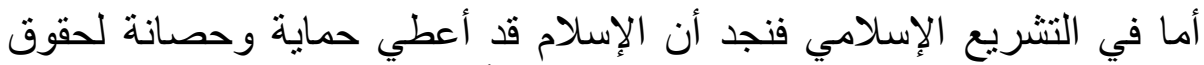

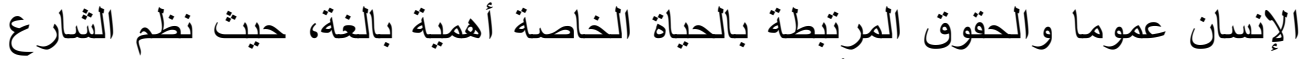

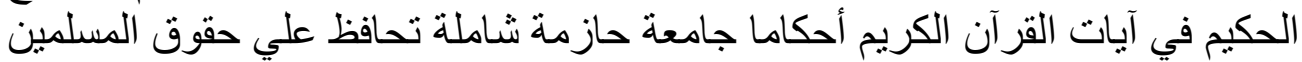

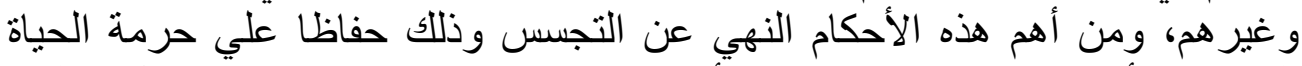

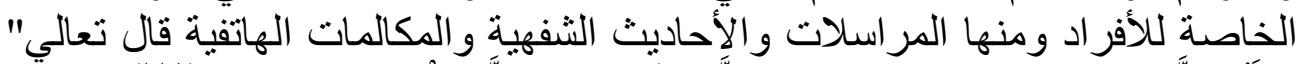

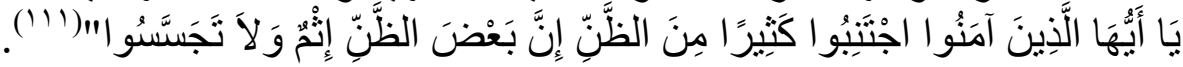

\section{المطاب الثناني

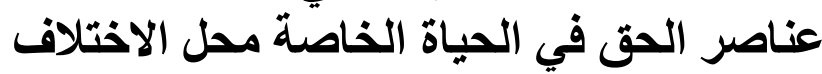

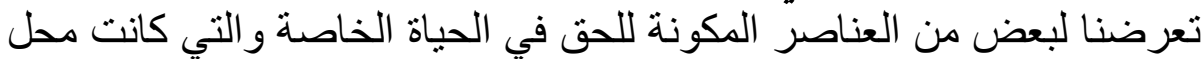

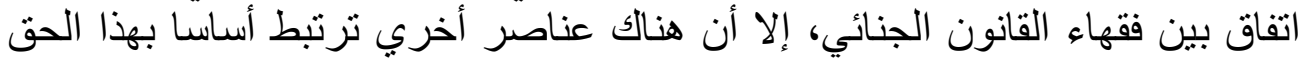

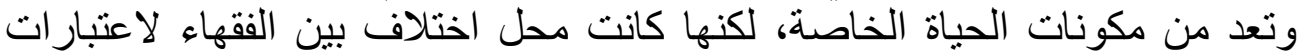

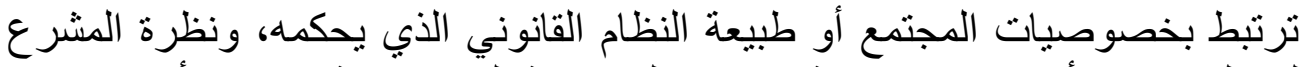

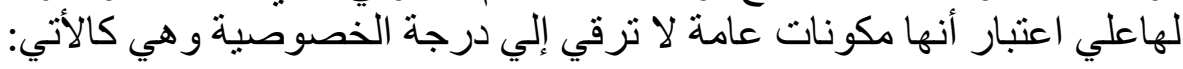

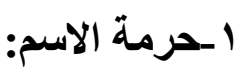

يعد الاسم هو العنصر الأول لتمييز الثخص عن بقية أفراد المجتمع وعنوانه

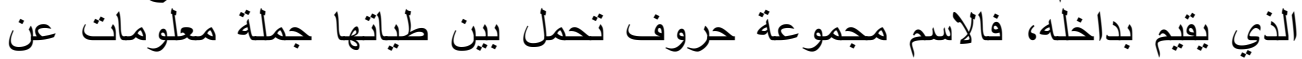

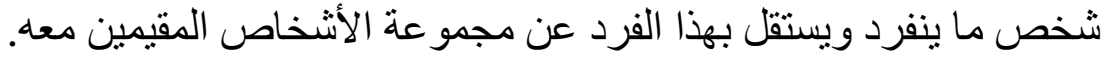

وقد عرف بعض الفقهاء اسم الثخص بأنه " اللفظ الذي يستخدم عادة لتحديد

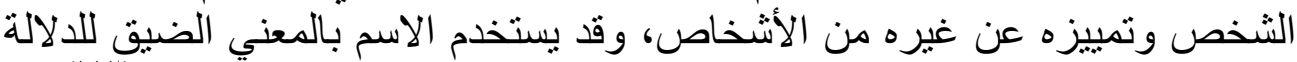

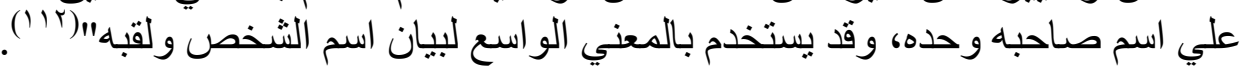
وينقسم الفقه الفرنسي بشأن مدي اعتبار الحق في الاسم عنصر من عناصر الحق في حرمة الحياة الخاصنة إلي ر أيين وهما:

الأول: يري أن الاسم احد عناصر الحق في الخصوصية، وذللك علي اعتبار أن الفرد له

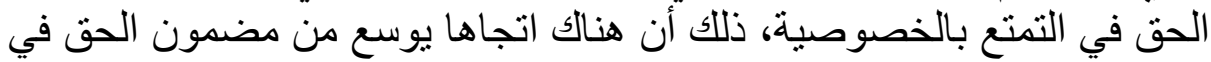

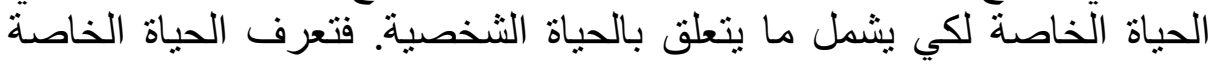

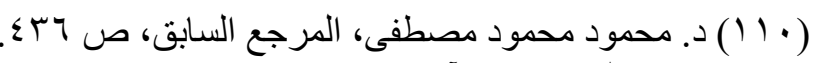

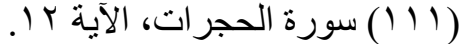

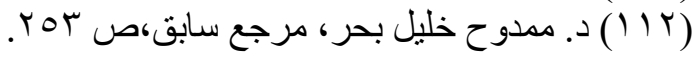

$$
\begin{aligned}
& \text { re }
\end{aligned}
$$


بأنها "حق الفرد في حماية اسمه وشرفه و اعتباره ومر اسلاته و اتصالاته وحياته

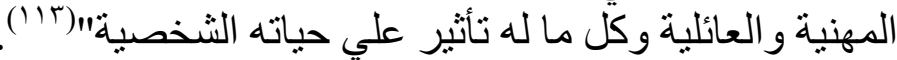

وتطبيقًا لذلك قُضي بأن الكثف عن الاسم قد بنتمي إلي الحياة الخاصة إذا كان

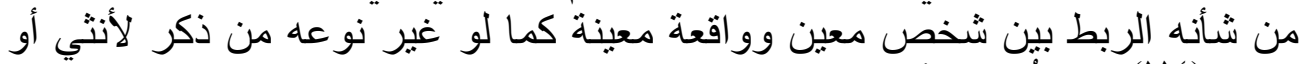

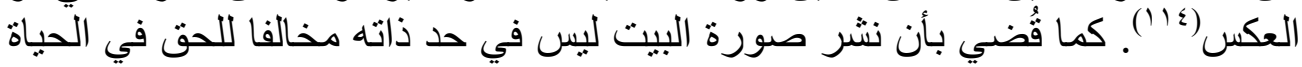

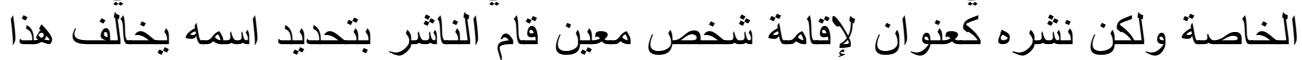

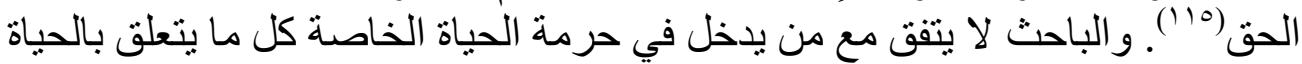
الشخصية، فهناك فرق بين الحياة الخاصة و الحياة الثخصية، واري ضرية ضرورة التمبيز

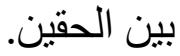

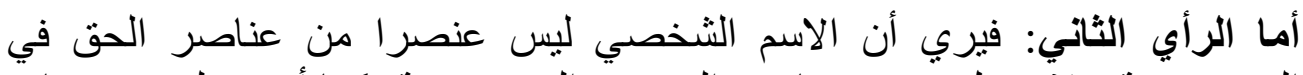

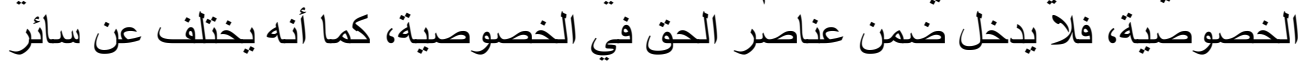
الحقوق الثخصية الأخري كالحق في الثرف وانية والاعتبار والحق في الهيئة و الصورة:(117).

وتطبيقًا لذلك فبالر غم من تعلق البيانات الشخصية مثل الاسم و العنوان... و التي

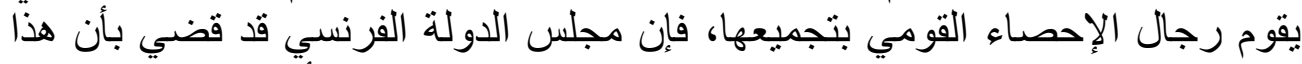

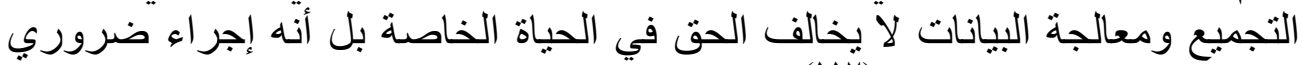

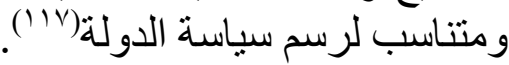

كما أن الأمر اذا تعلق بملفات إجرامية كبري مضي عليها فترة زمينة كبيرة

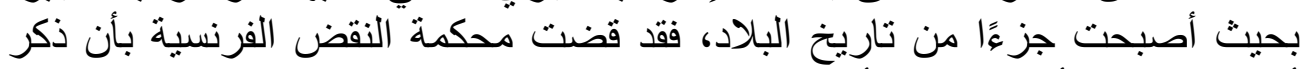

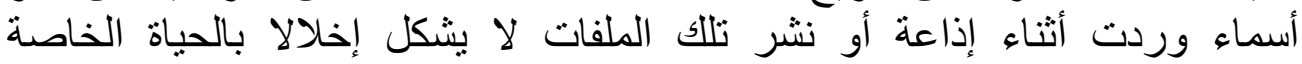

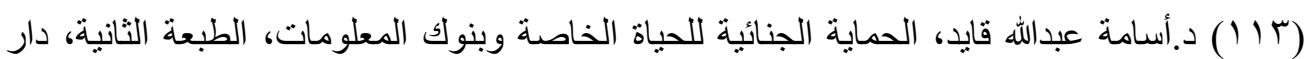

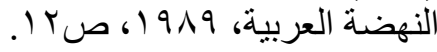
(114) Cass., ass. plén., 11 déc. 1992, 2 arrêts, JCP 1993. II. 21991, concl. M. Jéol, note G. Mémeteau

(115) Révélation du domicile et vie privée- Jean Hauser- RTD civ. 2003. 681 (17 117 ) د.حسام الدين كامل الأهو اني ،الحق في احترام الحياة الخاصة، الحق في الخصوصبة ،دراسة

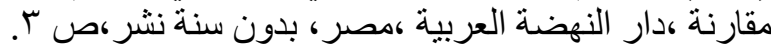
(117) Arrêt rendu par Conseil d'Etat,10ème et 9ème sous-sections reunites, 16-07-2008, Recueil Lebon - Recueil des décisions du conseil d'Etat 2008, Le traitement automatisé des données recueillies lors d'un recensement ne porte pas atteinte au droit au respect de la vie privée et familiale- Conseil d'Etat 16 juillet 2008- Lebon 2008. 


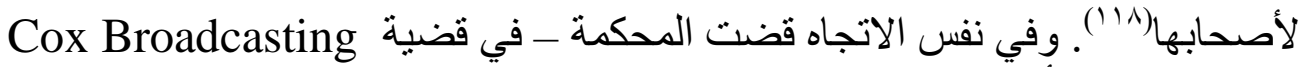

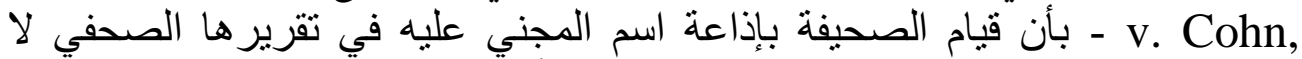

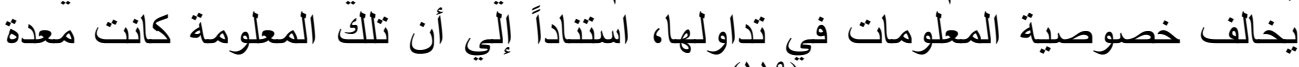

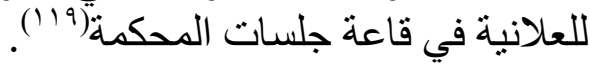

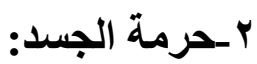

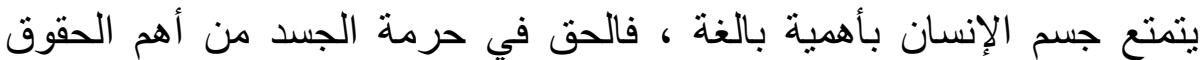

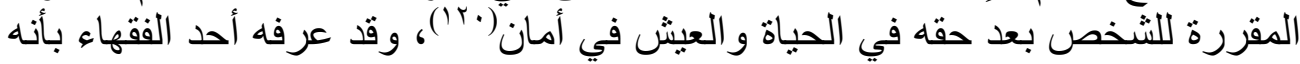

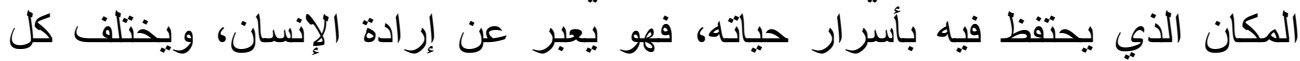

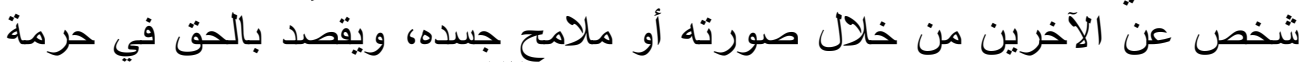

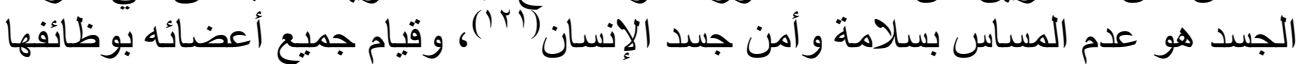

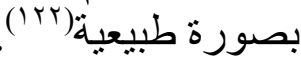

ومن ناحية القرار ات الثخصية التي تتعلق بجسم الإنسان ما قضت باد التهان المحكمة

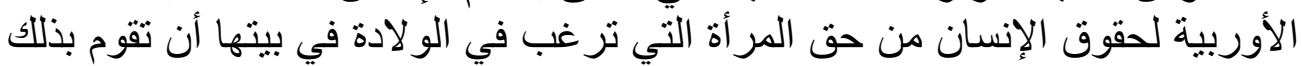

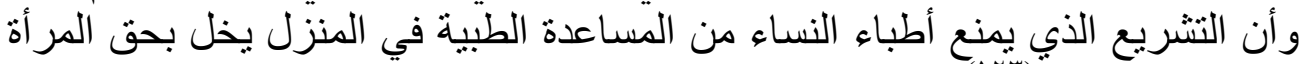

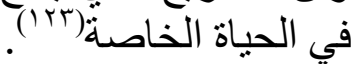

أما الجانب الأخر من الفقه فيري أن حرمة الجسد هو حق مستقل عن الحق في ألقاه

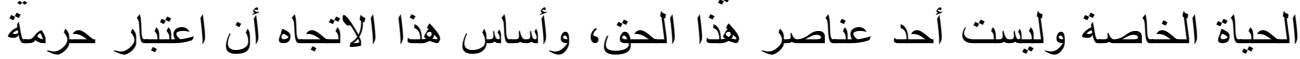

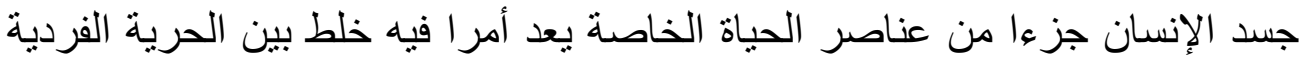

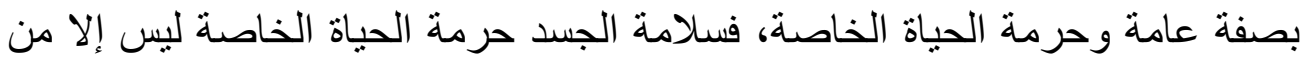

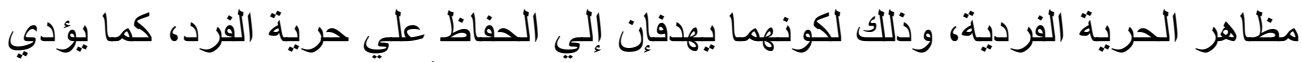

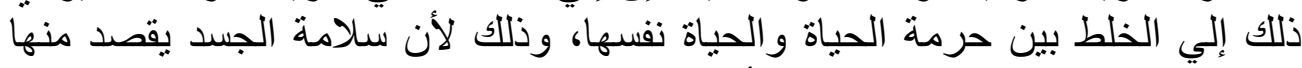

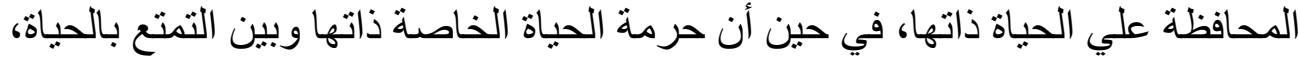

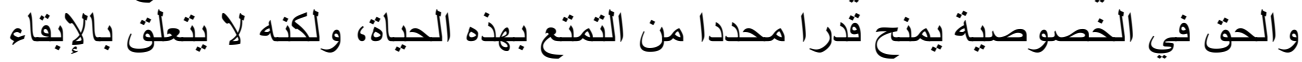

(118) L'affaire judiciaire qui appartient à l'histoire des grandes affaires criminelles n'est plus seulement réductible à la vie privée de la famille de la victime,- Cour de cassation, 1re civ. 13 novembre 2003- D. 2004. 1634.

(119) 420 U.S. 469 (1975).

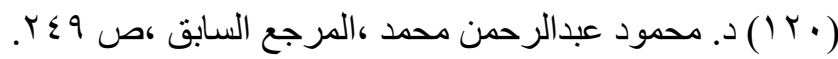

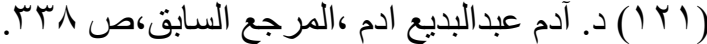

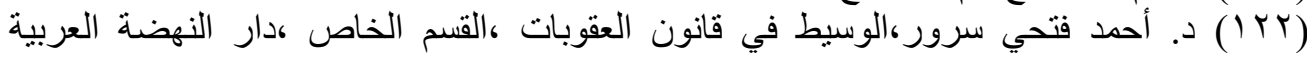
(مصر،

(123) Ternovszky c/ Hongrie (CEDH 14 déc. 2010, Ternovszky c/ Hongrie, req. no 67545/09), 


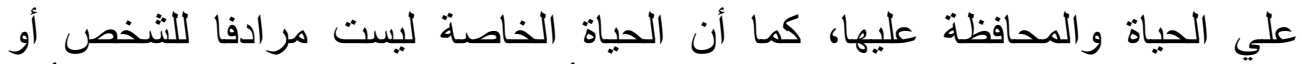

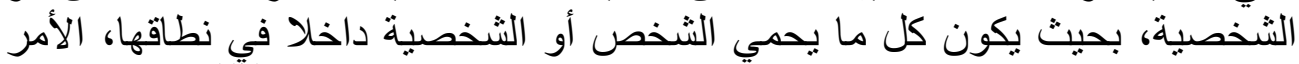

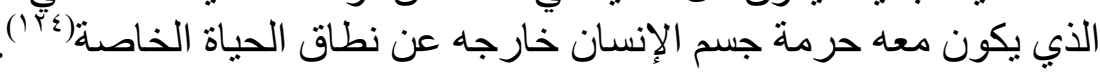

والأرجح عندي هو رأي من قال بأن حرمة جسم الإنسان تعد عنصرا من إن إنان

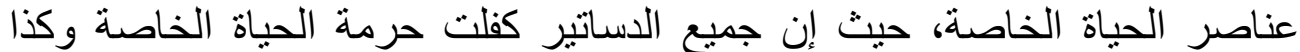
التشريعات الجنائية، و عليه فلا يجوز القبض علي الإني الإنسان وتفتيشه إلا في الأحوال

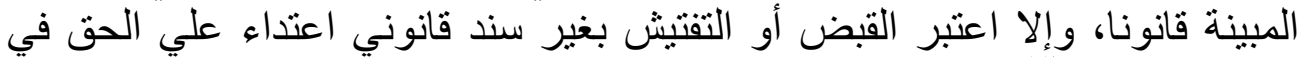

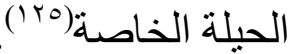

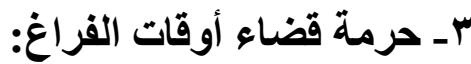

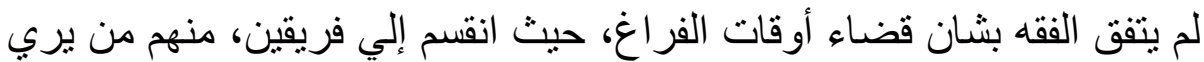

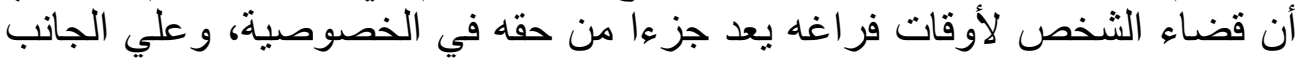

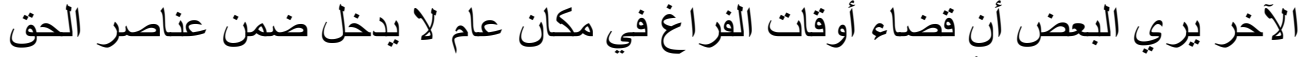

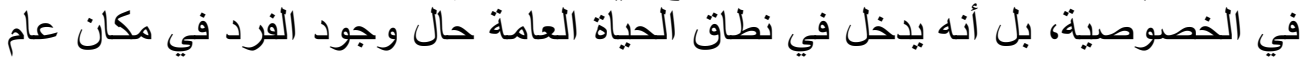

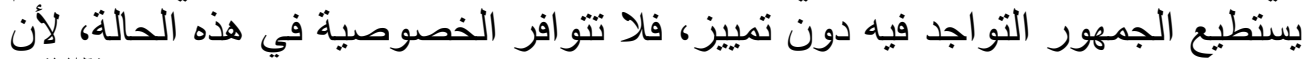

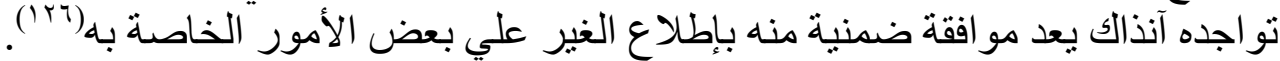

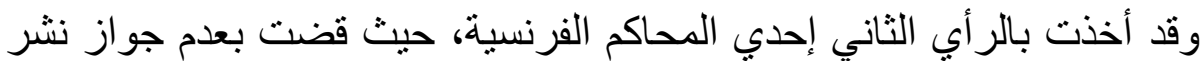

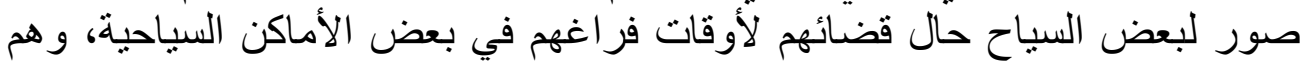

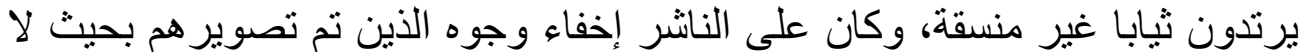

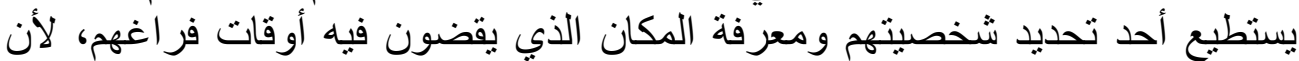

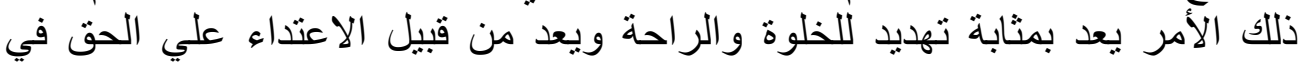

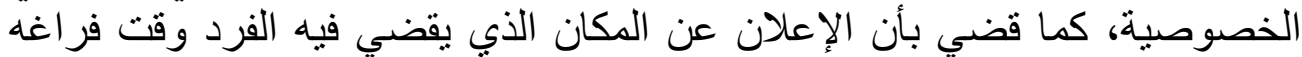

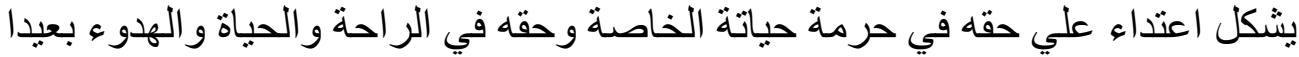

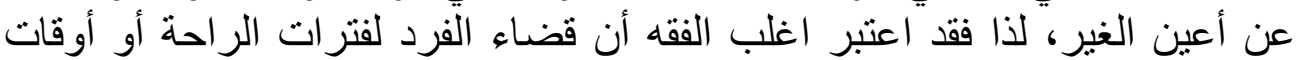

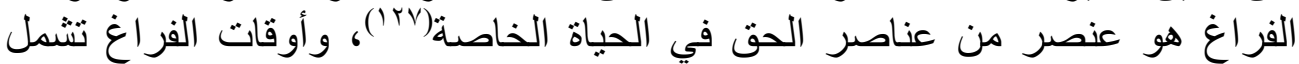

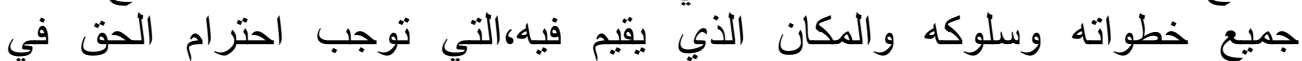

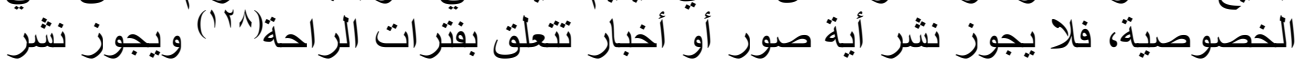

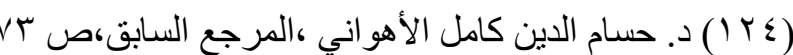

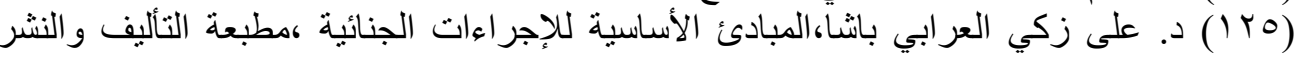

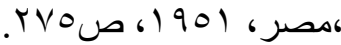

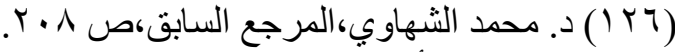

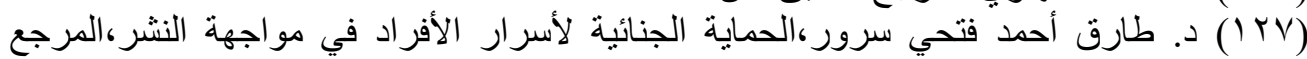

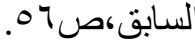

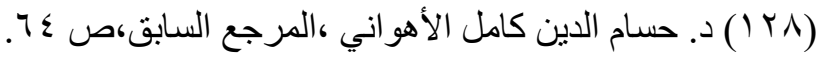
ro 
المعلومات الخاصة بأوقات الفراغ في حالة موافقة صاحب الثأن شريطة أن يكون

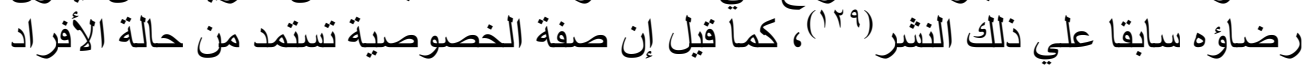

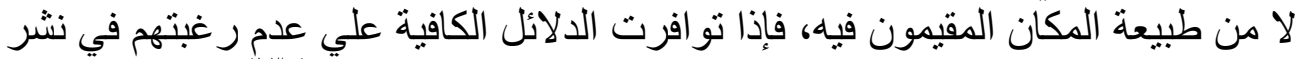

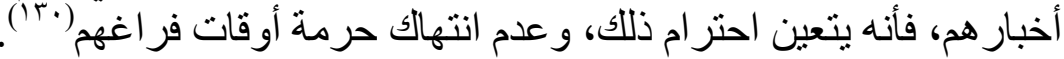

\section{ع ـحرمة النشاط الوظيفي والمهني:}

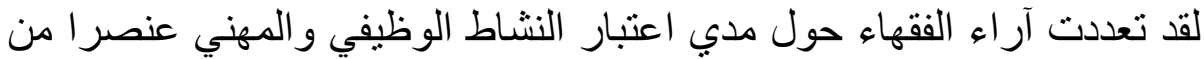

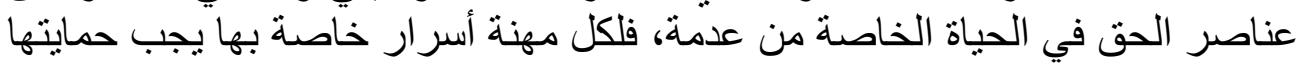

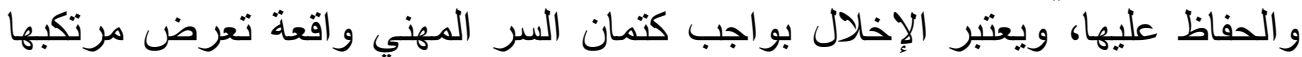

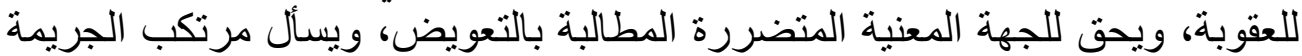

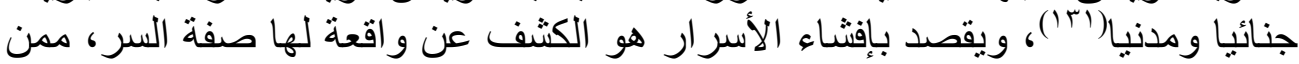
علم بها بمقتضي مهنته مع قصده ذللك(r' (1)، ومن أهم الآر اء الفقهيه مايلي:

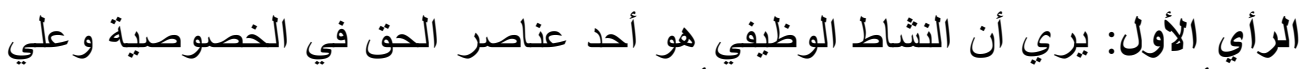
هذا الأساس عني المشر ع بالحفاظ علي أسرار المهنة وحظر إفشاءها.

وقد تعرضت المحكمة الأوربية لحقوق الإنسان للسر الطبي باعتباره يتعلق الإنقان الإنة

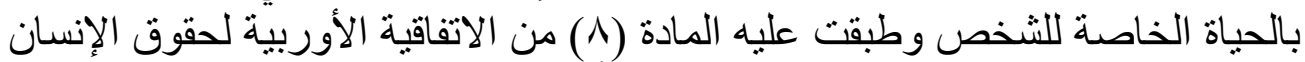

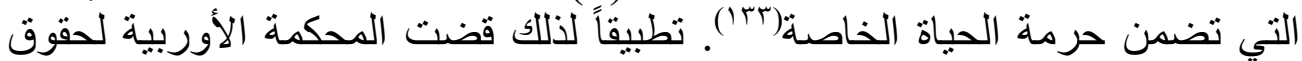

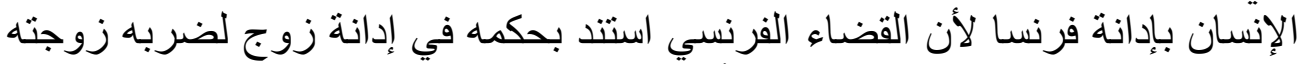

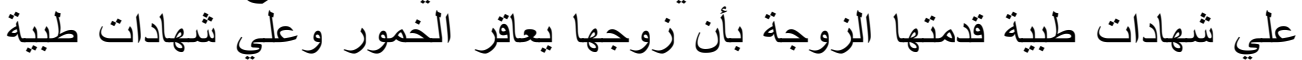

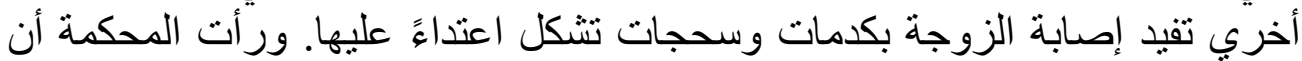

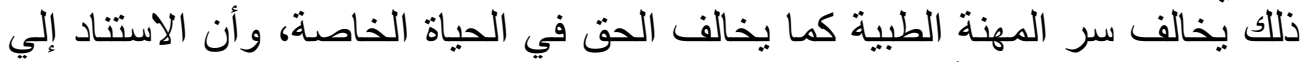

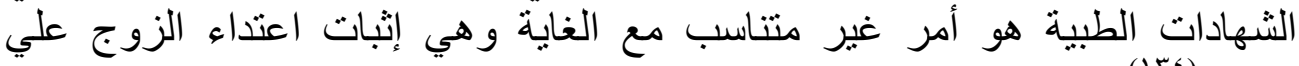

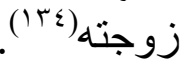

أما الرأي الثاني: فإنه يري أن هذا النشاط ليس أحد عناصر الحف في الحياة الخاصة،

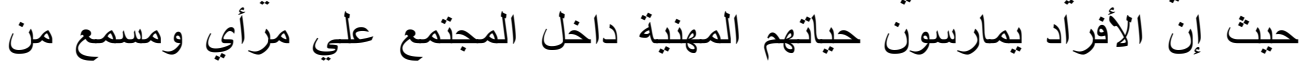

(1 (1) د. طارق أحمد فتحي سرور ،جرائم النشر والإعلام ،الطبعة الأولى،دار النهضة العربية

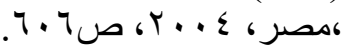

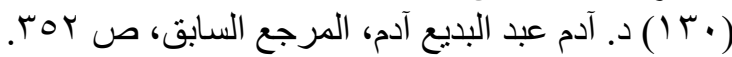

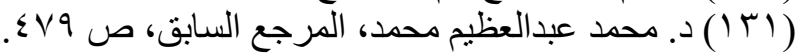

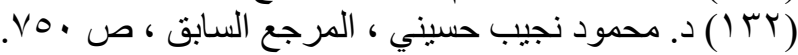

(133) CEDH 27 août 1997, M.S. c/ Suède, req. no 20837/92, § 41 de l'arrêt, D. 2000. 521, note Laurent-Merle.

(134) un arrêt de 2006 (CEDH 10 oct. 2006, L. L. c/ France, req. no 7508/02, D. 2006. IR 2692; D. 2006. 2693 ; RTD civ. 2007. 95, obs. Hauser ), 
الجمهور، فلا تعد أمور هم الوظيفية من عناصر الحق في حياتهم الخاصة، و هذا الاتجاه

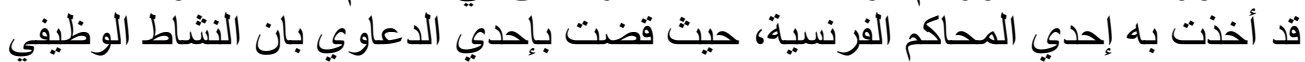

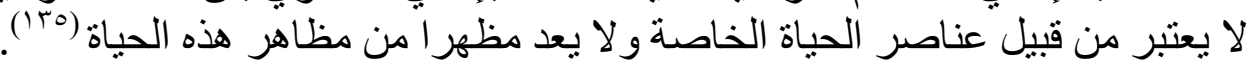

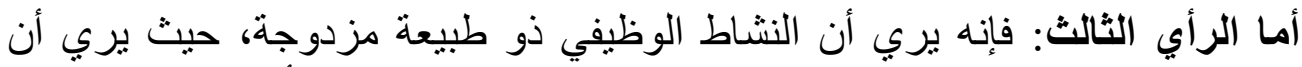

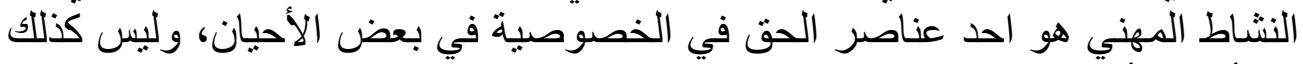

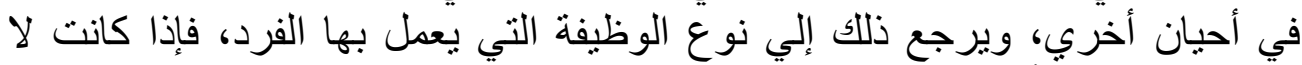

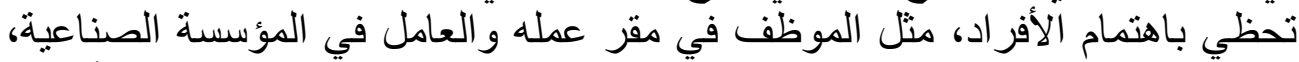

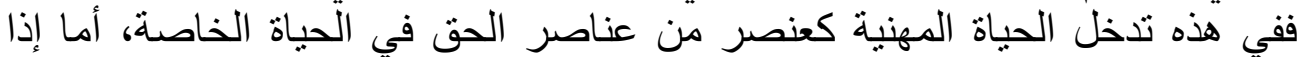

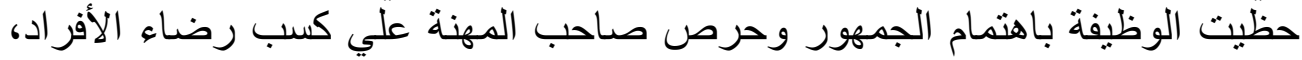

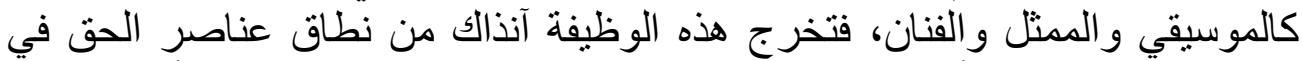

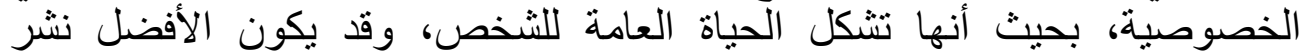

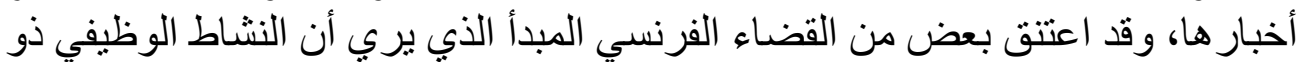

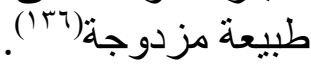

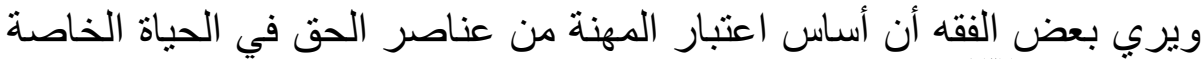

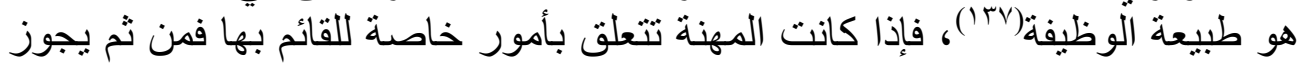

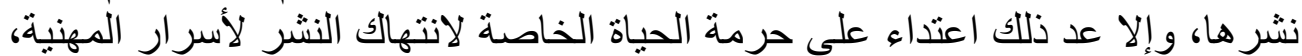

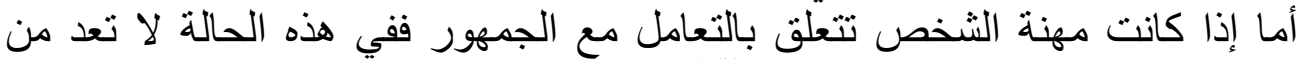

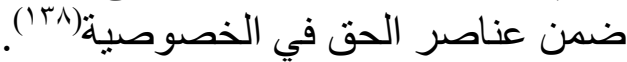

\section{هـحرمة الاخول في طي النسيان:}

يقصد بذللك حق الفرد في الدخول في دائرة النسيان وبقاء ماضيه الفيه محاط الفي بسياج

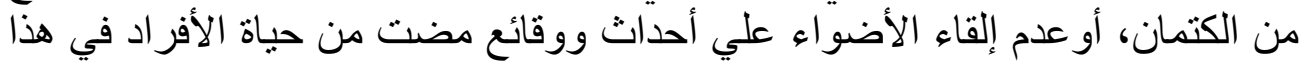

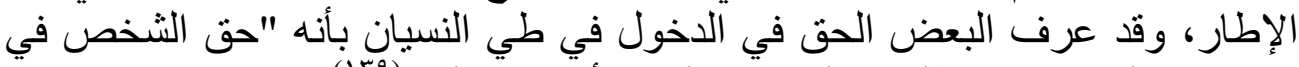

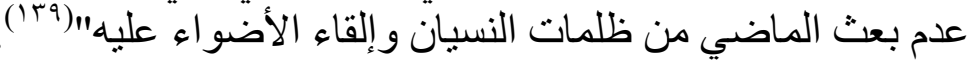

وقد إنقسم الفقه الفرنسي في تعرف الحق في الاخول طي النسيان إلي اتجاهين،

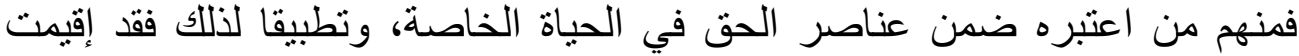
دعوي قذف عرفت باسم قضية "لاندرو" تخلص وقائع هذه الدعوي في أن هناك فيلما

(135) Cass Crim 29 mars 1989, D, 1990 ,P 45.

(136) Cass 26 Fév 1971, J.C.P, 1971-2, P16734 .

(Y T I ) د.حسين عبدالله قايد، حرية الصحافة ،رسالة دكتور اه، حقوق القاهرة ، دار النهضة العربية،

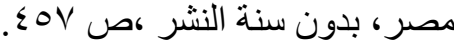
(1 ( ) د. نعيم عطية ،حق الأفراد في حياتهم الخاصة ،مجلة إدارة قضايا الحكومة ،بدون دار النشر

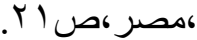

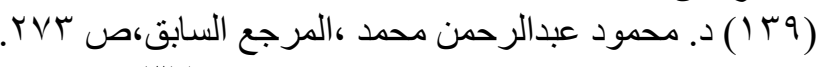
re 


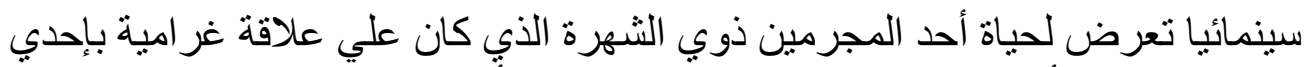

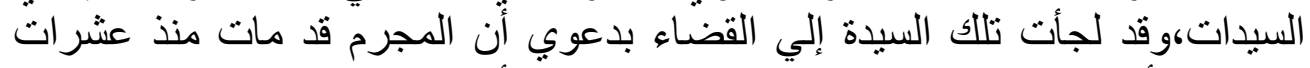

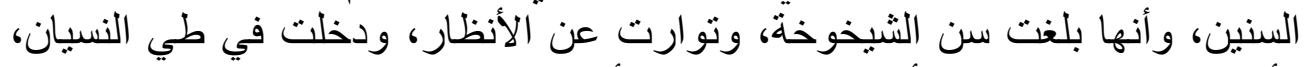

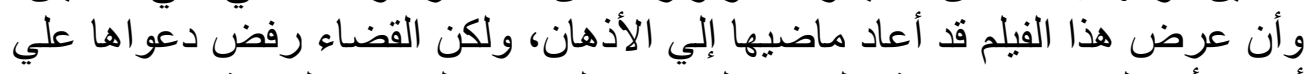

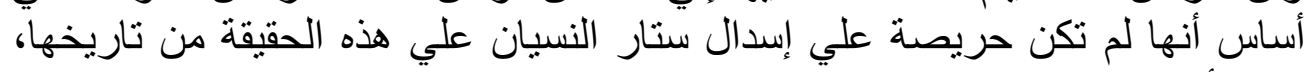

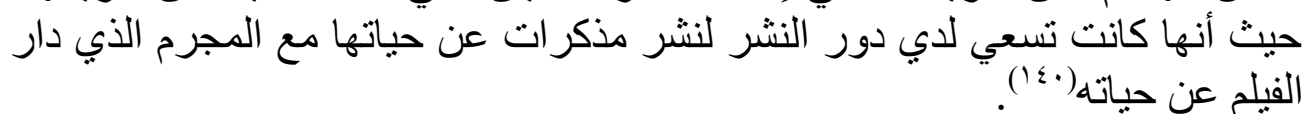

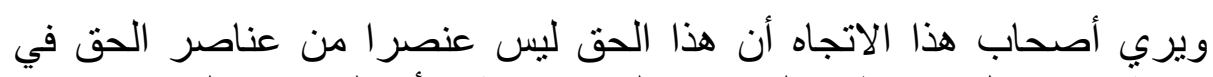

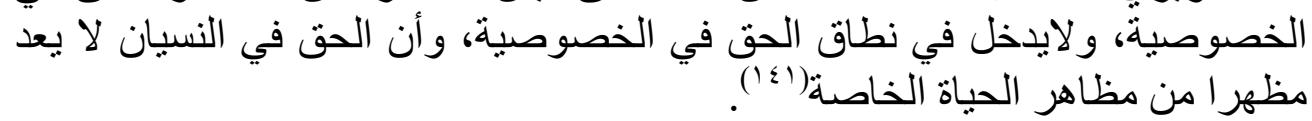

أما الجانب الأخر من الفقه فيري أن حق الدخول في طي النسيان هو أحد عناصر

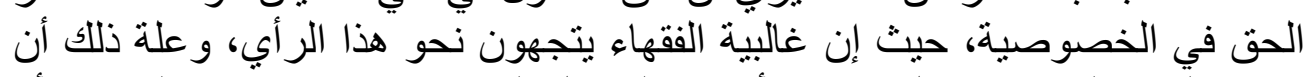

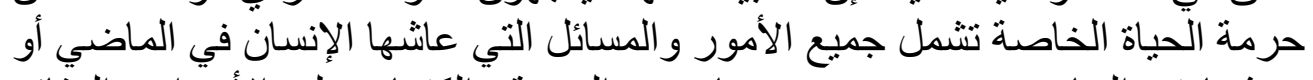

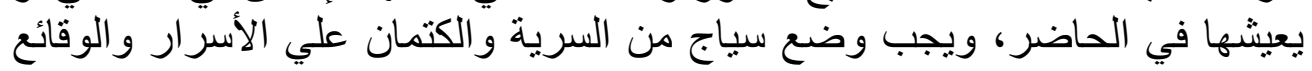

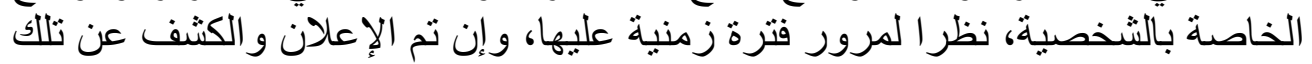

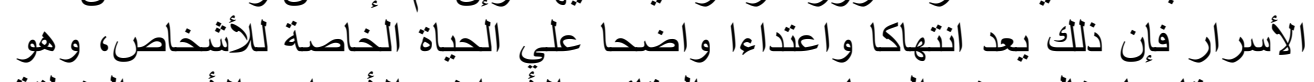

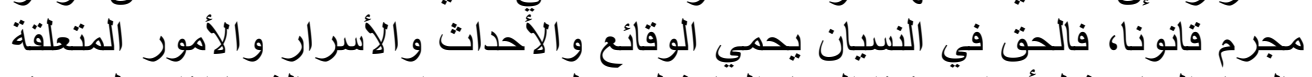

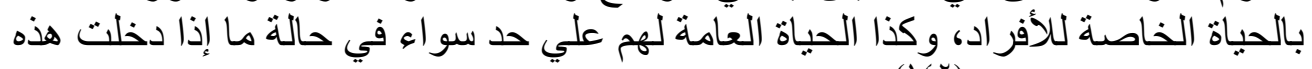

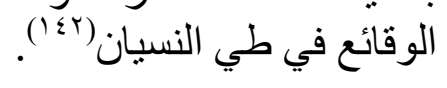

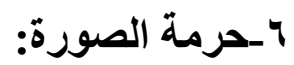

يعرّف أحد الفقهاء الفرنسيين الصورة بأنها "في الحقيقة شبه شخص مع مع شبه

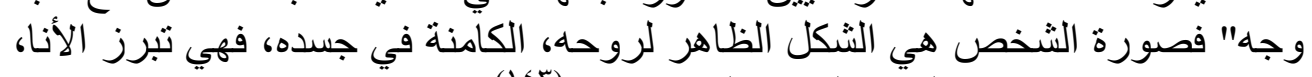

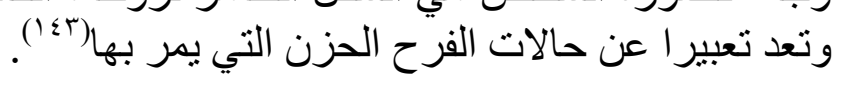

كما يعرف البعض الحق في الصورة بأنه الحق الذي يكون للنخص الذب الذي تم

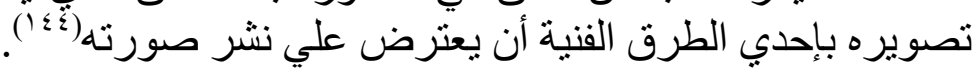

(140) Cass 4 oct1965, J.C.P, 1966-2,14482.

( (1) (أدمد محد محد حسان ،حماية الحياة الخاصة في العلاقة بين الدولة والأفراد، رسالة دكتوراه

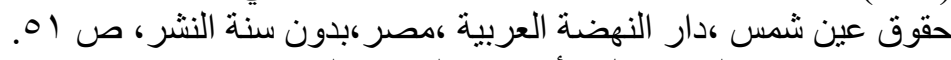

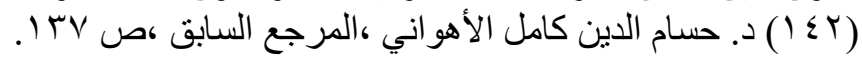

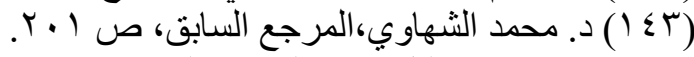

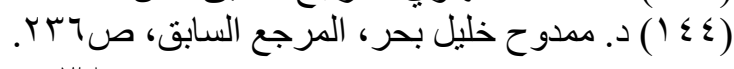

rᄉ 
إن صورة الإنسان تجسد صفات وسمات جسده المادية، وتعد مر آة لما يدور في

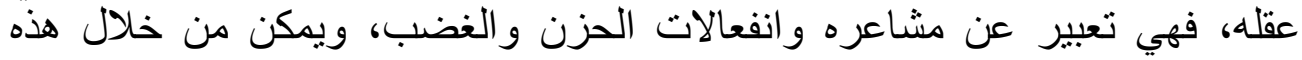

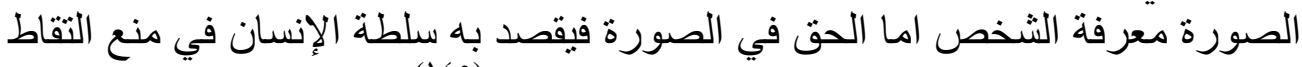

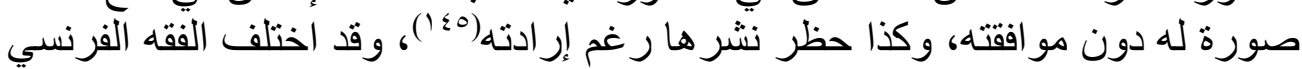
بشأن اعتبار الحق في الصورة أحد عناصر الحق في الخصوصية إلي ثناثة اتجاهات فقهية وهي: - ت اعنيان

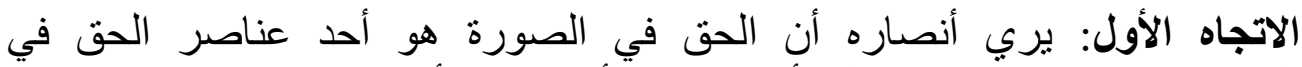

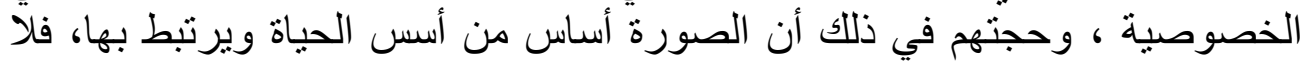

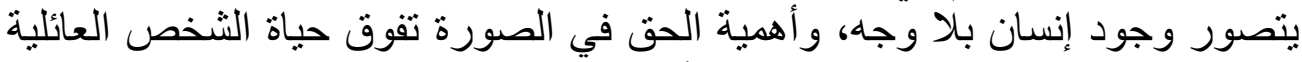

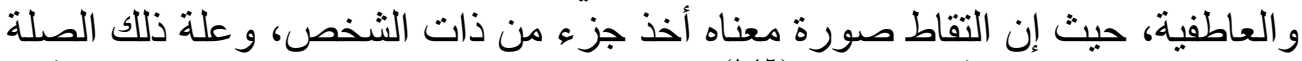

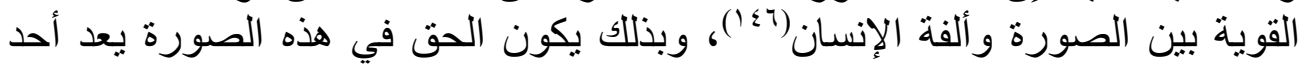
عناصر الحق في الحياة الخاصة.

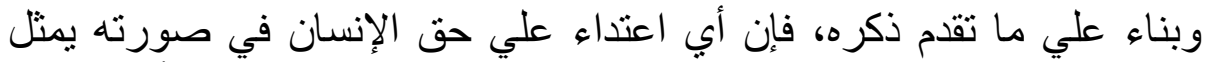

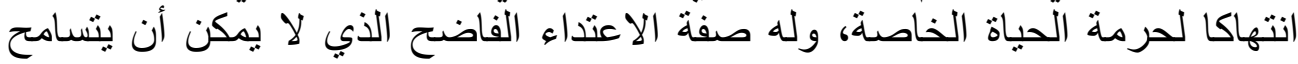
المجني عليه عنه.

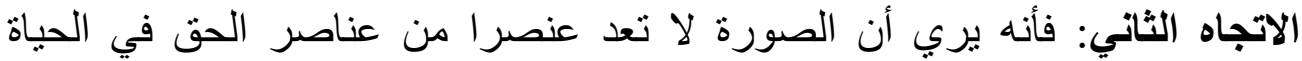

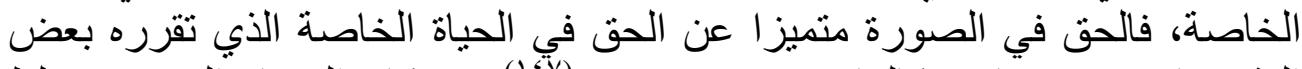

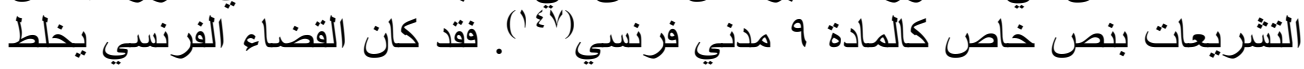

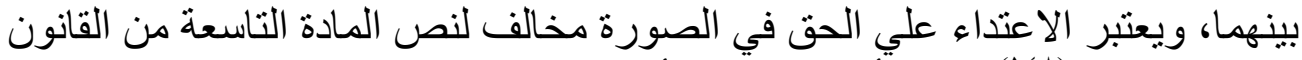

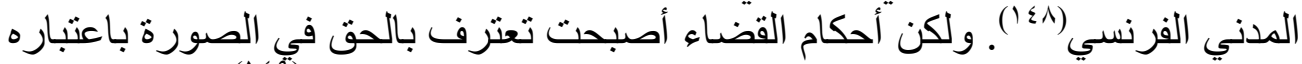
مكوناً من مكونات الحق في الشخصية droit à la personalité

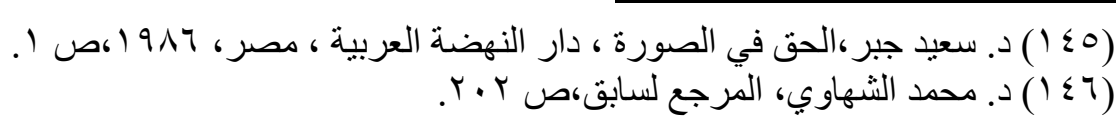
(147) Civ. 1re, 13 janv. 1998, no 95-13.694, JCP 1998. II. 10082, note G. Loiseau, D. 1999. Somm. 167, note Ch. Bigot ; Civ. 1re, 10 mai 2005, no 02-14.730, Bull. civ. I, no 206, D. 2005. IR 1380, D. 2005. Pan. 2644, obs. A. Lepage), Juris-Data, no 028325 ;

(148) Civ. 1re, 13 janv. 1998, no 95-13.694, JCP 1998. II. 10082, note G. Loiseau, D. 1999. Somm. 167, note Ch. Bigot

(149) TGI Nanterre, 25 sept. 2008, Légipresse 2008, I, p. 134), ou de droit à l'image (par ex.: TGI Paris, 22 sept. 1999, CCE 2000. Comm. 59, obs. A. Lepage 


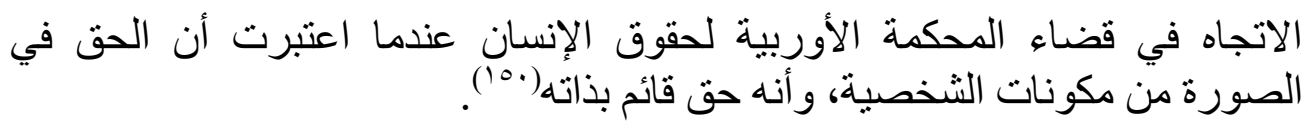
أما الاتجاه الثالث: فيري أن الحق في الصورة هو ذو طبيعة مزدوجة فقد يكون قائما

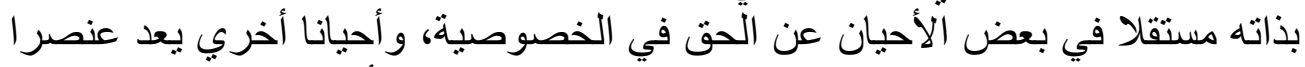

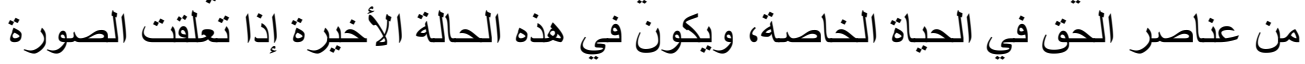

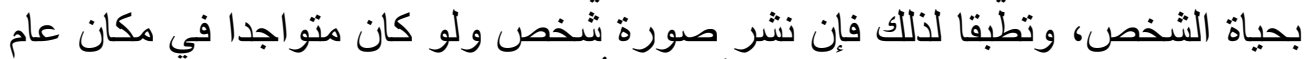

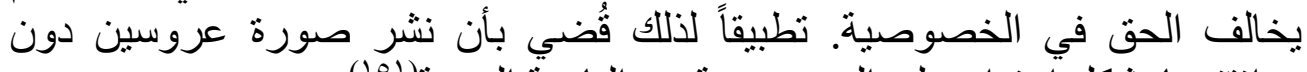

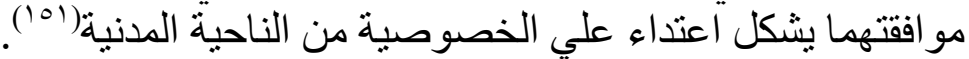

(150) les arrêts de Grande chambre Axel Springer AG C/ Allemagne et Von Hannover no 2 C/ Allemagne (CEDH, gr. ch., 7 févr. 2012, Axel Springer AG C/ Allemagne, req. nos 39954/08. - CEDH, gr. ch., 7 févr. 2012, Von Hannover no 2 C/ Allemagne, req. No. 40660/08)

(151) Vie privée des mariés à l'issue de la cérémonie - Cour d'appel de Paris 6 octobre 1999- D. 2000. 268. 


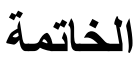

تناولنا بالدر اسة موضوع التعريف بالحق في الحياة الخاصة في مفهوم القانون الجنائي، وانتهينا إلي نتائج وتوصيات من أهمها ما يأتي:

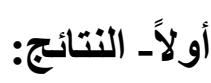

- لم يتفق القانو نيين علي مفهوم و احد للمقصود بالحياة الخاصة. - - تعتبر السيارة مكانًا خاصًا لا يجوز للصحفي التقاط صور لمن بستقلها. - يزول الحق في الحياة الخاصة إذا تكلم صاحب هذا الحق عن تفاصيل حياته الخاصة في علانية.

- م لا يعد الحق في الخصوصية من الحقوق المطلقة، بل هو من الحقوق النسبية

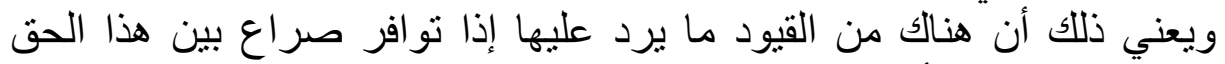
ومصالح اجتماعية أخري مثل حق الهتمع في الكثيف عن الجريمة.

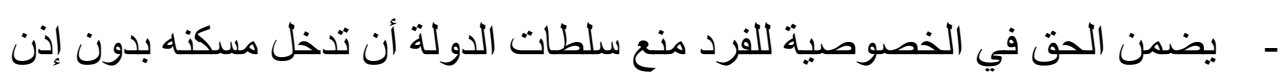
قضائي، باعتباره حقا دستوريا.

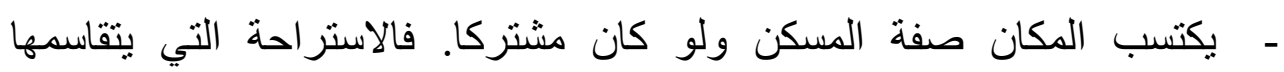
الثخص مع آخرين لا تفقده الحماية القانونية الدقررة للمسكن كمستودع للحياة التئي

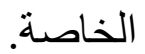
- تشكل المتتقدات الدينية التي يعتنقها الثخص عنصرًا من عناصر حياته الخاصة التي يحميها الحق في الحياة الخاصة. 
- وصي المشرع المصري أن ييين العناصر التي يتضمنها الحق في الحياة الخاصنة و هل تشمل الحق في اتخاذ قر ار ات تخص حياته العاطفية و النفسية.

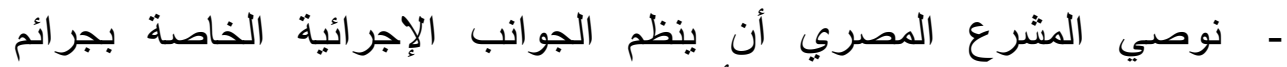

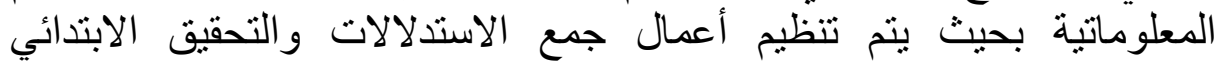

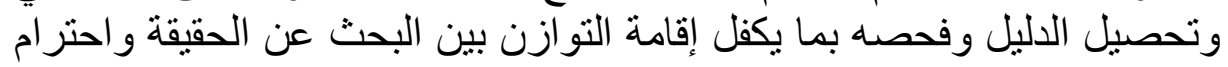
الحق في الحياة الخاصة.

- نوصي المشرع المصري أن يتوسع أكثر في تقرير الحماية الجنائية لحرمة الحياة

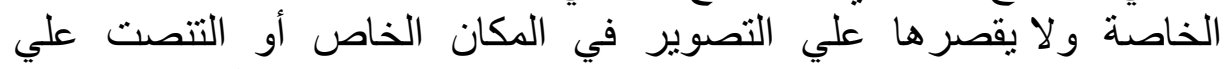

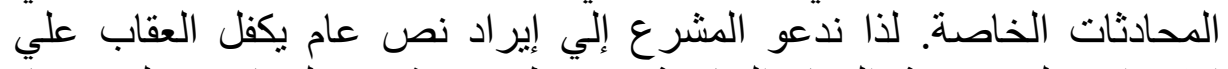

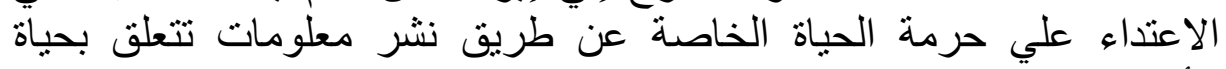
الأشخاص الخاصة.

- - ندعو المشرع إلي النظر بعين الاهتمام لما أصبحت أجهزة التصوير في المكان

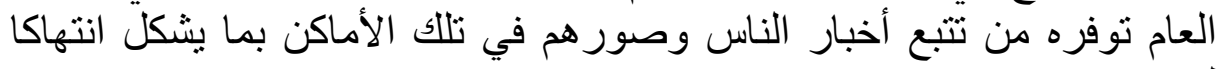
لخصوصياتهم.

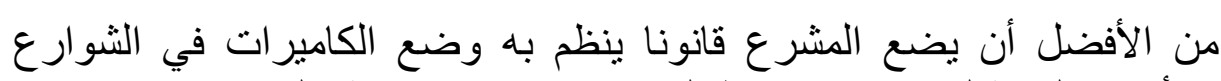

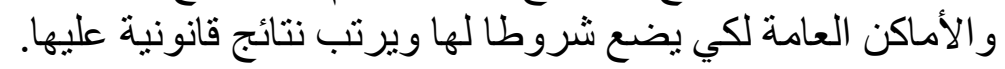

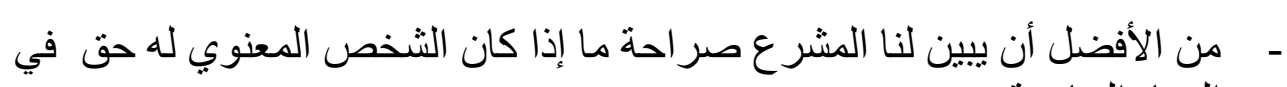
الحياة الخاصة.

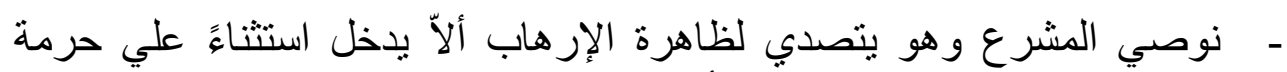

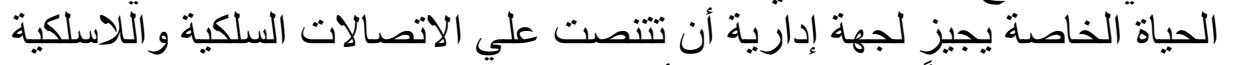

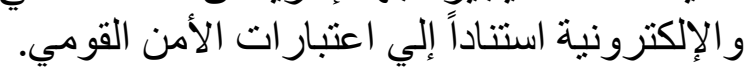

- من المستحسن أن ينظم المشرع القوة القانونية للاليل غير المشروع حسما للخلاف في أحكام القضاء 


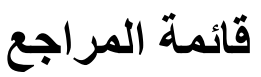

$$
\begin{aligned}
& \text { أولاًَ- مراجع باللغة العربية: }
\end{aligned}
$$

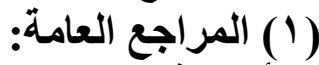

$$
\begin{aligned}
& \text { د. أحمد فتحي سرور: }
\end{aligned}
$$

- الوسيط في قانون الاجر اءوات الجنائية، القسم الخاص، دار النهضة العربية، عام

.1910

- الوسيط في قانون العقوبات، القسم الخاص، دار النهضة العربية، مصر، عام

- الوسيط في قانون الإجر اءات الجنائية، مكتبة رجال القضاء، عام بو9 199 أ.

$$
\text { د. توفيق محمد الشاوي: قانون الإجن: }
$$

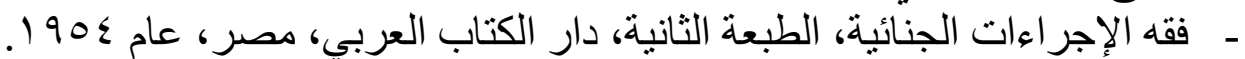
د. حسن صادق المرصفاوي:

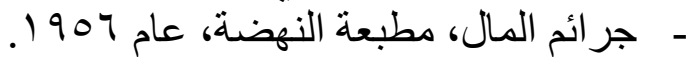

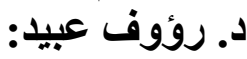

- مبادئ الإجراءات الجنائية في القانون المصري، الطبعة السادسة عشر، دار الجيل

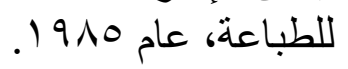

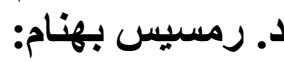

- الإجراءات الجنائية تأصيلا وتحليلا، منشأة المعارف بالإسكندرية، مصر، عام

$$
\text { . I } 9 \vee \wedge
$$

د. دامي الحسيني:

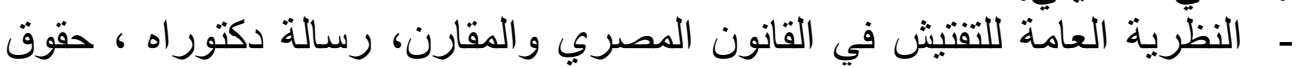

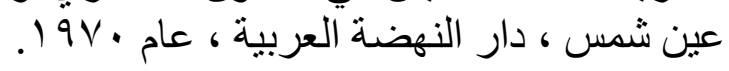

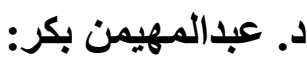

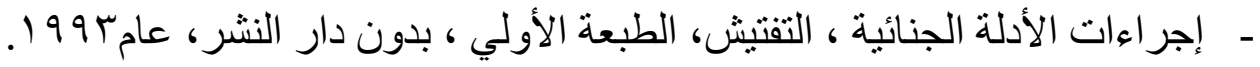

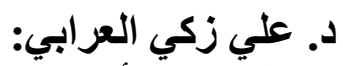

- المبادئ الأساسية للتحقيقات و الإجر اءات الجنائية، بدون دار النشر، عام ، ـ19 19.

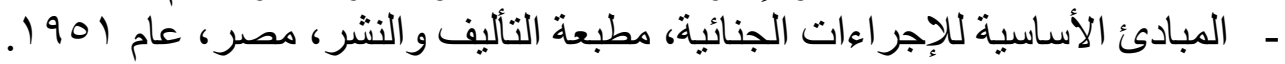

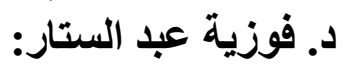

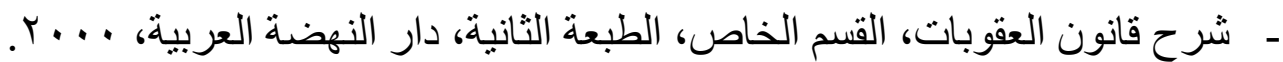

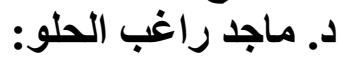

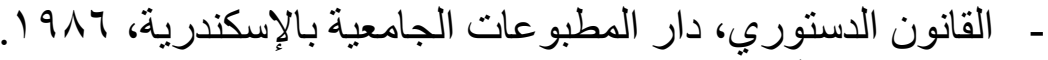

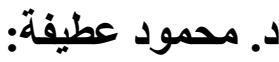

- محاضرات في الإجراءات الجنائية، المركز القومي للار اسات القضائية، سلسلة

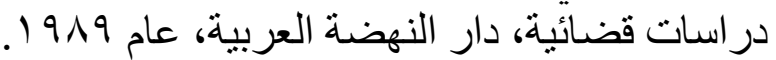

د. محمود محمود مصطفي: 
- ـ الإثبات في المواد الجنائية في القانون المقارن، الطبعة الأولي، بدون دار النشر،

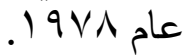

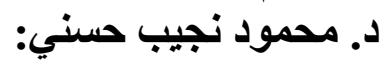

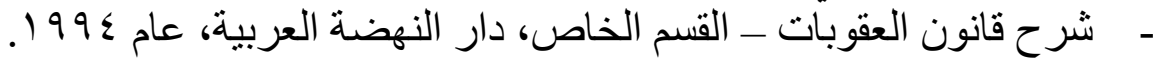

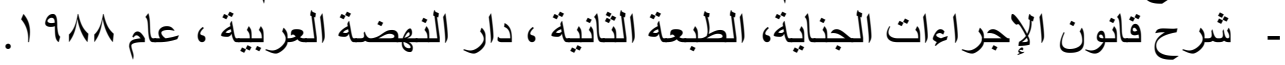

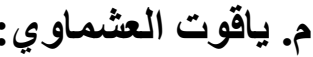

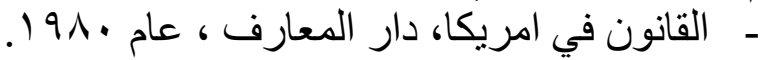

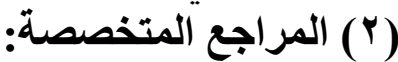

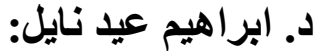

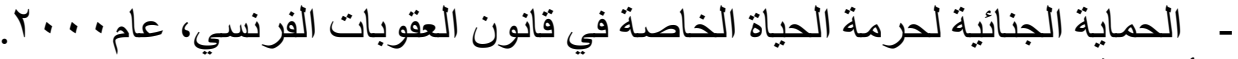

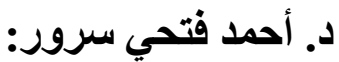

ـ الحماية الجنائية للحق في الحياة الخاصة ، دار النهضة العربية ، عام 91911 أ.

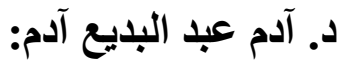

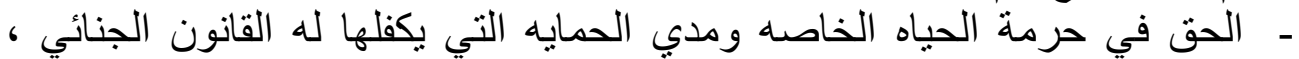

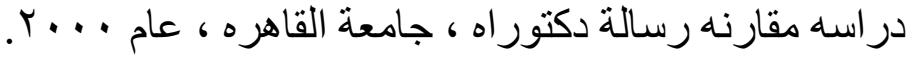

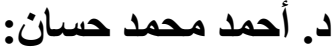

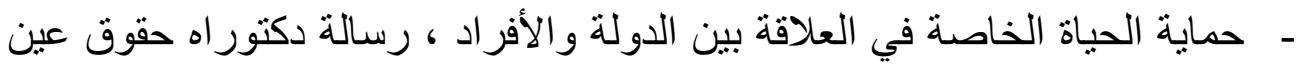

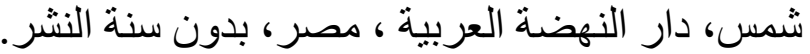

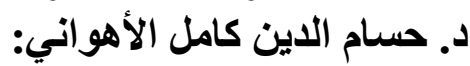

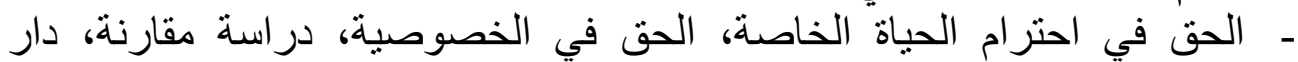
النهضة العربية، مصر، الدئر الدون سنة النشر. د. دمبين عبد الله قايد:

- حرية الصحافة، رسالة دكتور اهدة ، حقوق القاهرة ، دار النهضة العربية ، مصر، بدون سنة النشر.

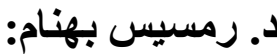

- نطاق الحق في حرمة الحياة الخاصة، بحث مقدم الي مؤتمر الحق في حرمة الحئة الحياة الخاصة ، المنعقد في كلية الحقوق، جامعة الإسكندرية، في الفترة من عـ ــ 7 يونية،

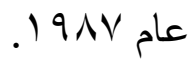

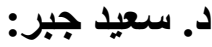

- ـ الحق في الصورة ، دار النهضة العربية ، مصر، عام 91919.

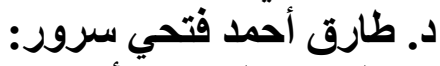

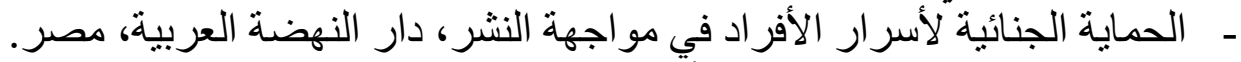

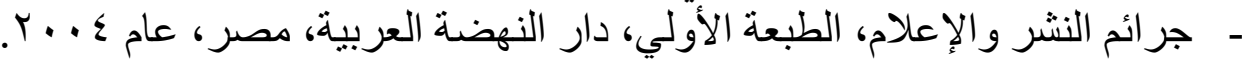

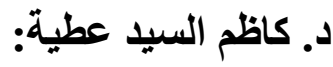


- الحماية الجنائية لحق المتهم في الخصوصية در اسة مقارنه، رسالة دكتور اه ، عام r...V

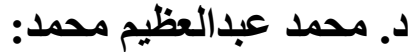

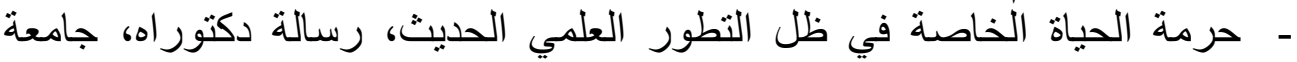

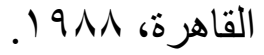

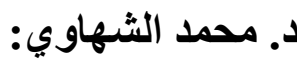

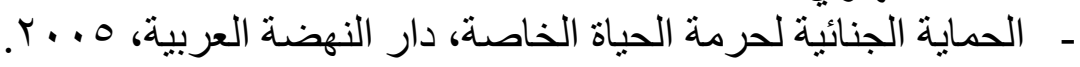
د. محمد محرم محمد علي: - مرمة استراق السمع وتسجيل المحادثات التليفونية، مجلة النيابة العامة، عام 1990

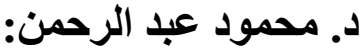

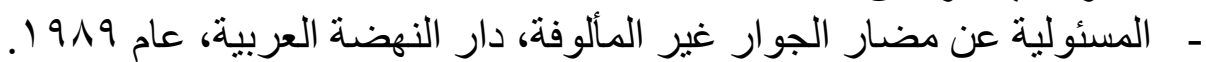

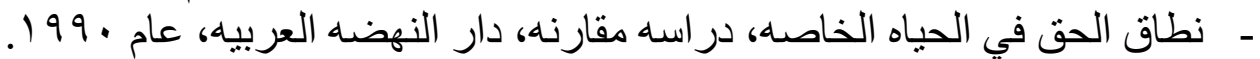

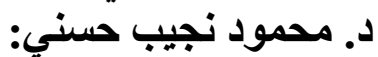

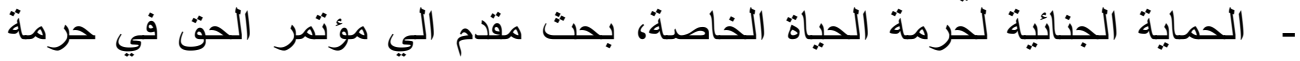

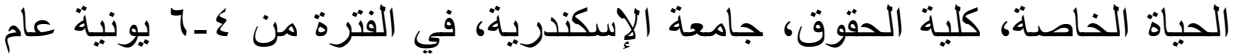
$.19 \wedge \mathrm{V}$ د. محمود عبد الرحمن محمد:

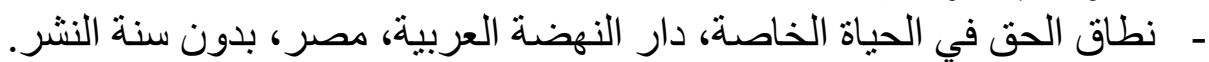

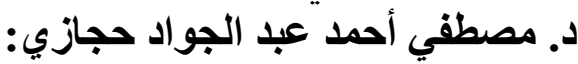

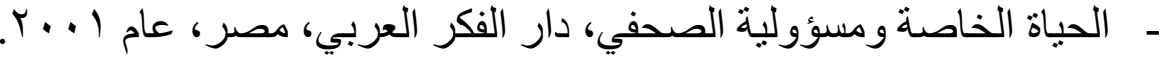

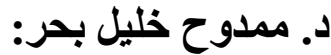
- حماية الحياه الخاصه في القانون الجنائي در اسة مقارنه ، دار النهضه العربيه، سنة r. .1 .

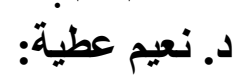
- حق الافر اد في حياتهم الخاصة،، مقال في مجلة ادارة قضايا الحكومة، العدد الر ابع،

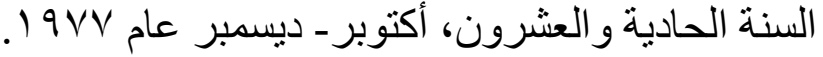

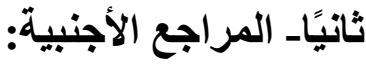

- Wintield : “torts"seventh edition 1963, p. 720.

- Nizer (1): "theright of privacy K ahalf centurys developments "Michigan law rev. 1941. vol. 39. p. 526.

- D ferrer : " la protection dela vie privee " these toulouse 1973 p 12 et 26. 
- Arret cour de paris 15 mai 1970 d 1970 j p 466 note d a et h m.

- Gohn H .F. Shattuck: "right of privacy", national text book company, 1977 P. 197.

- Doglas (Sh): "privacy opinions of justice" doglas published at gate law journal, Vol. 87 .no. july 1978, p. 157.

- A. Decaq "rapport sur le secret de la vie privee en droit francais", journees libanaises de 1 association. h. capitan, travaux de 1 association. h. capitan, t. 25, ed. dalloz Paris, 1974, p. 1; martin: "le secret de la vie privee" rev. trim. civ., 1959, p. 222.

- Carbonnier: dtiot civil, tom1, 1969, no. 41.

- Martin, le secret de lavie privee, op.cit. p. 290.

- Leio- Brittan: the right of privacy in england and us "Tulane law rev"1963, p. 236.

- A h Robertson: "privacy and human right" Manchester university press 1968 p. 27.

- Carbonier: "droit civil" tome 11969 no. 41.

- Nerson "la protection de la personnalite en droitprive francais" trvaux de 1 asso citation h capitant t 13, p. 79.

- Badintir: le droit au respect de la vie privee J.C.P. 19682136.

- Paris 6 juillet 1965 gaz pal 1366- 1 - 37.

- Martin "le secret de la vie privee" op.cit., p. 230.

- Badinter: "le droit au respect de la vie privee" J.C.P. 1968, 1236.

- Paris 17 mars 1966 Dalloz 1966- 749.

- T g I seine 24 nov 1965, J.C.P. 1966- 11- 14521. 
- Paris 27 fev 1967 dalloz 1967450 not foulon- piganiel.

- Paris 25 mars 1965 J.C.P. 1965- 1- 14305.

- Gerald messadie “ le fin de la vie privee" ed calmann levy 1974 - imprim en france p. 170.

- Cass, 11 janv, 1977, J.C.P, 1977-2, P. 8711.

- Cass, 9juil, 1980, D, 1981, P. 72.

- Cass, 24 sept, 1990, G.P, 1994,2, P992 .

- Cass Crim 29 mars 1989, D, 1990 ,P 45.

- Cass 26 Fév 1971, J.C.P, 1971-2, P16734 .

- Cass Crim 20 Oct 1976, Bull, civ 1976, no 279.

- Cass 4 oct1965, J.C.P, 1966-2,14482 .

- Nerson "la protection de 1 intimate" journ des trib 1959 p 713

- Carbonnier, briot civil, 1971, tome1, no71, p. 239.

- Conclusions de ml avocet general cabanes sous paris 15 mai 1970-466.

- Franciose- gailove (g) "le secret de la information" le monde 20 septembre 1970. 
قائمة المحتويات

مقدمة - مقة

الاول: مفهوم الحياة الخاصة

المطلب الأول: الاتجاهات الموضوعية لتعريف الحق في الحياة الخاصة

الفرع الاول: التعريف الايجابي للحياة الخاصة

الفرع الثاني: التعريف السلبي لفكرة الحياة الخاصة

النوع الأول: الاتجاه المعياري في تعريف الحياة العامة

النوع الثاني: الاتجاه التعدادي في تعريف الحباة العامة

المطلب الثاني: فكرة نسبية الحياة الخاصة

الفرع الأول: اختلاف فكرة الخصوصية باختلاف الأثخاص

الفرع الثاني: اختلاف الحياة الخاصة باختلاف الزمان و الدكان

المبحث الثاني: عناصر الحق في حرمة الحياة الخاصة

المطلب الأول: عناصر الحق في الحياة الخاصة محل الاتفاق

المطلب الثاني: عناصر الحق في الحياة الخاصة محل الاختلاف

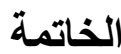

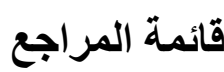

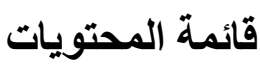

